\title{
THESIS
}

\section{HYDROLOGIC COMPARISON OF PRESCRIPTIVE AND WATER BALANCE COVERS}

\author{
Submitted by \\ Caleb Swenson Stock \\ Department of Civil and Environmental Engineering
}

In partial fulfillment of the requirements

for the Degree of Master of Science

Colorado State University

Fort Collins, Colorado

Summer 2018

Master's Committee:

Advisor: Christopher A. Bareither

Joseph Scalia IV

Mark W. Pascke 
Copyright by Caleb Swenson Stock, 2018

All Rights Reserved 


\section{ABSTRACT}

\section{HYDROLOGIC COMPARISON OF PRESCRIPTIVE AND WATER BALANCE COVERS}

The objective of this study was to compare the water balance of prescriptive and water balance cover (WBC) designs for Larimer County Landfill (LCL) via hydrologic modeling. A prescriptive cover is designed to limit percolation into underlying waste via a low permeability layer, whereas a WBC is designed to limit percolation via storing infiltrated precipitation and subsequently releasing the water through evaporation and transpiration. Guidance on WBC designs in Colorado are based on geographical location of the site and particle-size distribution of the available cover soils. Soil characteristics and engineering properties were determined from exhumed samples for a completed closure phase of LCL (Phase 1) and two borrow areas (Borrow Area 3 and Borrow Area 4). Hydrologic modeling was completed using VADOSE/W to predict the percolation rate through the prescriptive and water balance covers. The wettest ten consecutive years on record with a sufficiently complete meteorological data set (1992-2002) were selected for the analysis. Vegetation parameters were assigned to represent the revegetated state observed in Phase 1 and the natural conditions observed in the borrow areas. Predicted percolation through a prescriptive cover was $<0.1$ to $2.2 \mathrm{~mm} / \mathrm{yr}$, depending on assumed saturated hydraulic conductivity. Evaporation was the primary process for removing water from the prescriptive cover models. Predicted percolation through the WBC models ranged from 6.3 to $11.3 \mathrm{~mm} / \mathrm{yr}$ depending on the borrow area soil and vegetation parameters. Transpiration was the primary process for removing water from the WBC models. Within all of the regulatory acceptable cover models' evapotranspiration removed 94 to $102 \%$ of the precipitation received during the ten years modeled. Results of this study indicate that either a prescriptive cover with a total thickness of $106.7 \mathrm{~cm}(3.5 \mathrm{ft})$ or a WBC with a thickness of 76.2 $\mathrm{cm}(2.5 \mathrm{ft})$ will meet regulations for final closure cover at LCL. 


\section{ACKNOWLEDGEMENTS}

I want to begin my acknowledgements with my family as they have continually shaped me and supported me throughout my life and this endeavor. My wife Christina has been a rock, kept my life in balance, and picked up the slack while supporting me and our two children with endless love. Our children, Hannah and Oliver, provided me with a clear mind and laughter at the spur of a moment when I may have ordinarily been overwhelmed. As they grow I hope they will recognize the importance of education and hard work that I have demonstrated in completing my graduate degree. My parents taught me the value of hard work and perseverance which were critical to completing this achievement. In addition, my in-laws have pursued higher education degrees in their respective fields and provided an example for me to follow.

I am thankful to my advisor Dr. Chris Bareither who has provided supreme guidance throughout this process. Chris' reviews of my work and critical thinking have added significantly to my professional capabilities that will come to fruition the rest of my career. I also really appreciate Dr. Bareither's positive attitude that has given me confidence in my abilities. The other members of my committee, Dr. Joseph Scalia IV and Dr. Mark Paschke, have further contributed to my professional development and have always been there when needed.

I would not have completed my thesis without Mohammad Gorakhki providing laboratory testing services. Beyond that Mohammad has been willing to support my progress in every aspect, whether that be shoveling soil in the field on a hot day or with critical thinking of the laboratory and model results.

The personnel at Larimer County Landfill have shown unwavering support of my research since I first introduced my research proposal. I recognize the open book of knowledge about the site and access to the site, personnel, and equipment. 
Thank you to Tom Chapel who first realistically put the idea of a graduate degree into my head several years ago. Tom has always expressed belief that I could complete my degree while working and raising a family as he had previously demonstrated and I thank him for his mentorship. Tom and other coworkers at Tetra Tech provided empathy throughout my journey as only they could relate. Tetra Tech provided significant financial assistance towards my graduate degree for which I am most gracious. 


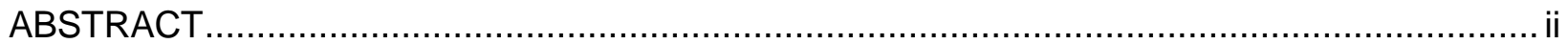

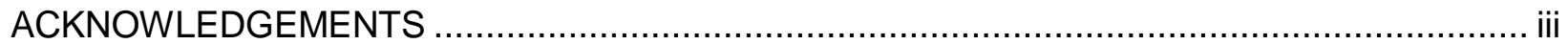

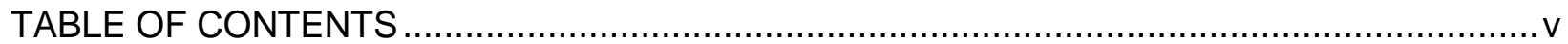

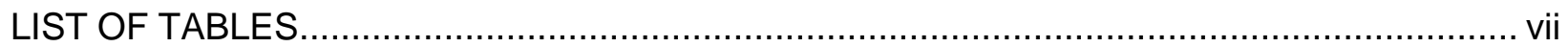

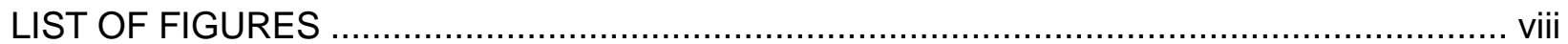

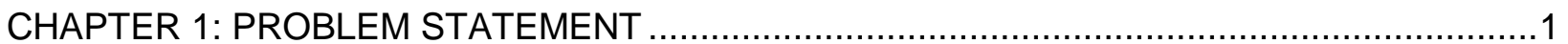

CHAPTER 2: INTRODUCTION TO WATER BALANCE COVERS ....................................

CHAPTER 3: SITE DESCRIPTION .........................................................................

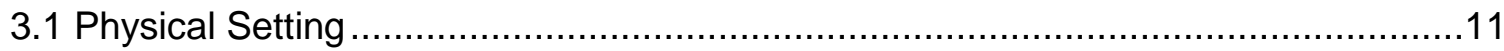

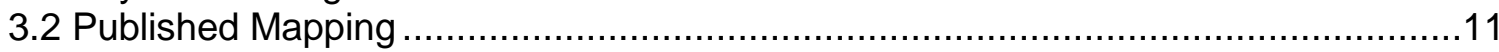

3.3 Previous Closure Activity ………...........................................................12

3.3.1 Phase 1 Closure ...................................................................13

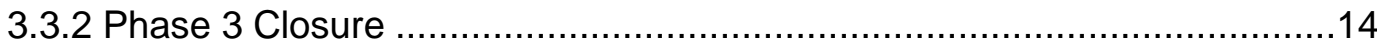

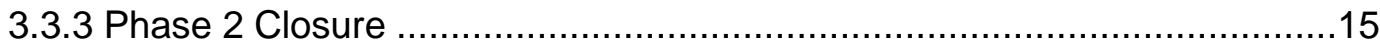

3.3.4 Phase 6A Closure ......................................................................

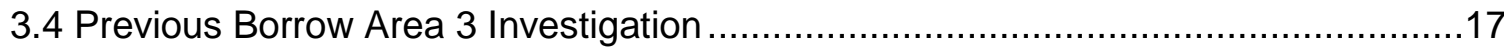

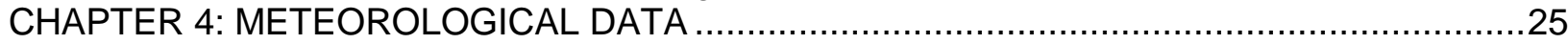

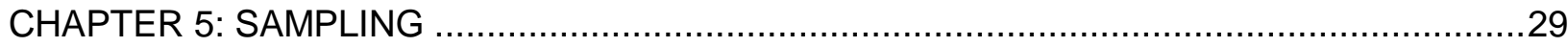

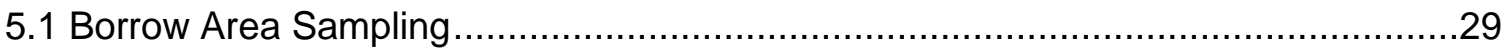

5.2 Existing Closure Cover Sampling ....................................................................

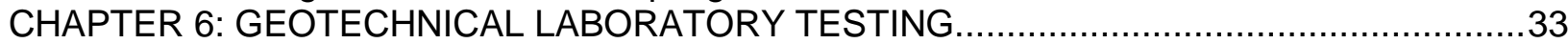

6.1 Borrow Area Soil Geotechnical Laboratory Testing................................................33

6.1.1 Characterization and Compaction Testing.............................................33

6.1.2 Permeability Testing.......................................................................34

6.1.3 Soil Water Retention Testing ...........................................................36

6.2 Existing Closure Cover Phase 1 Geotechnical Laboratory Testing …......................37

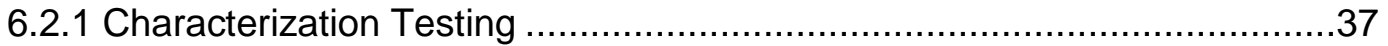

6.2.2 Permeability and Soil Water Retention Testing ...................................38

6.3 Phase 1 Comparison: Laboratory Results and Construction Certification Reports ...39

6.4 Comparison of Laboratory Test Results versus Literature …………...................40

6.4.1 Effect of Pedogenesis on Hydraulic Properties........................................40

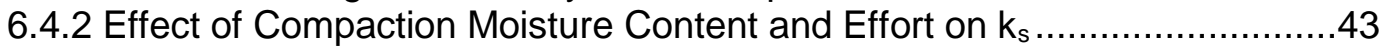

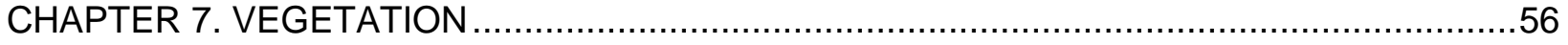

CHAPTER 8. DESCRIPTION OF MODEL AND MODEL PARAMETERS ……......................58

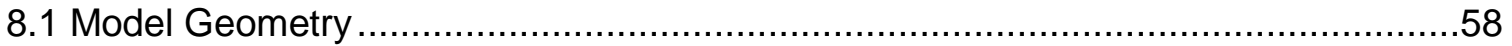

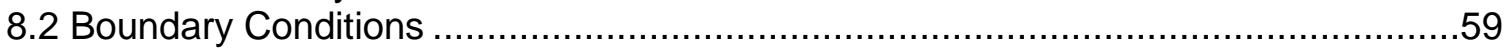

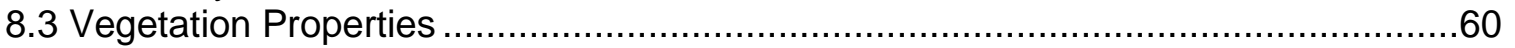

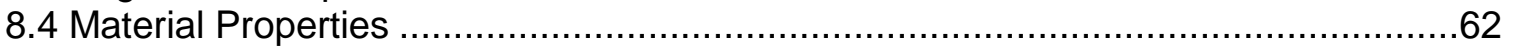

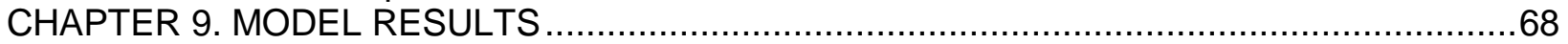

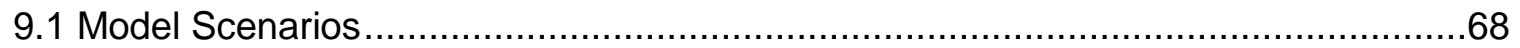

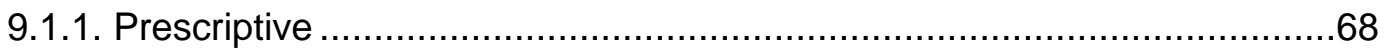

9.1.2. Water Balance Covers ...................................................................69

9.2 CDPHE Accepted Covers Model Results..........................................................69

9.3 Borrow Area 3 WBC Sensitivity Analysis Model Results ...................................72

9.4 Further Detail of Model Results ……………….............................................. 
9.5 Practical Implications of Research Results .................................................74

CHAPTER 10. SUMMARY, CONCLUSIONS, AND FUTURE WORK $\ldots \ldots \ldots \ldots \ldots \ldots \ldots \ldots \ldots \ldots . \ldots \ldots$

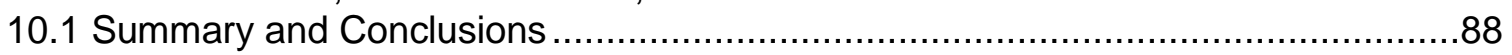

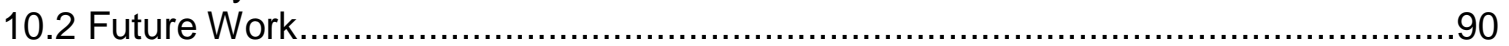

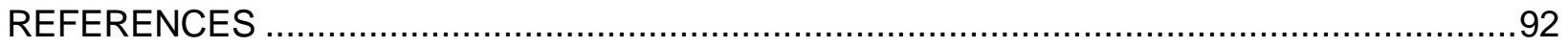




\section{LIST OF TABLES}

Table 3.1. Construction quality assurance hydraulic conductivity $\left(k_{s}\right)$ test results of samples collected with Shelby tubes $(75 \mathrm{~mm}$ diameter) immediately after final cover construction at Larimer County Landfill.

Table 5.1. Samples collected from borrow areas and Phase 1 closure cover.

Table 6.1. Laboratory characterization and engineering property test results for soil samples collected from the borrow areas at Larimer County Landfill.

Table 6.2. Saturated hydraulic conductivity $\left(k_{s}\right)$ and unsaturated hydraulic properties of soil samples collected from the borrow areas at Larimer County Landfill....

Table 6.3. Laboratory characterization and engineering property test results for soil samples collected from the Phase 1 existing closure cover at Larimer County Landfill.

Table 6.4. Saturated hydraulic conductivity $\left(k_{s}\right)$ and unsaturated hydraulic properties of Phase 1 existing closure cover Infiltration Layer.

Table 6.5. Saturated hydraulic conductivity $\left(k_{s}\right)$ of borrow area soils remolded to varying moisture contents and percent compaction in order from highest $k_{s}$ to lowest $k_{s}$ within soil samples collected from the borrow areas at Larimer County Landfill. .......48

Table 7.1. Larimer County Landfill Phase 1 final cover seed mixture. .57

Table 9.1 Water balance metrics for prescriptive and water balance covers that met CDPHE regulations.

Table 9.2 Water balance metrics for water balance covers simulated with Borrow Area 3 soil parameters but with varying vegetation parameters (revegetated versus natural) and cover thickness. 


\section{LIST OF FIGURES}

Fig. 2.1 Ecozone delineation from Figure 2.2.1-1 of CDPHE Final Guidance Document on Water Balance Covers in Colorado (CDPHE 2013).

Fig 2.2. Water storage layer thickness for Ecozone 3 from Figure 2.2.1-4 of CDPHE Final Guidance Document on Water Balance Covers in Colorado (CDPHE 2013)............9

Fig 2.3. Ratio of monthly percolation to potential evapotranspiration (P/PET) for Fort Collins compared to thresholds defined in Alright et al. (2010) for (a) average of 1981 through 2010 and (b) wettest year with sufficient data (1997). ..................... 10

Fig. 3.1a. Soil unit map for the area of Larimer County Landfill developed by NRCS (2017)...20

Fig. 3.1b. Soil unit identification from NRCS (2017) maps.

Fig. 3.2. Bedrock geology units identified in Tweto and Ogden (1979) overlain on an aerial photograph of Larimer County Landfill.

Fig. 3.3. Bedrock geology map by Braddock et al. (1989) provided by Larimer County Landfill.

Fig. 3.4. Larimer County Landfill closure phases and borrow areas.

Fig 4.1. Annual precipitation recorded at the Colorado State University Weather Station from 1889 through 2016. The Model Years for water balance modeling used in this study were from the start of 1992 through the end of 2001.

Fig 4.2. Daily precipitation recorded at the Colorado State University Weather Station during the Model Years (1992-2002) used in this study for water balance modeling.

Fig. 6.1. Saturated hydraulic conductivity of remolded borrow area soils versus (a) remolded moisture content and (b) remolded percent compaction and moisture content.

Fig. 6.2. Soil water characteristic curve and unsaturated flow laboratory test results from (a) Borrow Area 3 and (b) Borrow Area 4.

Fig. 6.3. Soil water characteristic curves for Phase 1 Infiltration Layer in (a) metric units and

(b) English units.

Fig. 6.4. Comparison of (a) fines content and (b) Atterberg limits determined from soil investigations conducted in 1998 and 2017 (this study).

Fig. 6.5 Test results from 1998 and 2017 laboratory investigations of the Infiltration Layer for (a) in-situ moisture content, (b) dry density (metric units), and (c) dry density (English units). 
Fig. 6.6 In-situ dry density of the Infiltration Layer from the 1998 and 2017 investigations....54

Fig. 6.7 Reproduced figure from Benson et al. (2007) supplemented with saturated hydraulic conductivity results from this study.

Fig. 8.1. Model geometry and boundary conditions for a 76.2-cm-thick (2.5 ft) cover simulation: (a) Stage 1 steady-state model and (b) Stages 2 and 3 transient models.

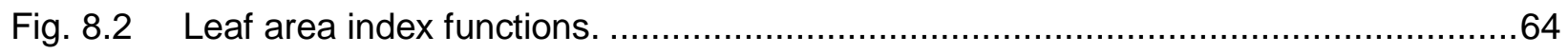

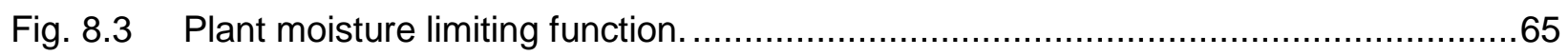

Fig. 8.4 Modeled soil water characteristic curves for (a) water balance cover and (b) Phase 1 final cover soils.

Fig. 8.5 Modeled hydraulic conductivity functions for (a) water balance cover and (b) Phase 1 final cover soils.

Fig. 9.1. Schematics of the prescriptive and water balance cover model scenarios analyzed for this study.

Fig 9.2. Model results for Ecozone 3 from Figure 19 of CDPHE Water Balance Guidance (2013).

Fig 9.3. Temporal trends from 1992-2002 of cumulative precipitation and percolation from the prescriptive and water balance cover model simulations completed for the covers that met CDPHE regulations.

Fig 9.4. Average annual evaporation, transpiration, and precipitation the prescriptive and water balance cover model simulations completed for the covers that met CDPHE regulations.

Fig. 9.5.(a) Percolation and volumetric water content from 1992-2002 at the bottom of the cover profile for water balance covers simulated with Borrow Area 3 soil, revegetated vegetation parameters, and varying thicknesses.

Fig. 9.5.(b) Percolation and volumetric water content during 1997 (wettest year modeled) at the bottom of the cover profile for water balance covers simulated with Borrow Area 3 soil, revegetated vegetation parameters, and varying thicknesses.

Fig. 9.5.(c) Percolation and volumetric water content during Spring Creek Floods of 1997 at the bottom of the cover profile for water balance covers simulated with Borrow Area 3 soil, revegetated vegetation parameters, and varying thicknesses.

Fig. 9.5.(d) Volumetric water content and incremental percolation during Spring Creek Floods of 1997 at the bottom of the cover profile for water balance covers simulated with Borrow Area 3 soil, revegetated vegetation parameters, and varying thicknesses. ...85

Fig. 9.6 Relationships of average volumetric water content versus (a) percent of cover thickness and (b) depth below the surface for three water balance covers with 
varying thickness simulated with Borrow Area 3 soil and revegeted vegetation parameters.

Fig. 9.7 Percolation and volumetric water content from 1992-2002 at $30.5 \mathrm{~cm}$ below the ground surface for water balance covers simulated with Borrow Area 3 soil, revegetated vegetation parameters, and varying thicknesses...... 


\section{CHAPTER 1: PROBLEM STATEMENT}

Final covers at landfills are designed and constructed to reduce the amount of percolation into the underlying waste after closure. Larimer County Landfill (LCL) currently has a prescriptive final cover constructed over four phases of the landfill based on designs approved by the Colorado Department of Public Health and Environment (CDPHE), Hazardous Materials and Waste Management Division. The CDPHE adheres to the Colorado Code of Regulations (CCR) 1007-2, Part 1, Part B, Section 3.5.3, which has the same requirements for final closure covers specified in the Code of Federal Regulations (CFR) Title 40, Subpart 258.60. The CFR requires "an infiltration layer that contains a minimum 18-inches of earthen material" with "a permeability less than or equal to the permeability of any bottom liner system or natural subsoils present, or a permeability no greater than $1 \times 10^{-5}$ centimeters per second $(\mathrm{cm} / \mathrm{s})$, whichever is less". Additionally, the CFR regulation requires "an erosion layer that contains a minimum 6inches of earthen material that is capable of sustaining native plant growth." The specific requirements for final closure covers in the CCR and CFR regulations lends to the nomenclature of a prescriptive cover.

Per both the CFR and CCR regulations, an alternative final cover, such as a water balance cover (WBC), may be approved if equivalency in percolation is demonstrated. Water balance covers have been demonstrated to achieve hydraulic equivalency to prescriptive covers through numerical modeling and field-scale experiments (Dwyer and Reavis, 2002; Zornberg et al. 2003; Schnabel et al. 2012), and have received regulatory approval for construction (Zornberg et al. 2003; McGuire et al. 2009). Water balance covers are typically constructed as a monolithic layer of loosely compacted on-site soils. A required thickness of the cover can be determined via empirical methods, numerical modeling, or field-scale experiments, and construction quality assurance is implemented to verify the soil classification is consistent with the evaluated soil. 
Prescriptive final covers rely on a hydraulic barrier to reduce percolation whereas WBC rely on the storage of water within the soil pore space and subsequent release of water through evaporation and transpiration to reduce percolation. The hydraulic performance of a prescriptive cover is typically measured through permeability testing on samples of the cover collected using drive or push samplers immediately following construction. Evaluating the hydraulic performance immediately after construction does not account for pedogenesis that occurs postclosure. Pedogenesis alters the hydrologic properties of cover soils, whereby the saturated hydraulic conductivity $\left(k_{s}\right)$ can increase with time (Othman and Benson 1992; Albright and Benson 2001; Benson et al. 2007). The increase in $k_{s}$ for a prescriptive cover can result in noncompliance by exceeding the regulatory maximum $k_{s}$. Water balance covers offer more resilient hydraulic performance because they do not rely on a hydraulic barrier, but instead rely on available storage within the soil matrix that is less likely to be negatively affected by pedogenesis (Benson et al. 2007). The maintained soil water storage capacity, along with other features such as maturing vegetation with thicker and deeper roots, allow a WBC to maintain or potentially improve hydraulic performance with regards to reducing percolation throughout postclosure.

The objective of this project was to compare the effectiveness of a prescriptive earthen final cover and a WBC in mitigating percolation at the Larimer County Landfill, located in northern Colorado, via variably saturated flow modeling. Modeling of both cover types was conducted for a 10 year period using local meteorological data and the finite element modeling program VADOSE/W (GeoSlope 2016). Model input parameters for the soil layers were based on laboratory test results of soils sampled from the existing final prescriptive cover as well as from on-site borrow areas that would be used to construct a potential WBC. The main hypothesis of the research was that a WBC at LCL could provide hydraulic equivalency to the existing prescriptive final cover. Furthermore, the WBC may be more effective at reducing 
percolation during post-closure if the hydraulic conductivity of the prescriptive cover has increased since construction as part of pedogenesis. 


\section{CHAPTER 2: INTRODUCTION TO WATER BALANCE COVERS}

The hydrologic performance of a soil cover can be summarized by the equation:

$$
P=R+E+T+S+P r
$$

where $P$ is precipitation, $R$ is runoff, $E$ is evaporation, $T$ is transpiration, $S$ is change in soil water storage, and $P_{r}$ is percolation. The nomenclature of "water balance cover" is chosen because the percolation through a cover can be minimized by balancing the rearranged Eq. 2.1 as Eq.

\section{2 .}

$$
P_{r}=P-R-E-T-S
$$

Water balance covers reduce percolation by relying on the storage of infiltrated precipitation and subsequent release back to the atmosphere through the processes of evaporation and transpiration. Water balance covers are also referred to as store-and-release covers or evapotranspirative (ET) covers.

Water balance covers are constructed using lower compaction effort than a prescriptive cover. The lower compaction effort retains more pore space for water storage within the soil matrix. More pore space aids in root growth by providing pathways for water and roots, which increases the transpiration contribution within the water balance equation. The additional pore space also increases evaporation by allowing more solar energy into the soil and requiring less energy to remove water upwards through the cover as a gas. Runoff is decreased with the lower compaction effort, which can increase the amount of precipitation entering the water storage layer within the WBC and result in increased percolation.

Water balance covers are typically constructed as a monolithic cover using on-site soils to provide cost savings versus importing or amending on-site soils to meet permeability requirements of a prescriptive cover. Ideally the on-site soils would be fine textured with low plasticity and less than $15 \%$ gravel. The ideal particle-size distribution depends on the site conditions, including climate, vegetation, and slopes. Water balance covers typically have a 
nutrient rich soil layer (e.g., topsoil) placed above the cover to assist in vegetation growth. The compaction effort applied during construction is recommended to be between 80 and $90 \%$ of the maximum dry density ( $\left.\rho_{\mathrm{dmax}}\right)$ as determined by standard Proctor (Albright et al. 2010). This compaction effort is enough to reduce erosion and settlement to tolerable levels while still providing more pore space within the soil versus a prescriptive cover.

A prescriptive cover is a multi-layer cover consisting of an infiltration layer beneath the erosion layer. The infiltration layer is commonly a clay soil compacted to $95 \%$ of $\rho_{\mathrm{dmax}}$ and 0 to $2 \%$ above optimum moisture content $\left(w_{\text {opt }}\right)$ as determined by standard Proctor. This compaction effort with a clay soil tends to meet the permeability requirement of $k_{s}<1 \times 10^{-5} \mathrm{~cm} / \mathrm{s}$. The extra effort of compaction and moisture conditioning adds to the construction cost. If on-site soils cannot achieve the permeability requirement, soil may need to be amended with clay or new soil imported that meets the permeability requirement, resulting in additional cost to the project.

Compacted clay soils are susceptible to formation of macropores due to desiccation, freeze-thaw cycles, and root penetration. The macropore structure of a surficial soil naturally forms from pedogenesis and can create pathways for percolation and further root penetration. These processes can result in an increase in $k_{s}$ up to three orders of magnitude when compared to the measured rates immediately following construction (Othman and Benson 1992; Albright and Benson 2001; Benson et al. 2007). The erosion layer of a prescriptive cover is intended to protect against these natural processes that cause cracking within a compacted clay layer and is typically constructed with available on-site fill. Finally the prescriptive cover is capped with topsoil similar to a WBC. The compaction effort within these upper two layers is less stringent than the infiltration layer as there are no performance specifications to meet per regulations.

Water balance covers have been demonstrated to reduce percolation to acceptable regulatory standards in numerous projects (Zornberg et al. 2003; Albright et al. 2004; Fayer and Gee 2006; Schnabel et al. 2012; McGuire et al. 2009; Apiwantragoon et al. 2014; Zhang and Sun 2014). The successful implementation of a WBC described by McGuire et al. (2009) is of 
particular interest because of the similar geographical and climate conditions to LCL (site was approximately $193 \mathrm{~km}$ (120 mi) south of LCL). As part of the study, eleven WBC were constructed and measured percolation rates in a lysimeter ranged from $1.9 \times 10^{-10}$ to $5.1 \times 10^{-10}$ $\mathrm{cm} / \mathrm{s}$ from 2001 to 2005 . The average annual precipitation over that period at the site was 36.6 $\mathrm{cm}(14.4 \mathrm{in})$, which is similar to the average annual precipitation of $38.4 \mathrm{~cm}(15.1 \mathrm{in})$ in Fort Collins (CSU 2017). The measured percolation rates were in agreement with the model results using input parameters obtained from laboratory testing of local borrow soils.

The CDPHE is the regulatory agency for landfills in Colorado and has published guidance for design, construction, and development of WBC in Colorado (CDPHE 2013). The CDPHE guidance offers a streamlined design approach for WBC based on "Ecozones" delineated throughout the state as shown in Fig. 2.1 and based on cover soil particle size distribution as shown in Fig. 2.2. The CDPHE guidance provides recommendations of construction moisture content, cover soil density, and vegetation. Larimer County Landfill is in Ecozone 3 (Fig. 2.1) and the thickness of acceptable WBC ranges from 76.2 to $122 \mathrm{~cm}(2.5$ to 4 ft) depending on the soil composition.

The required thickness of a WBC can be estimated using an empirical method outlined by Albright et al. (2010). This method uses a ratio of precipitation to potential evapotranspiration (P/PET) developed from site climate data to estimate required storage for a WBC. The monthly values of P/PET are compared to empirical thresholds and if a given monthly value exceeds the thresholds, required storage in that month is summed to calculate a total required storage. The total required soil water storage $\left(S_{r}\right)$ can then be converted to a soil layer thickness $(L)$ as shown in Eq. 2.3:

$$
L \geq \frac{S_{r}}{\theta_{c}-\theta_{m}}
$$

where $\theta_{c}$ is the volumetric water content at field capacity (soil suction $=33 \mathrm{kPa}$ ) and $\theta_{\mathrm{m}}$ is the volumetric water content at the wilting point (soil suction $=1,500 \mathrm{kPa}$ ). 
The average monthly P/PET from 1981 through 2010 (WRCC 2017) for Fort Collins, Colorado along with P/PET thresholds identified by Albright et al. (2010) for required storage are shown in Fig. 2.3a. The average annual P/PET ratio in Fort Collins was 0.17 , with a minimum of 0.11 in January and a maximum of 0.25 in May. Comparing the thresholds in Albright et al. (2010) to the average P/PET for Fort Collins, no monthly average P/PET exceeded the thresholds of 0.32 for spring / summer or 0.51 for fall / winter, which suggests no storage would be required for the proposed WBC. The same analysis was applied for the wettest year with sufficient data (1997, $3^{\text {rd }}$ wettest since 1889) and the 1997 P/PET versus Albright et al. (2010) thresholds are shown in Fig. 2.3b. The 1997 P/PET did exceed thresholds in April, July, and August; however, progressing through the empirical method for required storage in Albright et al. (2010) indicated that the 1997 analysis also yielded no required storage for the proposed WBC. Based on the calculations and analysis in Fig. 2.3 that indicated no required storage for estimating $S_{r}$ and subsequently $L$, Eq. 2.3 was deemed not applicable to LCL. Intuitively, there will be some amount of required storage capacity to store water within the cover and limit percolation into the waste. Thus, thickness of WBC developed for this study were based on CDPHE recommendations (CDPHE 2013). 


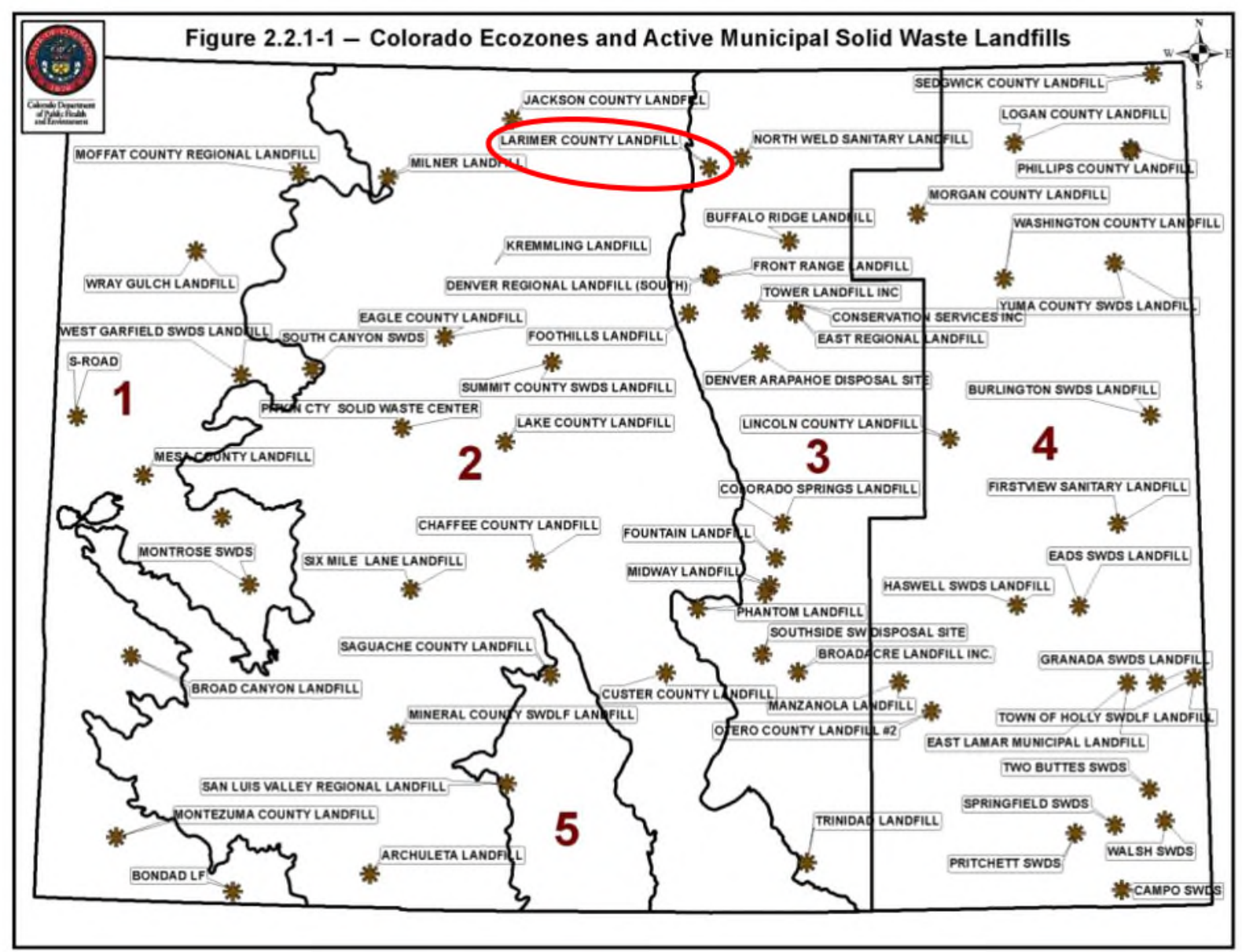

Fig. 2.1 Ecozone delineation from Figure 2.2.1-1 of CDPHE Final Guidance Document on Water Balance Covers in Colorado (CDPHE 2013). 
Figure 2.2.1-4

Water Storage Layer Thicknesses for

Ecozone 3

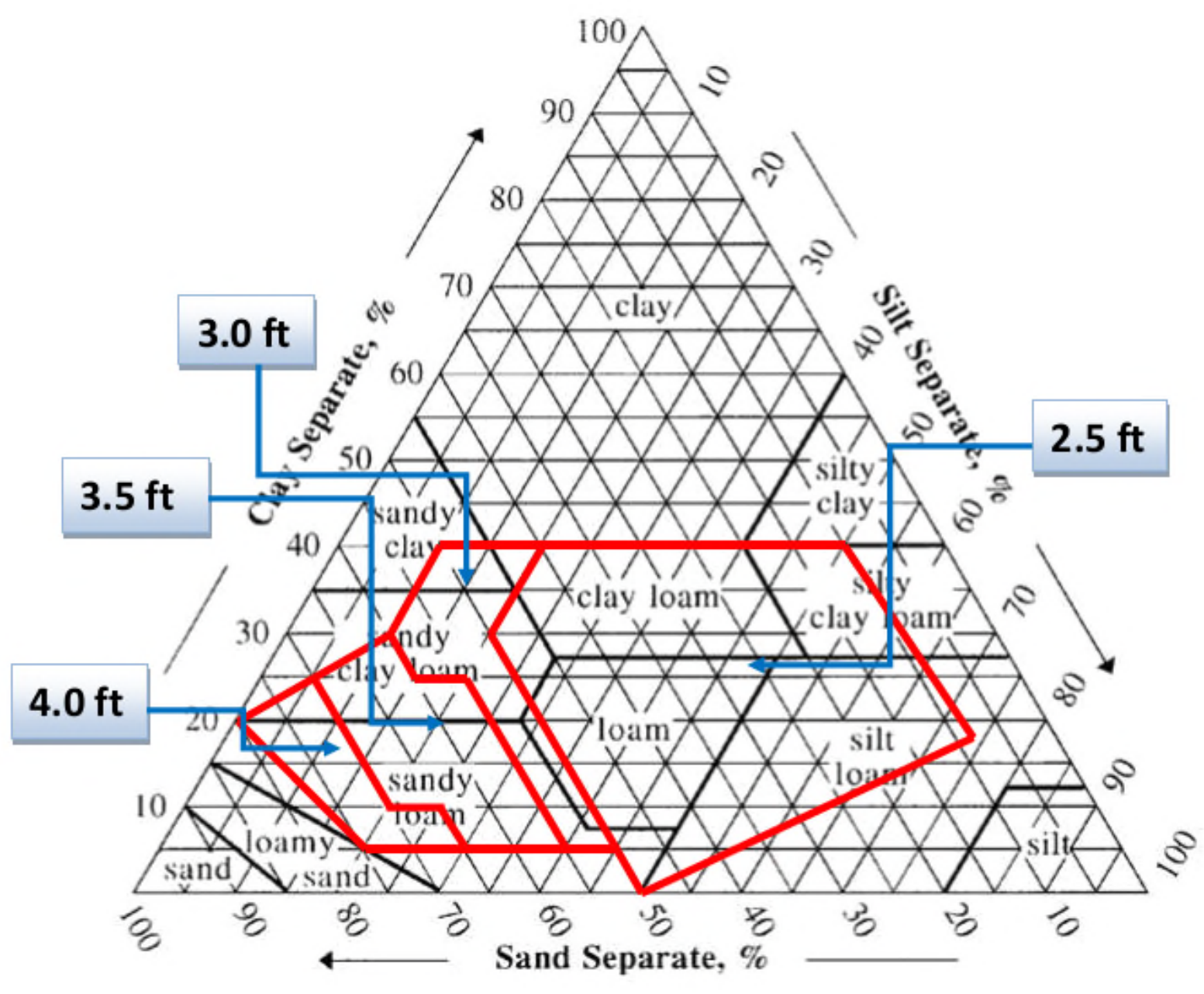

Fig 2.2. Water storage layer thickness for Ecozone 3 from Figure 2.2.1-4 of CDPHE Final Guidance Document on Water Balance Covers in Colorado (CDPHE 2013). 


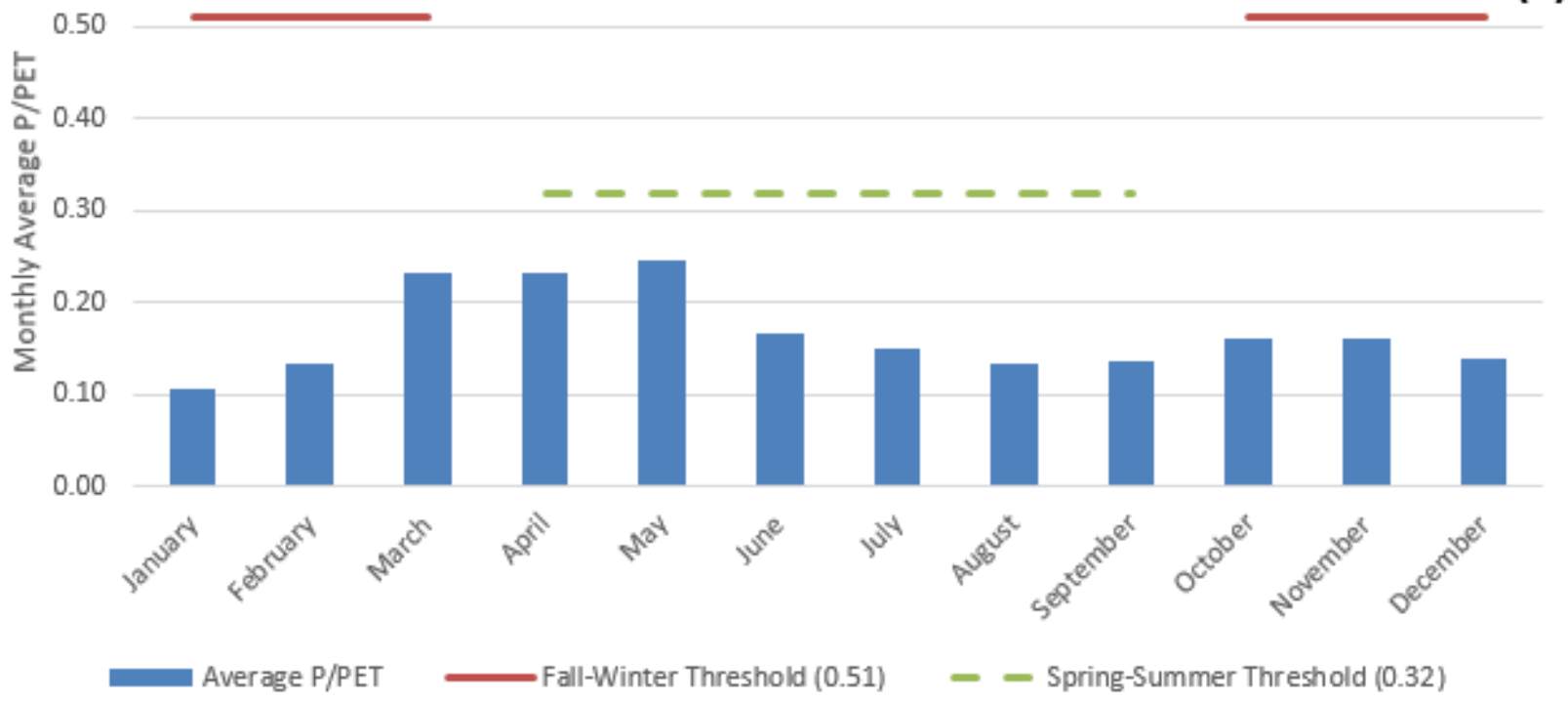

0.60

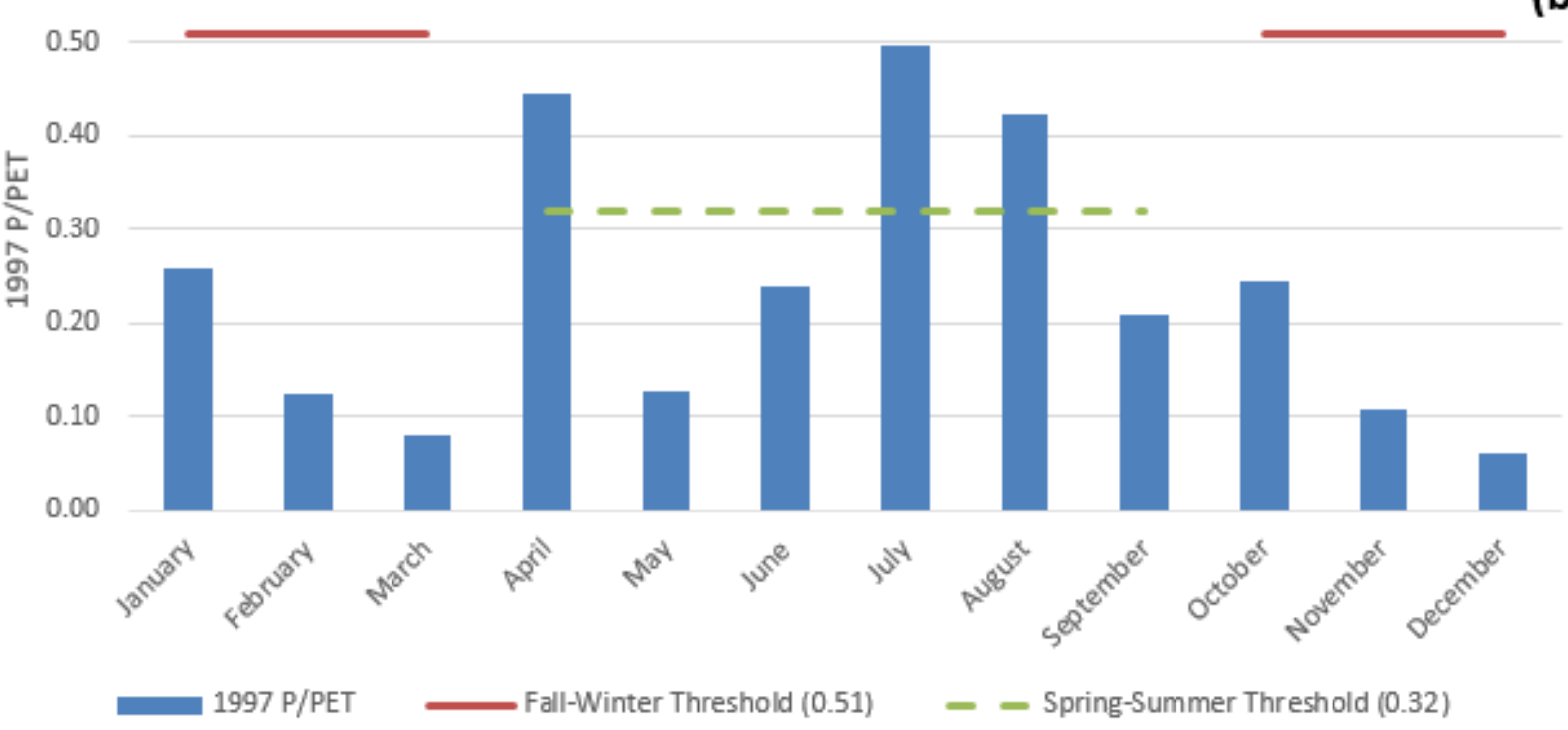

Fig 2.3. Ratio of monthly percolation to potential evapotranspiration (P/PET) for Fort Collins compared to thresholds defined in Alright et al. (2010) for (a) average of 1981 through 2010 and (b) wettest year with sufficient data (1997). 


\section{CHAPTER 3: SITE DESCRIPTION}

\subsection{Physical Setting}

The LCL is located in Larimer County, Colorado immediately outside of the city of Fort Collins limits to the southwest of the city. The climate in Fort Collins is classified as semi-arid, receiving, on average, $38.4 \mathrm{~cm}$ (15.1 in) of precipitation per year (CSU 2017). The landfill elevation ranges from 1580 to $1600 \mathrm{~m}$ (5184 to $5248 \mathrm{ft}$ ) above mean sea level (AMSL). The natural slope of the site is from west to east with the lowest elevation on the property at $1554 \mathrm{~m}$ (5099 ft) AMSL in a natural drainage on the east perimeter to the south of the landfill footprint. Vegetation in the area is reflective of a semi-arid climate with sparse grass and brush comprising the primary vegetation. The landfill has been in operation since 1963 and in 2016 received waste at rate of approximately $998 \mathrm{Mg} / \mathrm{d}(1,100$ tons/d). An estimated $6.8 \mathrm{million} \mathrm{Mg}$ (7.5 million tons) of waste have been deposited in the landfill at the end of 2016. The landfill does not have a bottom liner or a leachate collection system.

\subsection{Published Mapping}

Soil mapping by the Natural Resources Conservation Service (NRCS 2017) identified the soil types within the waste and borrow area footprint as Fort Collins loam, Kim-Thedalund loams, Kim loam, Heldt clay loam, Minnequa-Laporte complex, Longmont clay, Laporte rock outcrop, and Renohill clay loam (Fig. 3.1a and 3.1b). The United States Department of Agriculture (USDA) texture classifications of these unit names include clay, clay loam, sandy clay loam, silty clay loam, loam, silt loam, and sandy loam. Soil overlays bedrock across most of the site, with exception of some outcrops to the northwest and west of the landfill. The landfill vicinity includes various members of the Colorado Group (Tweto and Ogden 1979), which are sedimentary rock deposits from the Cretaceous period (Fig. 3.2), specifically the Pierre Shale-

Lower Unit. More detailed geologic mapping (Braddock et al. 1989) identified units of the 
Niobrara Formation (Smoky Hill Shale Member) and Pierre Shale underlying the landfill footprint (Fig. 3.3). The bedrock units have a north-south orientation and dip to the east. No known faulting is present within the landfill footprint.

\subsection{Previous Closure Activity}

The footprint of the landfill is approximately 72.8 ha $(180 \mathrm{ac})$ of which four closure phases (Phase 1, 2, 3, and 6A) have been completed for a total closure area of 28.3 ha (70 ac) or $39 \%$. The remaining landfill footprint is anticipated to be closed in the next eight years. The final cover of the previous four phases has been constructed under regulation of the CDPHE. Approval for closure by the CDPHE has either been through a design document approved with a letter dated 25 Sept. 1997 or an Engineering Design and Operations Plan approved on 1 Jul. 2003. The approved final cover design consists of four soil layers (from the surface down): 15.2cm (6 in) thick topsoil layer, 45.8-cm (18 in) thick rooting/frost protection layer, 45.8-cm (18 in) thick compacted clay infiltration (Infiltration) layer, and a foundation layer above the waste.

The 45.8-cm-thick Infiltration layer is required to have $k_{s}<1 \times 10^{-5} \mathrm{~cm} / \mathrm{s}$. Construction specifications for the Infiltration layer require the soil to be clay, sandy clay, and/or silty clay having a maximum particle or clod size of $76.2 \mathrm{~mm}$ ( 3 inches), $\geq 50 \%$ fines (particles passing a 0.075-mm sieve), and plasticity index $(P l)>10$. The Infiltration layer material must be compacted to $\geq 95 \%$ of $\rho_{\mathrm{dmax}}$ at a water content between -2 to $+4 \%$ of $w_{\text {opt. }}$ A maximum $k_{s}$ of 1 $x 10^{-5} \mathrm{~cm} / \mathrm{s}$ was to be verified by testing Shelby tube samples from the completed Infiltration layer. Compliance with the $k_{s}$ requirement immediately following construction of each closure phase is tabulated in Table 3.1. Following earthwork construction, the topsoil layer was seeded with grasses and mulched. Soil used to construct the cover has come from on-site borrow sources to the east (Borrow Area 2) and south (Borrow Areas 3 and 4) as shown in Fig. 3.4. 


\subsubsection{Phase 1 Closure}

Phase 1 of the landfill has an area of approximately 5.67 ha (14 ac) and is located in the northeast corner of the landfill footprint (Fig. 3.4). Phase 1 was closed in 1998 using soil from Borrow Area 2 located immediately to the east and south of Phase 1. In April 1998, eight test pits were excavated approximately $2.4 \mathrm{~m}(8 \mathrm{ft})$ below the existing surface for the purpose of obtaining samples for laboratory analysis. Logs detailing the observed subsurface are not available; however, descriptions of the samples and laboratory test results identified the samples as clay and claystone. In-situ moisture content $(w)$ content of the six specimens ranged from 11.9 to $14.1 \%$. Borrow soils were classified as either low- or high-plasticity clay (CL or $\mathrm{CH}$ ) according to the Unified Soil Classification System (USCS). These classifications were based on a fines content ranging from 96 to $99 \%$, liquid limit $(L L)$ ranging from 43 to 52 , and $P$ I ranging from 20 to 31 .

Standard Proctor testing on six samples indicated $\rho_{\mathrm{dmax}}$ ranging from 1.73 to 1.81 megagrams per cubic meter $\left(\mathrm{Mg} / \mathrm{m}^{3}\right)$ (108.0 to 113.2 pounds per cubic foot [pcf]) and $w_{\text {opt }}$ ranging from 16.5 to $19 \%$. Flexible wall permeability tests yielded $k_{s}$ ranging from $1.7 \times 10^{-7}$ to $5.8 \times 10^{-5} \mathrm{~cm} / \mathrm{s}$ on specimens remolded to $95 \%$ of $\gamma_{\mathrm{dmax}}$ at $w_{\text {opt. }}$

Construction quality assurance testing consisted of 310 in situ density tests on the Infiltration layer using a nuclear moisture-density gauge and thirteen laboratory permeability tests on Shelby tube samples collected following construction. The in-situ dry density $\left(\rho_{d}\right)$ (ranged from 1.56 to $1.92 \mathrm{Mg} / \mathrm{m}^{3}$ (97.5 to $120.1 \mathrm{pcf}$ ) with an average of $1.78 \mathrm{Mg} / \mathrm{m}^{3}$ (111.4 pcf). The $w$ ranged from 12.6 to $26.8 \%$ with an average of $17.0 \%$. The flexible wall permeability test results indicated a range of $k_{s}$ from $2.2 \times 10^{-8}$ to $1.2 \times 10^{-6} \mathrm{~cm} / \mathrm{s}$ with an average of $1.6 \times 10^{-7}$ $\mathrm{cm} / \mathrm{s}$. 


\subsubsection{Phase 3 Closure}

Phase 3 of the landfill was closed in 2004 and has an area of approximately 15.67 ha (4 ac) located in the northwest corner of the landfill footprint. Phase 3 is immediately to the west of Phase 2 and north of Phase 6A (Fig. 3.4). Soil used in construction of the Infiltration layer was from Borrow Area 2. In addition to previous testing during Phase 1 closure in 1998, four additional samples were collected for assessment in fall 2003. Samples were collected using hand-driven samplers and identified as weathered claystone by field personnel.

The $\rho_{\mathrm{d}}$ ranged from 1.72 to $1.86 \mathrm{Mg} / \mathrm{m}^{3}$ (107.1 to $114.5 \mathrm{pcf}$ ) and $w$ ranged from 9.8 to $18.3 \%$. The fines content ranged from 61 to $76 \%$. Atterberg limits of the specimens indicated $L L$ from 42 to 49 and $P I$ from 21 to 29. The fines content and Atterberg limits correspond to a USCS classification of CL.

Standard Proctor testing on the specimen from the "southwest corner" of Borrow Area 2 yielded $\rho_{\mathrm{dmax}}$ of $1.69 \mathrm{Mg} / \mathrm{m}^{3}$ (105.3 pcf) at $w_{\text {opt }}$ of $18.9 \%$ whereas $\rho_{\mathrm{dmax}}$ of $1.58 \mathrm{Mg} / \mathrm{m}^{3}$ (98.4 pcf) at $w_{\text {opt }}$ of $21.2 \%$ was calculated by testing the specimen from the "northeast corner" of Borrow Area 2. Another sampling event in March 2004 was focused on one "representative sample of native clay materials from the borrow area," which was identified as claystone bedrock. Particle size distributions indicated the fines content was $92.6 \%$ and Atterberg limits indicated an $L L$ of 47 and $P I$ of 30 , yielding a USCS classification of CL. Permeability testing resulted in $k_{s}$ of 2.51 $\times 10^{-6}, 1.64 \times 10^{-8}$, and $5.28 \times 10^{-9} \mathrm{~cm} / \mathrm{s}$ on specimens remolded at respective moisture conditions of $2 \%$ below $\mathrm{w}_{\mathrm{opt}}$, at $\mathrm{w}_{\mathrm{opt}}$, and $3 \%$ above $\mathrm{w}_{\mathrm{opt}}$. All three specimens were compacted to $95 \%$ of standard Proctor effort, which was based on $\rho_{\mathrm{dmax}}$ of $1.73 \mathrm{Mg} / \mathrm{m}^{3}$ (107.8 pcf) and $w_{\text {opt }}$ of $17.8 \%$.

Construction quality assurance testing of the cover soils consisted of 300 in situ density tests using a nuclear moisture-density gauge and sixteen laboratory permeability tests. Samples for permeability testing were collected using a California liner in a hand-drive sampler driven into the constructed cover. The in-situ $\rho_{d}$ ranged from 1.77 to $1.84 \mathrm{Mg} / \mathrm{m}^{3}$ (110.6 to $114.6 \mathrm{pcf}$ ) and 
the in-situ $w$ ranged from 13.8 to $17.2 \%$. Permeability tests resulted in $k_{s}$ from $1.5 \times 10^{-8}$ to $4.9 \times$ $10^{-6} \mathrm{~cm} / \mathrm{s}$ with an average of $4.3 \times 10^{-7} \mathrm{~cm} / \mathrm{s}$.

\subsubsection{Phase 2 Closure}

Phase 2 of the landfill encompasses approximately 10.9 ha (27 ac) and was closed in 2008. Phase 2 is located on the north central side of the waste footprint and was closed after Phase 1 to the east and Phase 3 to the west (Fig. 3.4). Borrow Area 2 was the primary source of cover fill and was the same source used in the Phase 1 and Phase 3 closures.

Borrow Area 2 testing data were provided from an investigation in 2003 and another during construction from July to September, 2008 in addition to the investigations described with the Phase 1 and 3 closures. The 2003 investigation included three borings to depths of $7.6 \mathrm{~m}$ or $9.1 \mathrm{~m} \mathrm{(25} \mathrm{or} 30 \mathrm{ft}$ ) below the existing ground surface. The boring logs show $15.2 \mathrm{~cm}(6 \mathrm{in})$ of topsoil above sandy lean clay to a depth of $61 \mathrm{~cm}(2 \mathrm{ft})$. Weathered siltstone/claystone extends to 1.2 to $1.8 \mathrm{~m} \mathrm{(4} \mathrm{to} 6 \mathrm{ft}$ ) below existing ground surface before comparatively unweathered siltstone/claystone was encountered until the borings were terminated.

Six specimens were selected for particle size distribution and Atterberg limit testing, which yielded fines content between 76 and $99 \%, L L$ from 44 to 53, and PI from 24 to 37 . Based on fines content and Atterberg limits, a USCS classification of either $\mathrm{CL}$ or $\mathrm{CH}$ is applicable. Standard Proctor testing resulted in a $\rho_{\text {dmax }}$ ranging from 1.50 to $1.58 \mathrm{Mg} / \mathrm{m}^{3}$ (93.5 to 98.5 pcf) at $w_{\text {opt }}$ from 22.5 to $25.5 \%$.

The 2008 geotechnical investigation in Borrow Area 2 provided testing results for four specimens taken from either "East or West Excavation Area". The fines content of the specimens ranged from 53 to $86 \%, L L$ ranged from 44 to 47 , and $P$ I ranged from 28 to 31 . These test results are consistent with a USCS classification of CL. Standard Proctor testing yielded $\rho_{\mathrm{dmax}}$ from 1.72 to $1.80 \mathrm{Mg} / \mathrm{m}^{3}$ (107.5 to $112.5 \mathrm{pcf}$ ) and $w_{\text {opt }}$ of either 16 or $16.5 \%$. 
An additional geotechnical investigation of an area to the south and west of the landfill footprint identified as "Borrow Area 4" and "Onsite Secondary Borrow Source" was presented in the Phase 2 closure report. Nine geotechnical borings were drilled in August 2002 and another six drilled in February 2006. Soils consisting of sandy lean clay or clayey sand extended to depths of 0 to $7.3 \mathrm{~m}$ ( 0 to $24 \mathrm{ft}$ ) with an average depth of $3.47 \mathrm{~m}(11.4 \mathrm{ft})$ until a claystone/siltstone/shale was encountered and extended to the termination depth of the borings.

The fines content ranged from 41 to $83 \%$ with an average of $70 \%$ among nine samples collected from the soil stratum. The $L L$ ranged from 34 to 47 and $P /$ ranged from 19 to 30 based on four specimens. The test results indicated a USCS classification of CL or clayey sand (SC). One sample of the bedrock from B-5 was selected for laboratory testing and the results indicated a fines content of $41 \%, L L$ of 32 , and $P I$ of 14 .

Construction quality assurance testing of the constructed cover included 602 in situ density tests with a nuclear moisture-density gauge and sixteen flexible-wall hydraulic conductivity tests conducted on samples collected using Shelby tubes or California samplers driven into the constructed cover. The laboratory $k_{s}$ ranged from $2.1 \times 10^{-9}$ to $3.0 \times 10^{-7} \mathrm{~cm} / \mathrm{s}$ with an average of $4.5 \times 10^{-8} \mathrm{~cm} / \mathrm{s}$.

\subsubsection{Phase 6A Closure}

Phase 6A of the landfill has an area of approximately $6.1(15 \mathrm{ac})$ and is located directly south of Phase 3 in the southwest corner of the landfill footprint (Fig. 3.4). Phase 6A was closed in 2011 using Borrow Area 3 as a fill source. A geotechnical investigation of Borrow Area 3

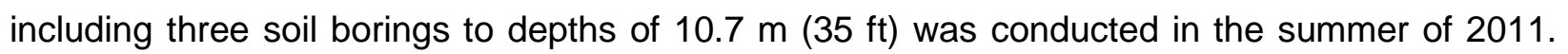
The boring logs indicate 1.5 to $7.3 \mathrm{~m} \mathrm{(5} \mathrm{to} 24 \mathrm{ft}$ ) of sandy clay with occasional gravels underlain by claystone, which continued until the borings were terminated.

Laboratory testing of the borrow soils yielded fines content between 73 and $83 \%, L L$ ranging from 37 to 49 , and $P /$ ranging from 25 to 36 , which correspond to a USCS classification 
of CL. Two standard Proctor tests indicated a $\rho_{\mathrm{dmax}}$ of 1.75 to $1.83 \mathrm{Mg} / \mathrm{m}^{3}$ (109 and $114 \mathrm{pcf}$ ) both at the same $w_{\text {opt }}$ of $16 \%$. Permeability testing on two specimens resulted in a $k_{s}$ of $1.6 \mathrm{x}$ $10^{-8}$ and $2.9 \times 10^{-8} \mathrm{~cm} / \mathrm{s}$. The condition of the permeability test specimens, either in-situ or remolded, is unclear based on the data available.

A sample identified as "flour" was tested for particle size distribution and Atterberg limits as well. Discussions with Larimer County personnel have revealed the "flour" is a locally found loosely deposited clayey soil. Test results indicated a fines content of $65 \%, L L$ of 45 , and $P I$ of 27, that corresponded to a USCS classification of CL.

Testing of two specimens of the claystone resulted in a fines content of 90 and $96 \%, L L$ of 46 and 48, and PI of 29 and 35, indicating a USCS classification of CL. A standard Proctor test on a sample of the claystone indicated a $\rho_{\mathrm{dmax}}$ of $1.79 \mathrm{Mg} / \mathrm{m}^{3}(111.5 \mathrm{pcf})$ at wopt $_{\text {of }} 16.5 \%$. A permeability test on a specimen of claystone, undetermined whether in-situ or remolded, resulted in a $k_{s}$ of $1.7 \times 10^{-8} \mathrm{~cm} / \mathrm{s}$.

Construction quality assurance testing included seventeen particle-size distributions, fourteen Atterberg limit tests, 141 field-compaction tests, and eight permeability tests on samples of the Infiltration layer. The particle-size distributions indicated fines content between 57 and $89 \%$. Atterberg limits testing yielded $L L$ ranging from 30 to 47 and $P /$ ranging from 14 to 30. Flexible wall permeability tests had a $k_{s}$ ranging from $5.1 \times 10^{-9}$ to $1.7 \times 10^{-8} \mathrm{~cm} / \mathrm{s}$ with an average of $1.0 \times 10^{-8} \mathrm{~cm} / \mathrm{s}$ on specimens of the Infiltration layer retrieved using Shelby tubes.

\subsection{Previous Borrow Area 3 Investigation}

A geotechnical investigation of Borrow Area 3 was completed in 2016 with the intent of gathering data for a future closure phase. The eight geotechnical borings identified clay soils to depths of 2.4 to $7.6 \mathrm{~m}$ ( 8 to $25 \mathrm{ft}$ ) where claystone bedrock was encountered or the boring was terminated. Particle-size distributions revealed a fines content between 85 and $97 \%$. The $L L$ ranged from 41 to 59 and the $P I$ ranged from 20 to 34, indicating a USCS classification of either 
$\mathrm{CL}$ or $\mathrm{CH}$. The specific gravity $\left(G_{s}\right)$ of the soil ranged from 2.72 to 2.76 . A standard Proctor test was conducted on the $\mathrm{CH}$ soil and yielded $\rho_{\mathrm{dmax}}$ of $1.62 \mathrm{Mg} / \mathrm{m}^{3}(101.1 \mathrm{pcf})$ at $\mathrm{w}_{\mathrm{opt}}$ of $20.8 \%$. A permeability test on a specimen remolded to $95 \%$ compaction and $1.7 \%$ below $\mathrm{w}_{\text {opt }}$ indicated a $k_{s}$ of $8.2 \times 10^{-8} \mathrm{~cm} / \mathrm{s}$.

Two samples of the claystone bedrock were tested for the same parameters. The fines contents were 95 and $82 \%, L L=44$ and 38 with $P I$ of 23 and 20, and $G_{s}$ were 2.73 and 2.72. A standard Proctor test on one of the samples resulted in a $\rho_{\mathrm{dmax}}$ of $1.79 \mathrm{Mg} / \mathrm{m}^{3}$ (111.8 pcf) at $\mathrm{w}_{\mathrm{opt}}$ of $16.4 \%$. A permeability test on a specimen remolded to $95 \%$ compaction and $1.5 \%$ below $\mathrm{w}_{\mathrm{opt}}$ indicated a $k_{s}$ of $1.8 \times 10^{-7} \mathrm{~cm} / \mathrm{s}$. 
Table 3.1. Construction quality assurance hydraulic conductivity $\left(k_{s}\right)$ test results of samples collected with Shelby tubes $(75 \mathrm{~mm}$ diameter) immediately after final cover construction at Larimer County Landfill.

\begin{tabular}{|c|c|c|c|c|}
\hline $\begin{array}{c}\text { Construction Phase } \\
\text { (year) }\end{array}$ & $\begin{array}{c}\text { Number of } \\
\text { Tests }\end{array}$ & $\begin{array}{c}\text { Average } k_{s} \\
(\mathrm{~cm} / \mathrm{s})\end{array}$ & $\begin{array}{c}\text { Maximum } k_{s} \\
(\mathrm{~cm} / \mathrm{s})\end{array}$ & $\begin{array}{c}\text { Minimum } k_{s} \\
(\mathrm{~cm} / \mathrm{s})\end{array}$ \\
\hline Phase 1 (1998) & 13 & $1.6 \times 10^{-7}$ & $1.2 \times 10^{-6}$ & $2.2 \times 10^{-8}$ \\
\hline Phase 3 (2004) & 16 & $4.3 \times 10^{-7}$ & $4.9 \times 10^{-6}$ & $1.5 \times 10^{-8}$ \\
\hline Phase 2 (2008) & 16 & $4.5 \times 10^{-8}$ & $3.0 \times 10^{-7}$ & $2.1 \times 10^{-9}$ \\
\hline Phase 6A (2011) & 8 & $1.0 \times 10^{-8}$ & $1.7 \times 10^{-8}$ & $5.1 \times 10^{-9}$ \\
\hline
\end{tabular}




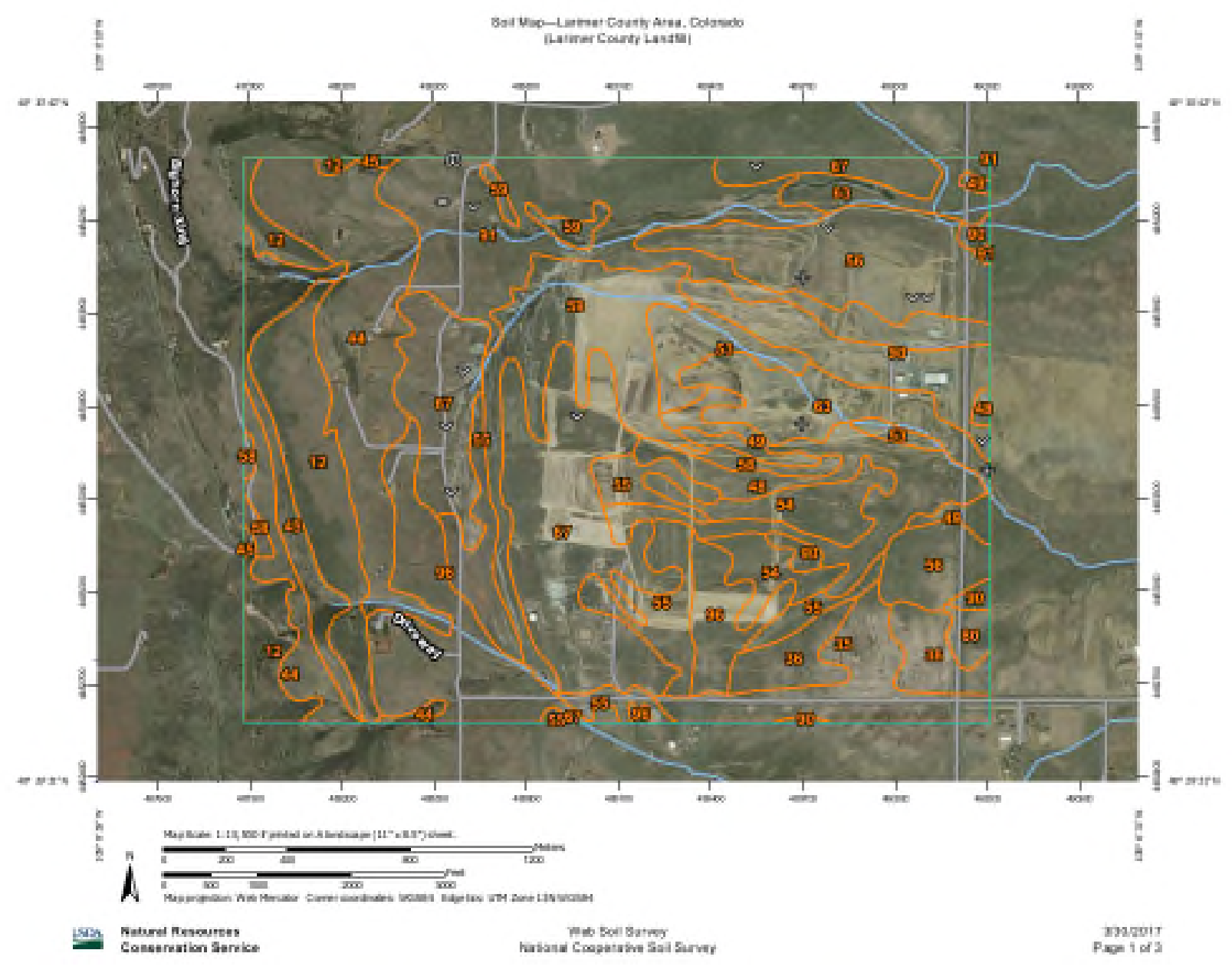

Fig. 3.1a. Soil unit map for the area of Larimer County Landfill developed by NRCS (2017). 


\section{Map Unit Legend}

\begin{tabular}{|c|c|c|c|}
\hline \multicolumn{4}{|c|}{ Larimer County Area, Colorado (CO644) } \\
\hline Map Unit Symbol & Map Unit Name & Acres in $\mathrm{AOI}$ & Percent of AOI \\
\hline 12 & $\begin{array}{l}\text { Baller-Rock outcrop complex, } \\
15 \text { to } 45 \text { percent slopes }\end{array}$ & 80.2 & $7.3 \%$ \\
\hline 35 & $\begin{array}{l}\text { Fort Collins loam, } 0 \text { to } 3 \\
\text { percent slopes }\end{array}$ & 40.2 & $3.6 \%$ \\
\hline 36 & $\begin{array}{l}\text { Fort Collins loam, } 3 \text { to } 5 \\
\text { percent slopes }\end{array}$ & 30.8 & $2.8 \%$ \\
\hline 44 & Haplustolls, hilly & 111.0 & $10.1 \%$ \\
\hline 45 & $\begin{array}{l}\text { Haplustolls-Rock outcrop } \\
\text { complex, steep }\end{array}$ & 30.3 & $2.7 \%$ \\
\hline 48 & $\begin{array}{l}\text { Heldt clay loam, } 0 \text { to } 3 \text { percent } \\
\text { slopes }\end{array}$ & 57.8 & $5.2 \%$ \\
\hline 49 & $\begin{array}{l}\text { Heldt clay loam, } 3 \text { to } 6 \text { percent } \\
\text { slopes }\end{array}$ & 10.3 & $0.9 \%$ \\
\hline 53 & $\begin{array}{l}\text { Kim loam, } 1 \text { to } 3 \text { percent } \\
\text { slopes }\end{array}$ & 22.7 & $2.1 \%$ \\
\hline 54 & $\begin{array}{l}\text { Kim loam, } 3 \text { to } 5 \text { percent } \\
\text { slopes }\end{array}$ & 34.0 & $3.1 \%$ \\
\hline 55 & $\begin{array}{l}\text { Kim loam, } 5 \text { to } 9 \text { percent } \\
\text { slopes }\end{array}$ & 62.6 & $5.7 \%$ \\
\hline 56 & $\begin{array}{l}\text { Kim-Thedalund loams, } 3 \text { to } 15 \\
\text { percent slopes }\end{array}$ & 88.4 & $8.0 \%$ \\
\hline 58 & $\begin{array}{l}\text { Kirtley-Purner complex, } 5 \text { to } 20 \\
\text { percent slopes }\end{array}$ & 3.3 & $0.3 \%$ \\
\hline 59 & $\begin{array}{l}\text { Laporte-Rock outcrop } \\
\text { complex, } 3 \text { to } 30 \text { percent } \\
\text { slopes }\end{array}$ & 74.4 & $6.7 \%$ \\
\hline 63 & $\begin{array}{l}\text { Longmont clay, } 0 \text { to } 3 \text { percent } \\
\text { slopes }\end{array}$ & 55.7 & $5.0 \%$ \\
\hline 67 & $\begin{array}{l}\text { Minnequa-Laporte complex, } 3 \\
\text { to } 15 \text { percent slopes }\end{array}$ & 148.0 & $13.4 \%$ \\
\hline 80 & $\begin{array}{l}\text { Otero-Nelson sandy loams, } 3 \\
\text { to } 25 \text { percent slopes }\end{array}$ & 5.8 & $0.5 \%$ \\
\hline 90 & $\begin{array}{l}\text { Renohill clay loam, } 3 \text { to } 9 \\
\text { percent slopes }\end{array}$ & 44.7 & $4.1 \%$ \\
\hline 91 & $\begin{array}{l}\text { Renohill-Midway clay loams, } 3 \\
\text { to } 15 \text { percent slopes }\end{array}$ & 120.2 & $10.9 \%$ \\
\hline 96 & $\begin{array}{l}\text { Satanta loam, } 3 \text { to } 5 \text { percent } \\
\text { slopes }\end{array}$ & 82.3 & $7.5 \%$ \\
\hline \multicolumn{2}{|l|}{ Totals for Area of Interest } & $1,103.0$ & $100.0 \%$ \\
\hline
\end{tabular}

Fig. 3.1b. Soil unit identification from NRCS (2017) maps. 


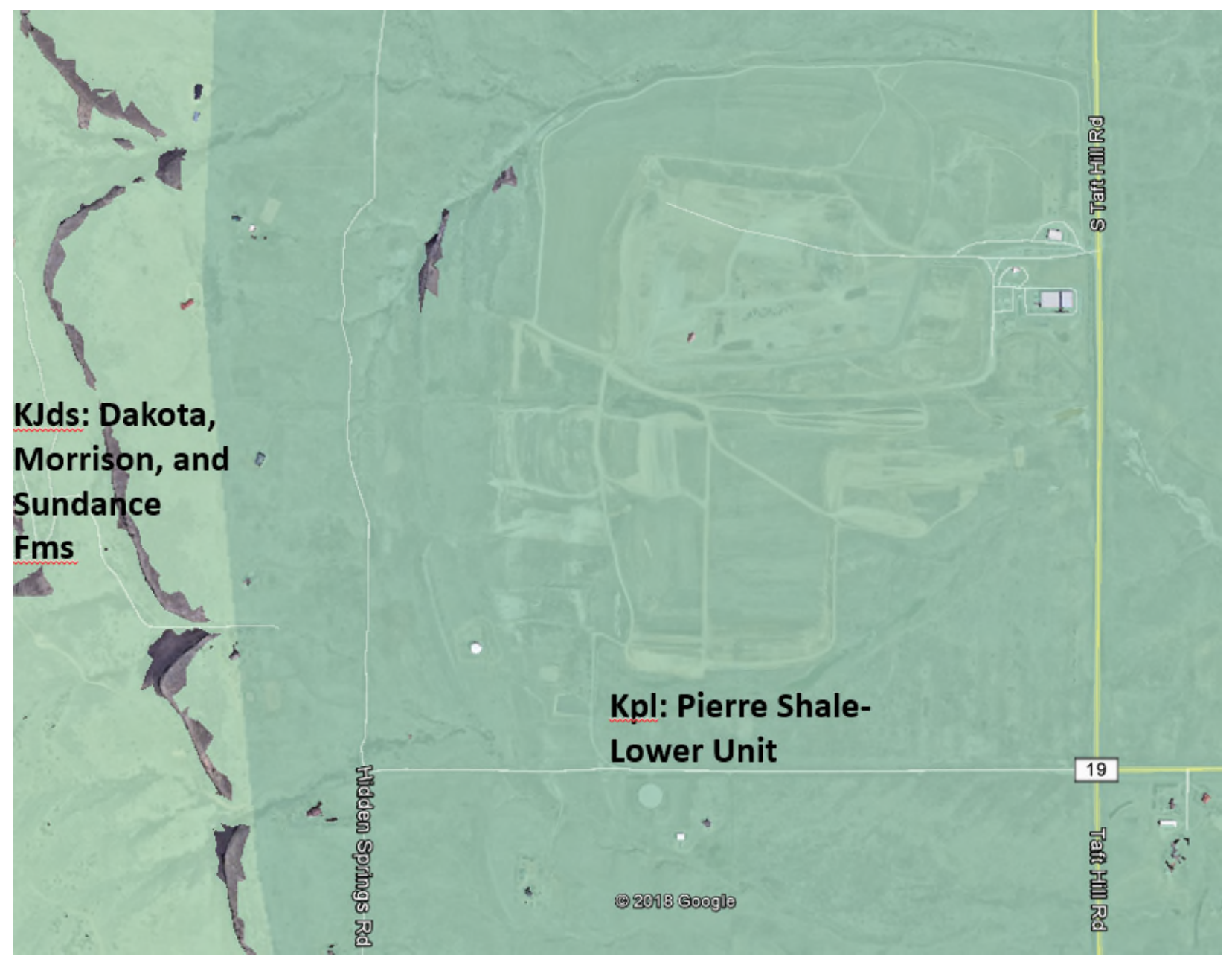

Fig. 3.2. Bedrock geology units identified in Tweto and Ogden (1979) overlain on an aerial photograph of Larimer County Landfill. 
Excerpted from: Geologic Map of the Horsetooth Reservoir Quadrangle, Larimer County, Colorado By William A. Braddock, Ronald H. Calvert, Joseph T. O'Connor, and Gordon A. Swann, 1989. Department of the Interior, U.S. Geological Survey

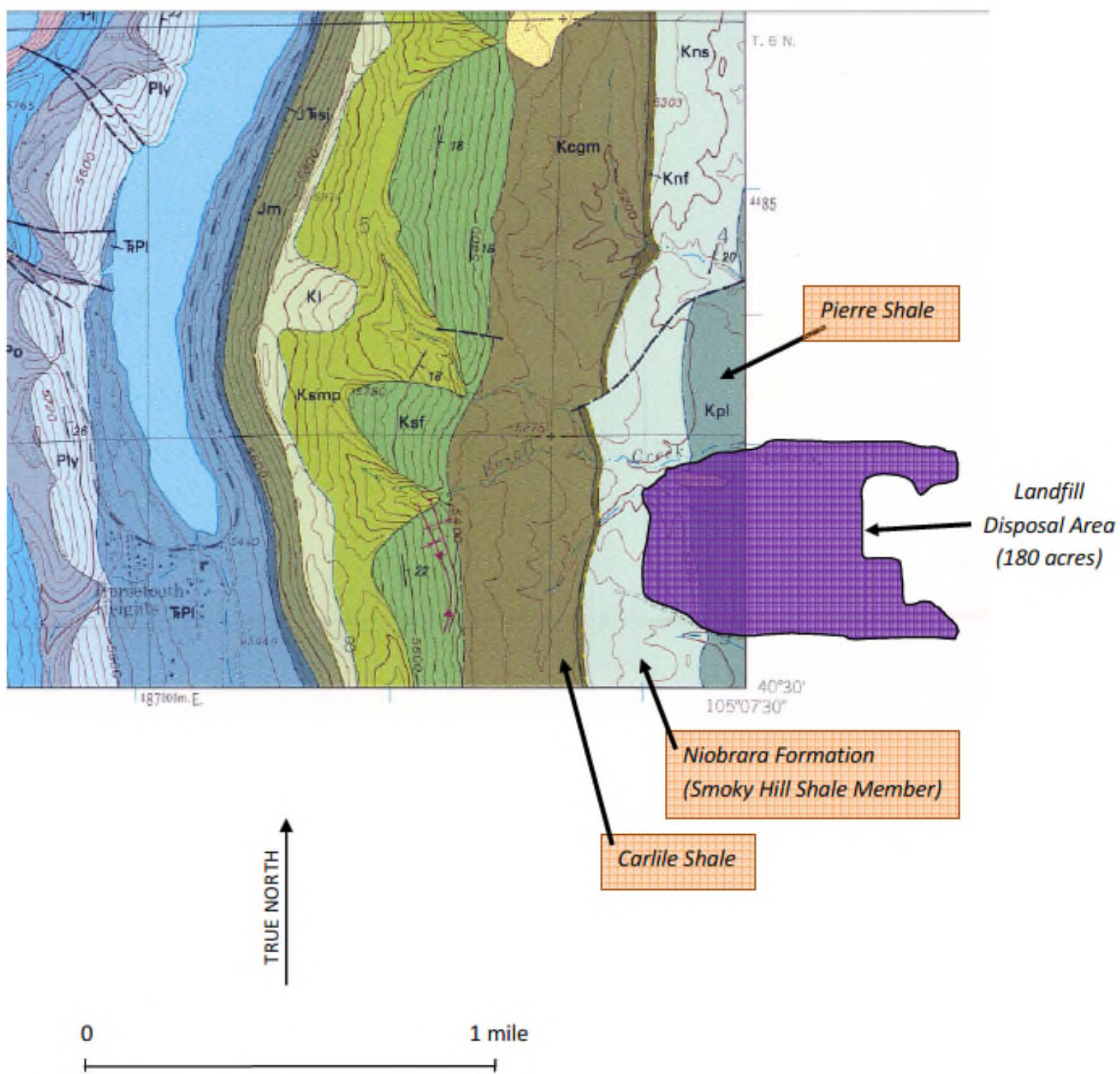

Fig. 3.3. Bedrock geology map by Braddock et al. (1989) provided by Larimer County Landfill. 


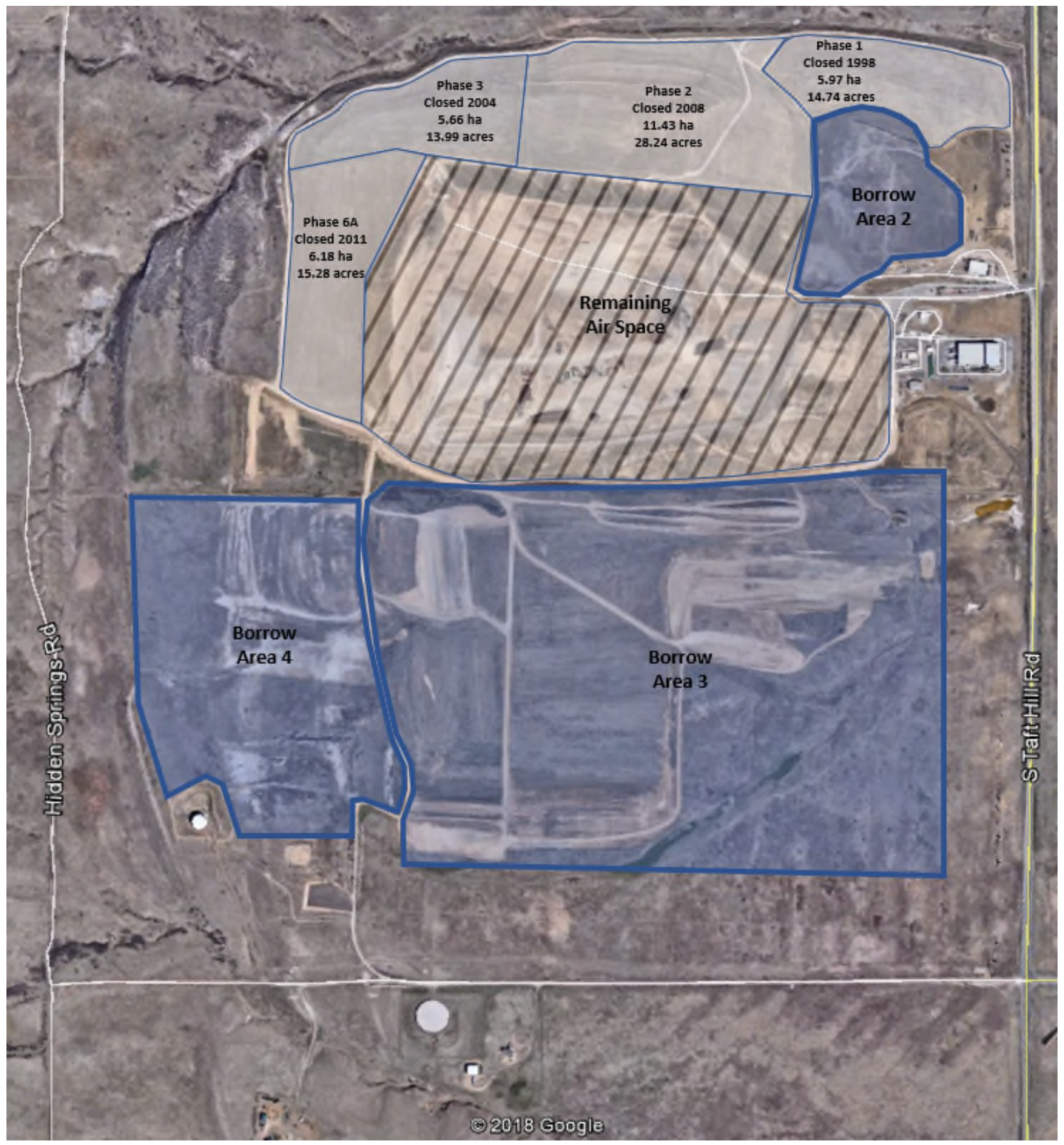

Fig. 3.4. Larimer County Landfill closure phases and borrow areas. 


\section{CHAPTER 4: METEOROLOGICAL DATA}

Hydrologic modeling to assess the water balance of a final cover with VADOSE/W requires daily meteorological (MET) data, including minimum and maximum temperatures, minimum and maximum relative humidity values, precipitation, average wind speed, and solar radiation. A conservative approach to assessing a potential cover design via hydrologic modeling is to use a temporal period representing wetter-than-average conditions (Albright et al. 2010). Annual precipitation recorded at the Fort Collins-Loveland Municipal Airport (Airport) (Weather Underground 2017) is shown in Fig. 4.1. The airport is located $10.5 \mathrm{~km}$ (6.5 mi) east of the landfill and the MET data set included measurements dating back to 1889. The wettest 10-yr period was from 1990 through 1999. However, the time period from 1992 through 2001 was selected for this study because this time period represented the $3^{\text {rd }}$ wettest ten-consecutive years on record and had a nearly complete MET data set for each year.

A nearly complete set of temperature and precipitation data from 1992 through the end of 2001 was also available from a weather station at Colorado State University (CSU 2017) located $8.9 \mathrm{~km}(5.5 \mathrm{mi})$ north of the landfill. A comparison of the daily temperature data between the Airport and CSU revealed the CSU data was, on average, $95 \%$ of the daily maximum and $98 \%$ of the daily minimum temperatures recorded at the airport. Considering similarities in the data sets, the Airport maximum and minimum daily temperatures were used for modeling to maintain consistency with the rest of the MET data. Precipitation data indicated that CSU received $173 \%$ of the precipitation received at the Airport from 1992-2001. In this case, the CSU station precipitation data were used in the model to favor a conservative estimate of the water balance at LCL.

The final MET data set assembled from 1992 through 2001 had 140 days of the total possible 3,653 days $(<4 \%)$ with at least one missing MET data parameter. Meteorological data were estimated for these missing days from 1992 through January 31, 1996, via computing an 
average from the day prior and after the missing data point. Missing MET data after February 1 , 1996 were obtained from the CSU weather station data. 


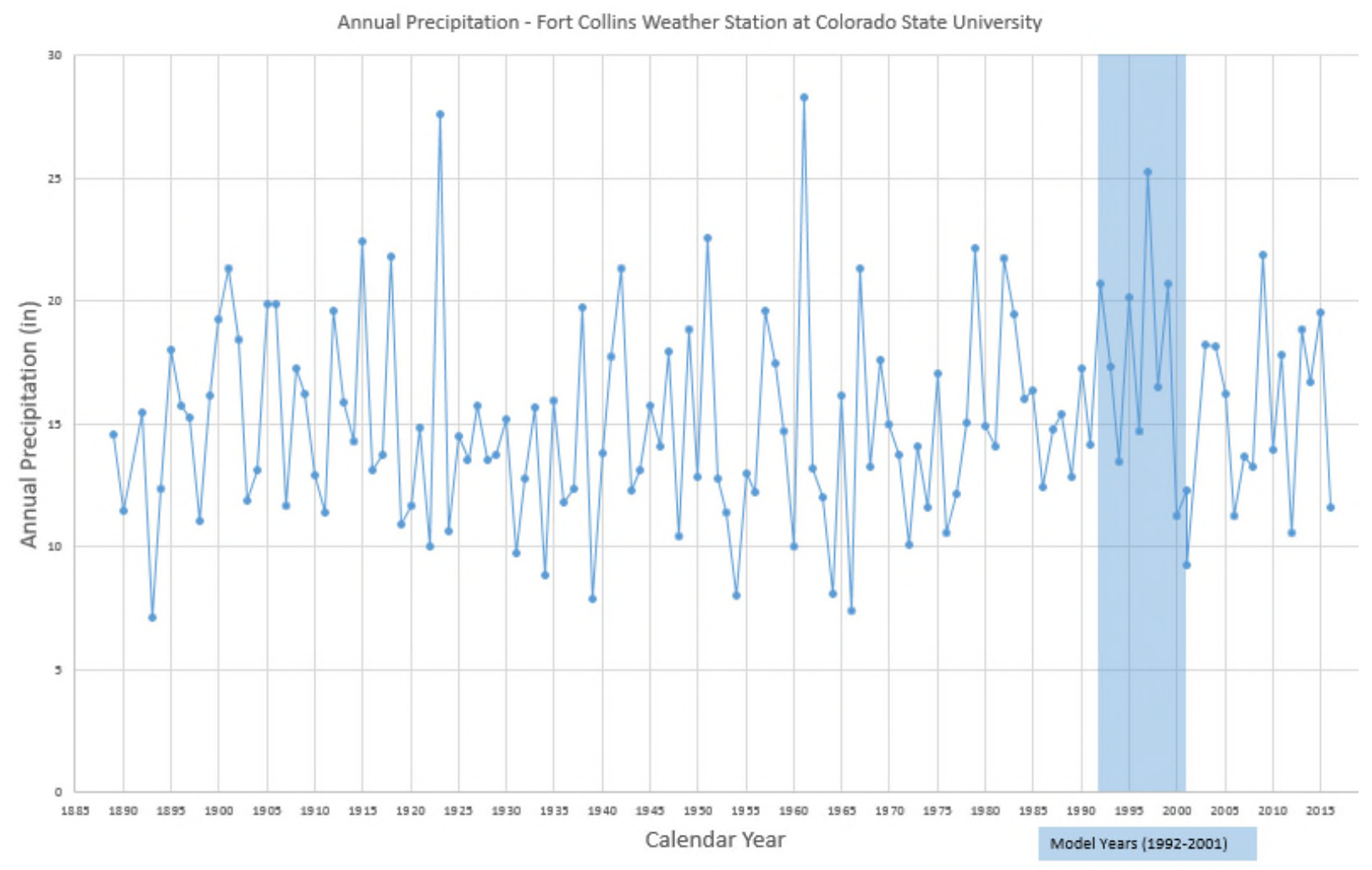

Fig 4.1. Annual precipitation recorded at the Colorado State University Weather Station from 1889 through 2016. The Model Years for water balance modeling used in this study were from the start of 1992 through the end of 2001. 


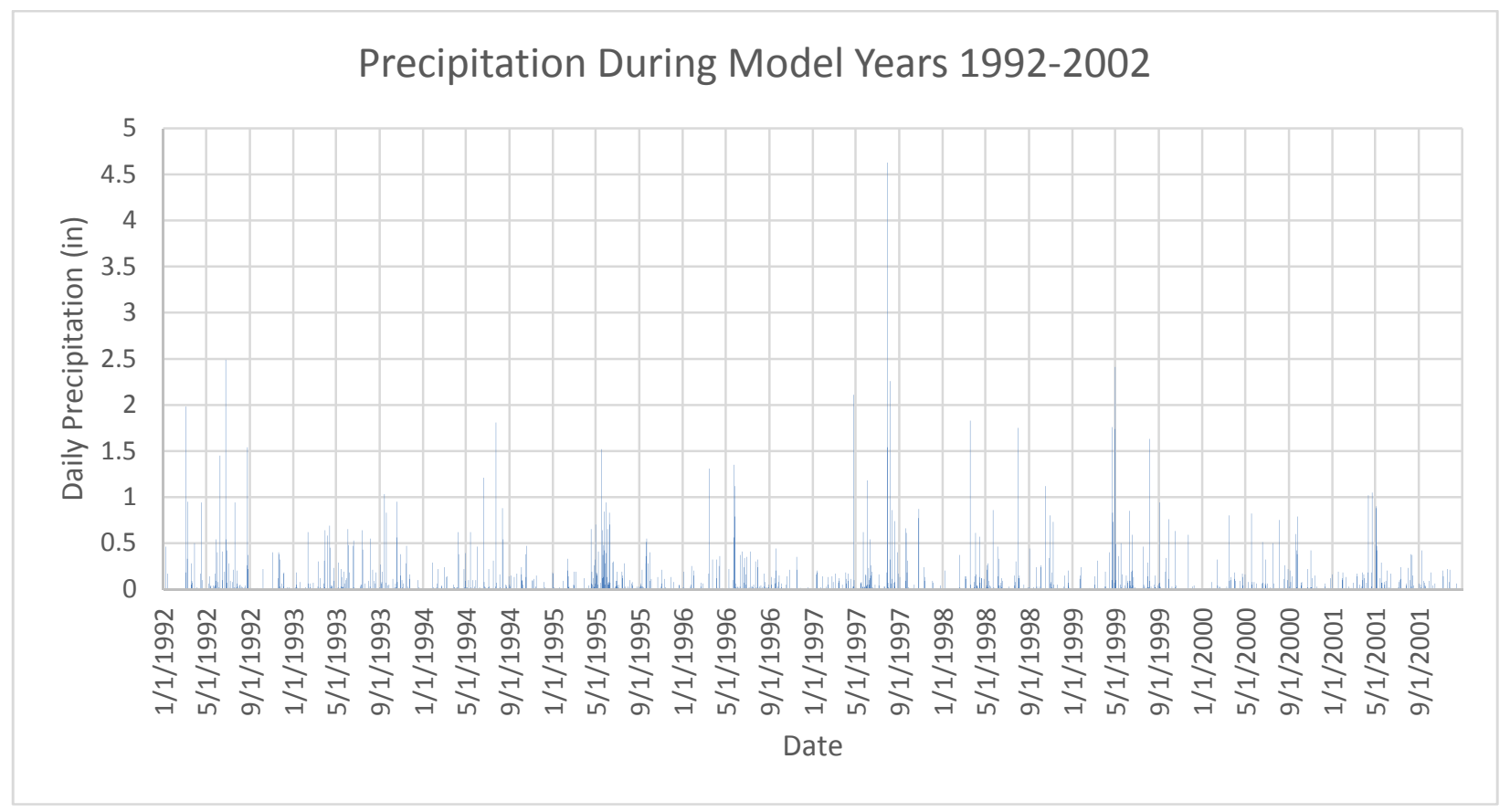

Fig 4.2. Daily precipitation recorded at the Colorado State University Weather Station during the Model Years (1992-2002) used in this study for water balance modeling. 


\section{CHAPTER 5: SAMPLING}

Soil sampling at LCL occurred on April 6 and June 27, 2017. Samples were collected from Borrow Area 3 and Borrow Area 4 on April 6 and from Phase 1 of the existing final cover on June 27.

\subsection{Borrow Area Sampling}

The intent of sampling the borrow areas was to obtain soil samples for laboratory testing to represent (i) an undisturbed state that can be expected to represent long-term cover conditions and (ii) re-molded / compacted state to simulate a newly constructed cover. Test pits,

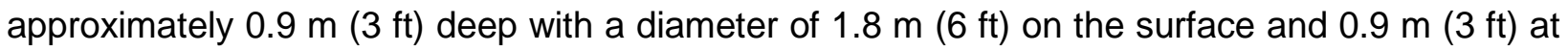
the bottom, were excavated in Borrow Area 3 and 4. Soil strata in the two borrow areas consisted of approximately $15 \mathrm{~cm}$ (6 in) of topsoil with a dense root structure in the upper 7.6 $\mathrm{cm}$ (3 in) and some roots penetrating to depths of $45.7 \mathrm{~cm}$ (18 in).

The topsoil was low plasticity clay with some gravel, loose, dark brown, moist, and no organic odor. Below the topsoil was a low plasticity clay, stiff, brown to light brown with depth, slightly moist to dry with depth, and mottling present. A list of samples collected from the borrow areas is presented in Table 5.1. During excavation of the topsoil, two grab samples were collected from each location. Excavation continued while keeping an intact column of soil in the center of the excavation to collect a block sample inside a $30.5 \mathrm{~cm}$ (12 in) tall by $35.6 \mathrm{~cm}$ (14 in) diameter polyvinylchloride (PVC) sampling ring. The PVC ring aided in collecting undisturbed samples, and when the PVC ring fit over a complete specimen, the bottom was sheared off and the sample was wrapped in plastic and secured with wood panels on the top and bottom of the sampling ring. Two block samples were collected in each borrow area, at consecutive $30.5 \mathrm{~cm}$ (12 in) depth increments starting at the bottom of the topsoil (final depth of excavation $\sim 0.9 \mathrm{~m}$ ). 
Two grab samples were collected to represent both $30.5 \mathrm{~cm}$ (12 in) depth increments where block samples were collected.

\subsection{Existing Closure Cover Sampling}

The Phase 1 closure cover was sampled for laboratory testing of the compacted clay cover 20-yr post-construction and to determine the existing profile for hydrologic modeling. A combination of hand tools and a backhoe were used to excavate a test pit $1.8 \mathrm{~m}(6 \mathrm{ft})$ deep with an approximate diameter of $2.7 \mathrm{~m}(9 \mathrm{ft})$ on the surface and $1.8 \mathrm{~m}(6 \mathrm{ft})$ at the bottom. A $30.5-\mathrm{cm}-$ thick (1 ft) topsoil layer was observed with a less dense root structure than the borrow area samples and the roots were primarily confined to the topsoil layer. The remainder of the excavation was clay fill with fragments of gray claystone, increasing in stiffness and plasticity with depth, brown with some gray, slightly moist to moist with depth, and decreasing desiccation with depth.

A difference in the level of compaction was estimated to occur at a depth of

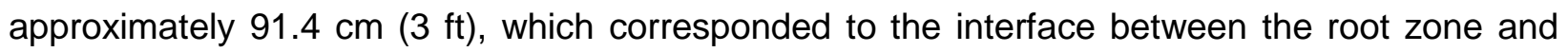
Infiltration layer that had respective compaction specifications of $\approx 92 \%$ and $>95 \%$ of the $\rho_{\mathrm{dmax}}$ as determined by standard Proctor effort (BE\&K/Terranext 1999). Actual layer thicknesses of

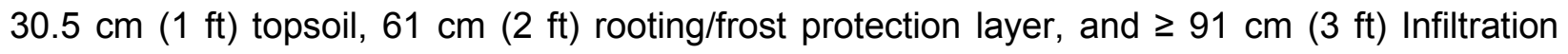
layer exceeded the specified thicknesses of $15.2 \mathrm{~cm}(0.5 \mathrm{ft})$ topsoil, $45.7 \mathrm{~cm}(1.5 \mathrm{ft})$ rooting/frost protection layer, and $45.7 \mathrm{~cm}(1.5 \mathrm{ft})$ Infiltration layer from the construction certification report. Contact with the underlying foundation layer, which would indicate the bottom of the Infiltration layer, was not noted in the field. However, the difference may not have been discernable as the foundation layer likely experienced densification during compaction of the final cover and was sourced from the same borrow area (Borrow Area 2).

Grab samples and block samples were collected from the Phase 1 final cover area in a similar manner as the borrow areas. A list of samples collected during the Phase 1 final cover 
sampling event is provided in Table 5.1. Block samples were collected from the root/frost protection and Infiltration layers. The excavation was backfilled in lifts using soil from the excavation and supplemental soil from the current borrow area. Each lift was moisture conditioned and compacted with the backhoe bucket and a jumping jack compactor. 
Table 5.1. Samples collected from borrow areas and Phase 1 closure cover.

\begin{tabular}{|c|c|c|c|}
\hline Sample ID & Sample Location & Approximate Sample Depth $(\mathrm{cm})^{\text {a }}$ & Sample Type $^{\text {b }}$ \\
\hline B3-TS & Borrow Area 3 & 0 to $15(0.0$ to 0.5$)$ & Bulk \\
\hline B3-BS1 & Borrow Area 3 & 15 to $45(0.5$ to 1.5$)$ & Bulk and Ring \\
\hline B3-BS2 & Borrow Area 3 & 45 to $76(1.5$ to 2.5$)$ & Bulk and Ring \\
\hline B4-TS & Borrow Area 4 & 0 to $15(0.0$ to 0.5$)$ & Bulk \\
\hline B4-BS1 & Borrow Area 4 & 15 to $45(0.5$ to 1.5$)$ & Bulk and Ring \\
\hline B4-BS2 & Borrow Area 4 & 45 to $76(1.5$ to 2.5$)$ & Bulk and Ring \\
\hline LCL-TS & Phase 1 & 0 to $31(0.0$ to 1.0$)$ & Bulk and Ring \\
\hline LCL-RZ & Phase 1 & 38 to $69(1.25$ to 2.25$)$ & Bulk and Ring \\
\hline LCL-CC1 & Phase 1 & 99 to $130(3.25$ to 4.25$)$ & Bulk and Ring \\
\hline LCL-CC2 & Phase 1 & 145 to $175(4.75$ to 5.75$)$ & Bulk and Ring \\
\hline
\end{tabular}

a Depths in feet provided in parentheses.

${ }^{\mathrm{b}}$ Bulk = grab sample collected from disturbed soil; Ring = block sample collected in $30.5 \mathrm{~cm}$ (12 in) tall by $35.6 \mathrm{~cm}$ (14 in) diameter polyvinylchloride (PVC) sampling ring 


\section{CHAPTER 6: GEOTECHNICAL LABORATORY TESTING}

Geotechnical laboratory testing of undisturbed block samples and remolded soil specimens from both borrow areas and Phase 1 was conducted at CSU. Laboratory testing included particle-size distribution (mechanical sieve and hydrometer), Atterberg limits, in situ density, in situ moisture content, specific gravity, standard Proctor, permeability, and soil water retention. American Standards for Testing Materials (ASTM) procedures were followed for the laboratory testing. Results are presented in regards to the location and soil layer of the samples.

\subsection{Borrow Area Soil Geotechnical Laboratory Testing}

Samples were collected from two borrow areas at depths of approximately 0 to $15 \mathrm{~cm}(0$ to $6 \mathrm{in}$ ), 15 to $46 \mathrm{~cm}$ (6 to $18 \mathrm{in}$ ), and 46 to $76 \mathrm{~cm}$ (18 to $30 \mathrm{in}$ ). A summary of geotechnical characteristics for borrow area samples is in Table 6.1. The USCS classifications were similar among different layers and between Borrow Area 3 and 4 with all soils yielding low-plasticity clay with sand $(\mathrm{CL})$. The USDA texture of the borrow area samples was a clay loam.

\subsubsection{Characterization and Compaction Testing}

The 0 to $15 \mathrm{~cm}$ (0 to 6 in) soil layer corresponded to topsoil (TS) for Borrow Areas 3 and 4. Particle-size distributions of this TS layer were nearly identical, with $36 \%$ sand, $40-41 \%$ silt, and $23-24 \%$ clay sized particles (Table 6.1). Atterberg limits were also similar between the two TS layers $(L L=35$ and 37 , and $P I=15)$. Although the in situ water content for TS from Borrow Area 3 was higher (25\%) compared to Borrow Area 4 (19\%), results from standard Proctor compaction testing were similar between both borrow area TS samples $\left(\rho_{\mathrm{dmax}}=1.58\right.$ and 1.64 $\mathrm{Mg} / \mathrm{m}^{3}$ [98.5 to $\left.102.1 \mathrm{pcf}\right]$ and $\mathrm{w}_{\mathrm{opt}}=19.5$ to $20.0 \%$, Table 6.1$)$.

The 15 to $46 \mathrm{~cm}$ (6 to $18 \mathrm{in})$ and 46 to $76 \mathrm{~cm}$ (18 to $30 \mathrm{in}$ ) samples from both borrow areas consisted of native material with lower organic content compared to the TS. These soil 
layers were identified as potential borrow material for the closure cover. Particle-size distribution of four samples yielded the following ranges: 32 to $38 \%$ sand, 34 to $40 \%$ silt, and 26 to $34 \%$ clay. Atterberg limits of the same four samples indicated $L L$ ranged from 38 to 46 and $P /$ ranged from 16 to 24 (Table 6.1). The in-situ water content ranged between 9 and $10 \%$, except for the specimen from 15 to $46 \mathrm{~cm}$ in Borrow Area 3 that had an in situ water content of $20 \%$. The in situ $\rho_{d}$ measured in block samples from Borrow Areas 3 and 4 were 1.38 and $1.32 \mathrm{Mg} / \mathrm{m}^{3}(86.4$ and 82.4 pcf), respectively, corresponding to $85.9 \%$ and $82.2 \%$ compaction. Standard Proctor compaction testing on the four samples from Borrow Areas 3 and 4 yielded comparable results, with $\rho_{\mathrm{dmax}}$ ranging between 1.60 and $1.65 \mathrm{Mg} / \mathrm{m}^{3}$ (100 to $103 \mathrm{pcf}$ ) and $w_{\text {opt }}$ ranging between 19.3 and $21.1 \%$. Specific gravity of the samples ranged from 2.61 to 2.64 .

\subsubsection{Permeability Testing}

Permeability testing adhering to ASTM D5084 (2016a) standards for flexible wall permeability testing using the falling head-rising tailwater method was used to measure $k_{s}$. Permeability testing was performed on block samples and remolded bulk samples. Block samples were extracted from the PVC ring and trimmed to a $305 \mathrm{~mm}$ (12 in) diameter with a height ranging from 150 to $220 \mathrm{~mm}$ (5.9 to $8.7 \mathrm{in}$ ). All remolded specimens were prepared at the target water content and target density in compaction molds with a $102 \mathrm{~mm}$ (4 in) inside diameter and $116 \mathrm{~mm}$ (4.5 in) height. After preparing the remolded specimens in compaction molds, the specimens were extruded using a hydraulic jack and placed in the permeameters.

All specimens were backpressure saturated to obtain a $B$-value $>0.95$ and consolidated to $15 \mathrm{kPa}$ (313 psf), which is a common effective stress representing soil in a cover application. Benson et al. (2007), Benson and Bareither (2012), Scalia et al. (2017) used effective stress ranging 14 to $19 \mathrm{kPa}$ (292 to $397 \mathrm{psf}$ ) for evaluating soil used in a cover. A hydraulic gradient of 5 to 10 was used for WBC materials (i.e., Borrow Area 3 and Borrow Area 4). Each experimental setup consisted of a permeameter, head water (influent), tailwater (effluent), and 
cell water. Head water, tailwater, and cell water were connected to pressure panels. The difference between the cell water and the average of the head water and tailwater was maintained at $15 \mathrm{kPa}(313 \mathrm{psf})$.

Tap water $(E C=13 \mathrm{mS} / \mathrm{m}$ and $\mathrm{pH}=6.9)$ was used within the permeameters to apply cell pressure as well as in the pressure panel inflow and outflow columns as permeant fluid. Visible air bubbles were flushed from the drainage tubes prior to testing and permeation was conducted upward through the specimen to aid in removing entrapped air bubbles. Filter paper and porous stones were placed on the top and bottom of the specimen. All porous stones were soaked in tap water prior to placement within the permeameter. Specimens were separated from the cell pressure fluid via conventional latex membranes sealed with O-rings.

Permeation of a given hydraulic conductivity specimen was performed until the following termination criteria were achieved for at least four consecutive measurements (ASTM D 5084; Daniel 1994): (i) ratio of effluent volume to influent volume $\left(V_{\text {out }} / V_{\text {in }}\right)$ was between 0.75 and 1.25 and (ii) $k_{s}$ was within $\pm 25 \%$ of the geometric mean $k_{s}$ for $k_{s} \geq 1 \times 10^{-10} \mathrm{~m} / \mathrm{s}$. Permeability testing of block samples from Borrow Areas 3 and 4 yielded $k_{s}$ of $1.1 \times 10^{-4} \mathrm{~cm} / \mathrm{s}$ and $2.4 \times 10^{-4} \mathrm{~cm} / \mathrm{s}$, respectively. A series of permeability tests were conducted on soil from bulk samples collected from Borrow Areas 3 and 4 that was remolded to different moisture contents and compaction efforts. The target water content and density were selected to simulate possible cover construction scenarios such as if (i) no construction water was added and the compaction effort varied, (ii) water was added to approximate $w_{\text {opt }}$ and compaction effort varied, or (iii) the material was compacted to the specifications of a prescriptive cover (Table 6.5).

Hydraulic conductivity measured on the remolded specimens are shown as a function of molding water content and percent relative compaction in Fig. 6.1. Moisture contents of remolded specimens ranged from $5.5 \%$ to $21.3 \%$ and relative compaction ranged from $78 \%$ to $95 \%$ (1.26 to $1.55 \mathrm{Mg} / \mathrm{m}^{3} ; 78.5$ to $\left.96.9 \mathrm{pcf}\right)$. These permeability tests on remolded specimens yielded $k_{s}$ ranging from $1.1 \times 10^{-6} \mathrm{~cm} / \mathrm{s}$ to $4.2 \times 10^{-4} \mathrm{~cm} / \mathrm{s}$. Trends in the data sets indicated that 
$k_{s}$ decreased significantly with increasing water content of the remolded specimen and $k_{s}$ decreased to a lesser degree with increasing compaction effort for a given moisture content.

\subsubsection{Soil Water Retention Testing}

Moisture retention tests were conducted in accordance with the drying curve method using a pressure chamber and gravimetric measurements described in ASTM D6836 Method C (ASTM 2016b). The pressure plate chamber was used to apply air pressures from $5 \mathrm{kPa}$ to $1500 \mathrm{kPa}$ (104 to $31,330 \mathrm{psf}$ ) that were converted to soil suction $(\Psi)$ by axis translation. Relatively undisturbed specimens trimmed from block samples were prepared in oedometer rings with inside diameter $=150 \mathrm{~mm}(5.9 \mathrm{in})$ and height $=76.2 \mathrm{~mm}(3 \mathrm{in})$. Samples of in-situ or remolded soil specimens were prepared in oedometer rings with inside diameter $=63.5 \mathrm{~mm}(2.5$ in) and height $=25.4 \mathrm{~mm}(1 \mathrm{in})$. Weight loss at each testing stage (i.e., each $\Psi$ ) was measured and then converted to a change in volumetric water content.

Soil water retention testing yielded relationships between volumetric water content $(\theta)$ and soil suction ( $\Psi$ ) (i.e., soil water characteristic curves, SWCCs) that were fit with the van Genuchten equation (1980):

$$
\theta=\theta_{r}+\left(\theta_{s}-\theta_{r}\right)\left\{\frac{1}{1+(\alpha \cdot \psi)^{n}}\right\}^{m}
$$

where $\theta_{\mathrm{r}}$ is residual volumetric water content, $\theta_{\mathrm{s}}$ is saturated volumetric water content (i.e., porosity), and $\alpha, m$, and $n$ are fitting parameters. Eq. 6.1 was fit to $\psi-\theta$ data to develop a soil water characteristic curve using a non-linear least squares optimization that allowed $\alpha$ and $n$ to vary with the constraint that $m=1-n^{-1}$. The $\theta_{\mathrm{s}}$ was computed by weight-volume relationships and fixed during fitting of Eq. 6.1. The $\theta_{r}$ was held constant based on values presented in Rawls et al. (1982) organized by USDA soil texture or from the Rosetta Model (USDA, 2008) developed by the USDA for estimating unsaturated hydraulic functions. The Rosetta Model uses the density and percentages of sand, silt, and clay to predict van Genuchten parameters. 
Unsaturated hydraulic properties obtained from soil water retention tests and van Genuchten equation fits are presented in Table 6.2. Relationships of $\theta$ versus $\psi$ along with fitted soil water characteristic curves based on the van Genuchten equation are shown in Fig. 6.2. van Genuchten parameters for the Borrow Area 3 block sample were $\alpha=0.348 \mathrm{kPa}^{-1}$ $\left(0.017 \mathrm{psf}^{-1}\right)$ and $n=1.261$ with $\theta_{\mathrm{s}}=0.481$ and $\theta_{\mathrm{r}}=0.04$. The same procedure on the Borrow Area 4 block samples resulted in $\alpha=0.061 \mathrm{kPa}^{-1}\left(0.003 \mathrm{psf}^{-1}\right)$ and $n=1.633$ with $\theta_{\mathrm{s}}=0.495$ and $\theta_{r}=0.04$.

\subsection{Existing Closure Cover Phase 1 Geotechnical Laboratory Testing}

Samples collected from the Phase 1 closure cover were separated by presumed construction layers (topsoil, rooting/frost protection, Infiltration layer) associated with the sample depth and excavation observations. Geotechnical characteristics of four samples from the three layers (two samples from Infiltration layer) sampled from the Phase 1 closure cover are in Table 6.3. The topsoil layer and rooting-zone layer were similar and classified as $\mathrm{CL}$, whereas the two samples collected from the Infiltration layer classified as $\mathrm{CH}$ (high-plasticity clay). This difference in classification was anticipated since LCL had used select soil for the Infiltration layer that had higher plasticity and lower hydraulic conductivity (described subsequently). All three layers of the Phase 1 cover had a USDA soil texture of a silty clay.

\subsubsection{Characterization Testing}

The topsoil consisted of $3 \%$ sand, $51 \%$ silt, and $45 \%$ clay, with $L L=45$ and $P I=23$. The in situ $w$ was measured as $9.4 \%$. Standard Proctor compaction testing indicated $\rho_{\mathrm{dmax}}=$ $1.58 \mathrm{Mg} / \mathrm{m}^{3}(98.7 \mathrm{pcf})$ and $\mathrm{w}_{\mathrm{opt}}=20.7 \%$. The rooting-zone layer was $57 \%$ silt and $43 \%$ clay, and exhibited $L L=46$ and $P I=24$. The in situ moisture content of the rooting-zone specimen was $13.8 \%$. 
The two samples from the Infiltration layer were collected from depths of approximately 107 to $137 \mathrm{~cm}$ ( $3 \frac{1}{2}$ to $4 \frac{1}{2}$ feet) and 137 to $168 \mathrm{~cm}\left(4^{1 / 2}\right.$ to $51 / 2$ feet). Both samples were $100 \%$ fine-grained particles, contained 44 to $45 \%$ clay-sized particles, had $L L=53$ to 55 , and $P I=30$ to 32 (Table 6.3). The in situ $w$ and $\rho_{d}$ were $16.0 \%$ and $1.79 \mathrm{Mg} / \mathrm{m}^{3}$ (111.9 pcf) for the upper sample and $14.7 \%$ and $1.91 \mathrm{Mg} / \mathrm{m}^{3}$ (119.3 pcf) for the lower sample. Standard Proctor compaction testing yielded $\rho_{\mathrm{dmax}}=1.74 \mathrm{Mg} / \mathrm{m}^{3}(108.7 \mathrm{pcf})$ and $w_{o p t}=17.7 \%$ for the upper sample and $\rho_{\mathrm{d} \max }=1.75 \mathrm{Mg} / \mathrm{m}^{3}(109 \mathrm{pcf})$ and $w_{\text {opt }}=18.4 \%$ for the lower sample. Test results indicate a relative compaction of 103 and $109 \%$ for the upper and lower Infiltration layer samples.

\subsubsection{Permeability and Soil Water Retention Testing}

Permeability and soil water retention tests results are summarized in Table 6.4. These experiments were carried-out following similar procedures as described previously with the exception of using a hydraulic gradient of 20 to 30 for existing Phase 1 cover material because this soil had a lower permeability than the WBC soils. Permeability testing of the Infiltration layer block samples resulted in $k_{s}=1.2 \times 10^{-7} \mathrm{~cm} / \mathrm{s}$ for the upper sample and $8.9 \times 10^{-8} \mathrm{~cm} / \mathrm{s}$ for the lower sample. The $k_{s}$ was measured as $6.5 \times 10^{-8} \mathrm{~cm} / \mathrm{s}$ and $7.3 \times 10^{-8} \mathrm{~cm} / \mathrm{s}$ when the upper and lower bulk samples were remolded to approximately $95 \%$ compaction at $2 \%$ wet of $w_{\text {opt }}$ determined by standard Proctor. Relationships of $\theta$ versus $\Psi$ along with fitted SWCCs based on the van Genuchten equation are shown in Fig. 6.3 and the fitting parameters are presented in Table 6.4. van Genuchten parameters for the upper Infiltration layer block sample were $\alpha=$ $0.028 \mathrm{kPa}^{-1}\left(0.0013 \mathrm{psf}^{-1}\right)$ and $n=1.737$ with $\theta_{\mathrm{s}}=0.264$ and $\theta_{\mathrm{r}}=0.078$. The van Genuchten parameters for the lower Infiltration layer block sample resulted in $\alpha=0.026 \mathrm{kPa}^{-1}\left(0.0012 \mathrm{psf}^{-1}\right)$ and $n=1.319$ with $\theta_{s}=0.290$ and $\theta_{r}=0.078$. 


\subsection{Phase 1 Comparison: Laboratory Results and Construction Certification Reports}

Geotechnical characterization of samples collected from the Phase 1 final cover as part of this study were compared to available data from Borrow Area 2 that was used to construct the Phase 1 final cover in 1998. The soil classification test results from this study and the 1998 construction are presented in Fig. 6.4. The 2017 samples had fines content of $100 \%$ for all four samples. The $L L$ ranged from 45 to 55 and $P /$ ranged from 23 to 33 . These test results yielded USCS classifications of $\mathrm{CH}$ or CL. The 1998 Borrow Area 2 investigation test results also yielded a USCS classification of $\mathrm{CH}$ or CL based on a fines content ranging from 96 to $99, L L$ ranging from 43 to 52 , and $P /$ ranging from 20 to 31 . The two data sets show a strong correlation between laboratory test results from the constructed Phase 1 cover and the Borrow Area 2 investigation before construction of the final cover.

A moisture content of $13.8 \%$ was measured on a sample collected from the rooting/frost protection layer of the Phase 1 cover, which compared favorably to construction documentation indicating the rooting/frost protection layer was placed at $w$ between 12.0 and $17.3 \%$ with an average $w=14.4 \%$ based on 20 nuclear moisture-density test results. The $\rho_{d}$ of the sample of the rooting/frost protection layer was $1.74 \mathrm{Mg} / \mathrm{m}^{3}$ (108.8 pcf) versus a range of 1.67 to 1.86 $\mathrm{Mg} / \mathrm{m}^{3}$ (104.2 to $116.2 \mathrm{pcf}$ ) with an average $\rho_{\mathrm{d}}=1.78 \mathrm{Mg} / \mathrm{m}^{3}$ (111.1 pcf) from 20 nuclear moisture-density test results. Comparison of exhumed and construction quality assurance test results indicate the sample tested was near the average and within the range recorded during construction quality assurance testing conducted in 1998.

The Infiltration layer in situ $w$ and $\rho_{d}$ from the 1998 and 2017 investigations are shown in Fig 6.5. The laboratory measured $w$ of the exhumed upper and lower Infiltration layer specimens in 2017 were $16.0 \%$ and $14.7 \%$ respectively. Quality assurance testing of the Infiltration layer using a nuclear moisture-density gauge for 310 tests from Phase 1 construction indicated $w$ at the time of placement ranged from 12.6 to $26.8 \%$, with an average $w=17.0 \%$. The laboratory measured $\rho_{d}$ from the exhumed samples was 1.79 and $1.91 \mathrm{Mg} / \mathrm{m}^{3}$ (111.9 and $\left.119.3 \mathrm{pcf}\right)$ 
compared to construction quality assurance testing results of a $\rho_{d}$ ranging from 1.56 to 1.92 $\mathrm{Mg} / \mathrm{m}^{3}$ (97.5 to $120.1 \mathrm{pcf}$ ) with an average of $1.79 \mathrm{Mg} / \mathrm{m}^{3}$ (111.4 pcf). The test results indicate that the in situ $w$ and $\rho_{d}$ of the exhumed Phase 1 samples were within the ranges of the construction quality assurance testing from 1998.

Permeability test results of samples from Phase 1 cover construction are compared to permeability test results from samples collected as part of this study in Fig. 6.6. Thirteen Shelby tube samples were collected as part of Phase 1 construction in 1998 and permeability testing yielded $k_{s}$ ranging from $2.2 \times 10^{-8}$ to $1.2 \times 10^{-6} \mathrm{~cm} / \mathrm{s}$, with an average of $1.6 \times 10^{-7} \mathrm{~cm} / \mathrm{s}$. The block samples of the Infiltration layer from this study yielded $k_{s}=1.2 \times 10^{-7} \mathrm{~cm} / \mathrm{s}$ for the upper sample and $k_{s}=8.9 \times 10^{-8} \mathrm{~cm} / \mathrm{s}$ for the lower sample. Comparing the test results from postconstruction in 1988 versus the exhumed 2017 block samples indicates the $k_{s}$ is still within the range of the 1998 samples and is within $45 \%$ of the average of the previous test results.

Permeability testing was also conducted on exhumed Phase 1 bulk samples that were remolded to $95 \%$ compaction and $2 \%$ wet of $w_{o p t}$ as determined by standard Proctor. The remolded permeability test results were $k_{s}=6.5 \times 10^{-8} \mathrm{~cm} / \mathrm{s}$ for the upper sample and $k_{s}=7.3 \mathrm{x}$ $10^{-8} \mathrm{~cm} / \mathrm{s}$ for the lower sample, which indicates the in-situ $k_{s}$ of the block samples has increased $82 \%$ and $22 \%$, respectively, since construction if originally compacted under the same conditions.

\subsection{Comparison of Laboratory Test Results versus Literature}

\subsubsection{Effect of Pedogenesis on Hydraulic Properties}

Benson et al. (2007) monitored ten WBC over a four-year period to assess changes in soil hydraulic properties. The relationship between post-construction $k_{s}$ and as-built $k_{s}$ from Benson et al. (2007) is shown in Fig. 6.7. Their results indicated that post-construction $k_{s}$ of cover soils at all ten sites increased by a factor ranging from 10 to 10,000 compared to the asbuilt $k_{s}$. The change was more pronounced in soils with lower as-constructed $k_{s}$, such that post- 
construction $k_{s}$ at nearly all sites ranged between $10^{-3}$ and $10^{-5} \mathrm{~cm} / \mathrm{s}$ after four years, termed the "In-Service Condition". The main explanation for the increase in $k_{s}$ from as-built to postconstruction was pedogenesis, which is a natural soil formation process that leads to formation of a macropore structure due to processes such as freeze-thaw, wet-dry cycling, root growth and decay, and burrowing animals (Buol et al. 1997; Othman and Benson,1994; Albrecht and Benson 2001).

The $k_{s}$ measured on block samples collected from exhumed Phase 1 samples in this study are plotted in Fig. 6.7 with respect to the average $k_{s}$ measured on Shelby tube samples from Phase 1 that represent the as-built condition. Comparing the as-built $k_{s}$ of the Phase 1 Infiltration layer to the 2017 exhumed samples indicates the post-construction $k_{s}$ decreased 35 $\%$, which is contrary to observations in Benson et al. (2007). A likely explanation for this contrast is that block samples of the Infiltration layer were collected from 107 to $168 \mathrm{~cm} \mathrm{(3} 1 / 2$ to $\left.4 \frac{1}{1} 2 \mathrm{ft}\right)$ deep, which appears to have been sufficiently deep to avoid macropore formation due to pedogenesis. The processes contributing to pedogenesis likely did not penetrate the upper 107 $\mathrm{cm}$ ( $3 \frac{1}{2} 2$ feet) of topsoil and rooting zone to impact the Infiltration layer at LCL. Another explanation could be the limited post-construction samples (i.e., two) or the difference between the as-built sampling method (75-mm diameter Shelby tube) versus the post-construction sampling method (300-mm-diameter block samples). A study by Benson et al. (1999a) indicated that 14 of 17 samples had higher $k_{s}$ in the laboratory when sampled using a 305 -mm-diameter (12 in) block samples versus a 75-mm-diameter ( 3 in) Shelby tube samples.

The $k_{s}$ measured on block samples from Borrow Areas 3 and 4 are plotted along with $k_{s}$ measured on remolded specimens in Fig. 6.7. The block samples yielded $k_{s}$ of $1.1 \times 10^{-4} \mathrm{~cm} / \mathrm{s}$ and $2.4 \times 10^{-4} \mathrm{~cm} / \mathrm{s}$, which is near the middle of the "In-Service Condition" reported by Benson et al. (2007). Although specimens from the borrow areas were never placed as a constructed cover, they were collected from the upper $76 \mathrm{~cm}\left(2 \frac{1}{2} \mathrm{ft}\right)$ where pedogenesis processes are more influential. Comparing $k_{s}$ of the in situ samples versus the $k_{s}$ of the bulk samples remolded 
under different compaction scenarios resulted in $k_{s}$ ranging from 0.25 to 53 times greater (average of 20 times greater) $k_{s}$ in the in situ samples versus remolded samples, which is in agreement with observations by Benson et al. (2007).

Benson et al. (2007) also studied changes in the van Genuchten parameters $\theta_{\mathrm{s}}, \alpha$, and $n$ with time. They observed that $\theta_{s}$ increased up to a factor of two over four years and the change was more prevalent in soils that started with $\theta_{\mathrm{s}}$ lower than 0.35 such as calculated at LCL. The increase in $\theta_{s}$ was attributed to pedogenesis decreasing the soil density, which has an inverse relationship with $\theta_{\mathrm{s}}$. The 2017 measured $\rho_{\mathrm{d}}$ of 1.79 and $1.91 \mathrm{Mg} / \mathrm{m}^{3}$ (111.9 and $119.3 \mathrm{pcf}$ ) are equal to or higher than the average value of $1.79 \mathrm{Mg} / \mathrm{m}^{3}$ (111.4 pcf) from the 1998 construction quality assurance test results correlating to an equal or lower $\theta_{s}$ with time, which is contrary to the Benson et al. (2007) conclusion. Comparing $\rho_{d}$ of the remolded borrow area samples versus in situ $\rho_{d}$ indicates a $14 \%$ (Borrow Area 3) and $18 \%$ (Borrow Area 4) difference in $\rho_{d}$, which would demonstrate an increase in $\theta_{s}$ if the in situ borrow soils had been placed as compacted fill.

Comparison of $\alpha$ and $n$ values from 1998 and 2017 cannot be performed because moisture retention testing was not completed in 1998. Benson et al. (2007) indicated that $\alpha$ increased with time and that all values ended up within a range from 0.002 to $0.2 \mathrm{kPa}^{-1}(0.042$ to $4.17 \mathrm{ps}^{-1}$ ) regardless of the initial $\alpha$. Both Phase 1 Infiltration layer samples tested for soil water retention as part of this study were within the range from Benson et al. (2007) as was the sample from Borrow Area 4. The exception was the sample from Borrow Area 3 with $\alpha=0.348$ $\mathrm{kPa}^{-1}\left(0.017 \mathrm{psf}^{-1}\right)$, which was higher and corresponds to a coarser-grained soil. The $n$ parameter decreased with time in the observations by Benson et al. (2007) and they state that 1 $<n<2$ for fine-textured soils (Tinjum et al. 1997; Gurdal et al. 2003), which was true for $n$ values from all four samples evaluated from the Phase 1 and borrow areas that were finegrained soils (> $50 \%$ passing \#200 sieve). 


\subsubsection{Effect of Compaction Moisture Content and Effort on $k_{s}$}

The series of permeability testing on six Borrow Area 3 and six Borrow Area 4 samples at varying moisture contents and compaction efforts was compared to observations by Benson et al. (1999a) who sampled and tested compacted clay liners from 85 sites. Benson et al concluded that $k_{s}$ was more sensitive to moisture content at the time of compaction than the compaction effort applied. Permeability testing of the remolded borrow area samples indicated that an increase in $w$ at the time of remolding generally resulted in a decrease in $k_{s}$ (Fig. 6.1a). Less of a correlation was observed when comparing the percent compaction to $k_{s}$ (Fig. 6.1b). Fig. $6.1 \mathrm{~b}$ illustrates correlations of $k_{s}$ to both $w$ and percent compaction and again demonstrates that the remolded moisture content was the most sensitive parameter. Observations from this study are consistent with conclusions by Benson et al. (1999a). 
Table 6.1. Laboratory characterization and engineering property test results for soil samples collected from the borrow areas at Larimer County Landfill.

\begin{tabular}{|c|c|c|c|c|c|c|c|}
\hline Sample Location & Units & \multicolumn{3}{|c|}{ Borrow Area 3} & \multicolumn{3}{|c|}{ Borrow Area 4} \\
\hline ID & $\mathrm{N} / \mathrm{A}$ & TS & BS1 & BS2 & TS & BS1 & BS2 \\
\hline$L L$ & $(\%)$ & 37.4 & 40.7 & 45.7 & 35.3 & 39.9 & 38.3 \\
\hline$P L$ & $(\%)$ & 22.3 & 21.6 & 21.4 & 19.9 & 20.2 & 22.6 \\
\hline$P I$ & $(\%)$ & 15.1 & 19.1 & 24.3 & 15.3 & 19.6 & 15.7 \\
\hline USCS & $\mathrm{N} / \mathrm{A}$ & $C L$ & $\mathrm{CL}$ & $C L$ & $\mathrm{CL}$ & $\mathrm{CL}$ & $\mathrm{CL}$ \\
\hline Sand Content & $(\%)$ & 36 & 38.1 & 31.6 & 35.7 & 34.3 & 36.5 \\
\hline Fines Content & $(\%)$ & 64 & 61.9 & 68.4 & 64.3 & 65.7 & 63.5 \\
\hline Silt Content & $(\%)$ & 41.3 & 36.2 & 34.2 & 40 & 38.9 & 4.6 \\
\hline Clay Content & $(\%)$ & 22.6 & 25.7 & 34.3 & 24.3 & 26.9 & 25.9 \\
\hline $\begin{array}{l}\text { In-Situ Moisture } \\
\text { Content }\end{array}$ & $(\%)$ & 25 & 20 & 9 & 19 & 10 & 10 \\
\hline $\begin{array}{l}\text { In-Situ Dry } \\
\text { Density }\end{array}$ & $\begin{array}{c}\left(\mathrm{Mg} / \mathrm{m}^{3}-\right. \\
\left.\mathrm{lb} / \mathrm{ft}^{3}\right)\end{array}$ & NM & $\begin{array}{l}1.38- \\
86.4\end{array}$ & NM & NM & $\begin{array}{l}1.32- \\
82.4\end{array}$ & NM \\
\hline$w_{o p t}$ & $(\%)$ & 20 & 21.1 & 19.6 & 19.5 & 20.1 & 19.3 \\
\hline Ydmax & $\begin{array}{c}\left(\mathrm{Mg} / \mathrm{m}^{3}-\right. \\
\left.\mathrm{lb} / \mathrm{ft}^{3}\right)\end{array}$ & $\begin{array}{l}1.58- \\
98.5\end{array}$ & $\begin{array}{l}1.61- \\
100.6\end{array}$ & $\begin{array}{l}1.60- \\
100.0\end{array}$ & $\begin{array}{l}1.64- \\
102.1\end{array}$ & $\begin{array}{l}1.61- \\
100.2\end{array}$ & $\begin{array}{l}1.65- \\
103.0\end{array}$ \\
\hline$G_{s}$ & $\mathrm{~N} / \mathrm{A}$ & 2.46 & NM & 2.61 & 2.51 & 2.64 & 2.64 \\
\hline
\end{tabular}

Note: N/A: Not applicable, TS: topsoil, BS1: Block Sample 1, $15-45 \mathrm{~cm}(0.5-1.5 \mathrm{ft})$, BS2: Block Sample 2, $45-76 \mathrm{~cm}(1.5-2.5 \mathrm{ft})$. LL = liquid limit; PL = plastic limit; PI = plasticity index; USCS $=$ Unified Soil Classification System; $\mathrm{w}_{\mathrm{opt}}=$ optimum moisture content; $\mathrm{Y}_{\mathrm{dmax}}=$ maximum dry density; $\mathrm{G}_{\mathrm{s}}=$ specific gravity; $\mathrm{NM}=$ Not measured 
Table 6.2. Saturated hydraulic conductivity $\left(k_{s}\right)$ and unsaturated hydraulic properties of soil samples collected from the borrow areas at Larimer County Landfill.

\begin{tabular}{|c|c|c|c|c|c|c|}
\hline $\begin{array}{c}\text { Sample } \\
\text { Location }\end{array}$ & ID & $k_{s}(\mathrm{~cm} / \mathrm{s})$ & $\alpha\left(\mathrm{kPa}^{-1}\right)^{\mathrm{a}}$ & $\mathrm{n}$ & $\theta_{\mathrm{s}}$ & $\theta_{\mathrm{r}}$ \\
\hline Borrow Area 3 & $\mathrm{BS} 1$ & $1.06 \times 10^{-04}$ & $0.348(0.017)$ & 1.261 & 0.481 & 0.04 \\
\hline Borrow Area 4 & BS1 & $2.43 \times 10^{-04}$ & $0.061(0.003)$ & 1.633 & 0.495 & 0.04 \\
\hline
\end{tabular}

Note: $\alpha$ and $n=$ van Genuchten equation parameters, $\theta_{s}=$ saturated water content, $\theta_{r}=$ residual water content

a Units of $\mathrm{psf}^{-1}$ included in parentheses. 
Table 6.3. Laboratory characterization and engineering property test results for soil samples collected from the Phase 1 existing closure cover at Larimer County Landfill.

\begin{tabular}{|l|c|c|c|c|c|}
\hline $\begin{array}{c}\text { Presumed } \\
\text { Construction Layer }\end{array}$ & & Topsoil & Rooting Zone & $\begin{array}{c}\text { Infiltration } \\
\text { (upper } \\
\text { sample) }\end{array}$ & $\begin{array}{c}\text { Infiltration } \\
\text { (lower sample) }\end{array}$ \\
\hline ID & $\mathrm{N} / \mathrm{A}$ & $\mathrm{TS}$ & $\mathrm{RZ}$ & $\mathrm{CC} 1$ & $\mathrm{CC} 2$ \\
\hline LL & $(\%)$ & 44.5 & 45.7 & 54.5 & 52.6 \\
\hline$P L$ & $(\%)$ & 22.1 & 22.2 & 22.1 & 22.8 \\
\hline$P I$ & $(\%)$ & 22.5 & 23.5 & 32.4 & 29.8 \\
\hline USCS & $\mathrm{N} / \mathrm{A}$ & $\mathrm{CL}$ & $\mathrm{CL}$ & $\mathrm{CH}$ & $\mathrm{CH}$ \\
\hline Sand Content & $(\%)$ & 3.33 & 0 & 0 & 0 \\
\hline Fines Content & $(\%)$ & 96.7 & 100 & 100 & 100 \\
\hline Silt Content & $(\%)$ & 51.3 & 57.5 & 56.2 & 54.6 \\
\hline Clay Content & $(\%)$ & 45.4 & 42.5 & 43.8 & 45.4 \\
\hline In-Situ Moisture & $(\%)$ & 9.4 & 13.8 & 16 & 14.7 \\
\hline Content & $\left(\mathrm{Mg} / \mathrm{m}^{3}\right)^{\mathrm{a}}$ & $\mathrm{NM}$ & $\mathrm{NM}$ & $1.79(111.9)$ & $1.91(119.3)$ \\
\hline In-Situ Dry Density & $(\%)$ & 20.7 & 19.4 & 17.7 & 18.4 \\
\hline Wopt & $\left(\mathrm{Mg} / \mathrm{m}^{3}\right)^{\mathrm{a}}$ & $1.58(98.7)$ & $1.74(108.8)$ & $1.74(108.7)$ & $1.75(109)$ \\
\hline Yd-max & $\mathrm{N} / \mathrm{A}$ & $\mathrm{NM}$ & $\mathrm{NM}$ & $\mathrm{NM}$ & $\mathrm{NM}$ \\
\hline G & & & & & \\
\hline
\end{tabular}

Note: $\mathrm{N} / \mathrm{A}=$ Not applicable; $\mathrm{LL}$ = liquid limit; $\mathrm{PL}$ = plastic limit; $\mathrm{PI}$ = plasticity index; USCS = Unified Soil Classification System; $W_{\mathrm{opt}}=$ optimum moisture content; $\mathrm{Ydmax}_{\mathrm{d}}=$ maximum dry density; $\mathrm{G}_{\mathrm{s}}=$ specific gravity; $\mathrm{NM}=$ Not measured

${ }^{a}$ Units of $\mathrm{lb} / \mathrm{t}^{3}$ included in parentheses. 
Table 6.4. Saturated hydraulic conductivity $\left(k_{s}\right)$ and unsaturated hydraulic properties of Phase 1 existing closure cover Infiltration Layer.

\begin{tabular}{|c|c|c|c|c|c|c|}
\hline $\begin{array}{c}\text { Presumed } \\
\text { Construction } \\
\text { Layer }\end{array}$ & ID & $k_{s}(\mathrm{~cm} / \mathrm{s})$ & $\alpha\left(\mathrm{kPa}^{-1}\right)^{\mathrm{a}}$ & $\mathrm{n}$ & $\theta_{\mathrm{s}}$ & $\theta_{\mathrm{r}}$ \\
\hline $\begin{array}{c}\text { Infiltration } \\
\text { (upper sample) }\end{array}$ & $\mathrm{CC} 1$ & $1.18 \times 10^{-7}$ & $0.028(0.0013)$ & 1.737 & 0.264 & 0.078 \\
\hline $\begin{array}{c}\text { Infiltration } \\
\text { (lower sample) }\end{array}$ & $\mathrm{CC} 2$ & $8.87 \times 10^{-8}$ & $0.026(0.0012)$ & 1.319 & 0.290 & 0.078 \\
\hline
\end{tabular}

Note: $\alpha$ and $n=$ van Genuchten equation parameters, $\theta_{s}=$ saturated water content, $\theta_{r}=$ residual water content

a Units of $\mathrm{psf}^{-1}$ included in parentheses. 
Table 6.5. Saturated hydraulic conductivity $\left(k_{s}\right)$ of borrow area soils remolded to varying moisture contents and percent compaction in order from highest $k_{s}$ to lowest $k_{s}$ within soil samples collected from the borrow areas at Larimer County Landfill.

\begin{tabular}{|c|c|c|c|c|c|c|}
\hline $\begin{array}{c}\text { Borrow } \\
\text { Area }\end{array}$ & $\begin{array}{c}\text { Sample } \\
\text { ID }\end{array}$ & $\begin{array}{c}\text { Moisture Content } \\
\text { Relative to } \\
\text { Optimum (\%) }\end{array}$ & $\begin{array}{c}\text { Moisture } \\
\text { Content (\%) }\end{array}$ & $\begin{array}{c}\text { Dry Density } \\
\left(\mathrm{Mg} / \mathrm{m}^{3}\right)^{\mathrm{a}}\end{array}$ & $\begin{array}{c}\text { Compaction } \\
(\%)\end{array}$ & $k_{s}(\mathrm{~cm} / \mathrm{s})$ \\
\hline 3 & BS2 & -11.6 & 8.0 & $1.26(78.5)$ & 78.5 & $4.2 \times 10^{-4}$ \\
\hline 3 & BS2 & -12.6 & 7.0 (In-situ) & $1.33(83.2)$ & 83.2 & $1.3 \times 10^{-4}$ \\
\hline 3 & BS2 & +0.5 & 20.1 & $1.32(82.7)$ & 82.7 & $5.7 \times 10^{-6}$ \\
\hline 3 & BS1 & -1.3 & 19.8 (In-situ) & $1.45(90.6)$ & 90.0 & $3.8 \times 10^{-6}$ \\
\hline 3 & BS1 & -1.1 & 20.0 (In-situ) & $1.45(90.5)$ & 90.0 & $3.8 \times 10^{-6}$ \\
\hline 3 & BS1 & 0.0 & 21.1 (In-situ) & $1.52(95.2)$ & 94.6 & $2.0 \times 10^{-6}$ \\
\hline 4 & BS2 & -13.8 & 5.5 & $1.39(87.0)$ & 84.5 & $8.0 \times 10^{-5}$ \\
\hline 4 & BS1 & -10.1 & 10.0 (In-situ) & $1.51(94.5)$ & 94.3 & $3.0 \times 10^{-5}$ \\
\hline 4 & BS2 & -9.3 & 10.0 (In-situ) & $1.38(86.2)$ & 83.7 & $2.5 \times 10^{-5}$ \\
\hline 4 & BS2 & -9.3 & 10.0 (In-situ) & $1.52(94.8)$ & 92.0 & $2.5 \times 10^{-5}$ \\
\hline 4 & BS2 & +2.0 & 21.3 & $1.31(81.9)$ & 79.5 & $8.4 \times 10^{-6}$ \\
\hline 4 & TS & -0.1 & 19.2 (In-situ) & $1.45(90.3)$ & 91.7 & $4.6 \times 10^{-6}$ \\
\hline 4 & BS2 & +2.0 & 21.3 & $1.55(96.9)$ & 94.1 & $1.1 \times 10^{-6}$ \\
\hline
\end{tabular}

Notes: TS: topsoil, BS1: Block Sample 1, $15-45 \mathrm{~cm}$ (0.5 - 1.5 ft), BS2: Block Sample 2, $45-76$ $\mathrm{cm}(1.5-2.5 \mathrm{ft})$, In-situ: remolded moisture content similar to in-situ moisture content of block sample

${ }^{a}$ Units of $\mathrm{lb} / \mathrm{ft}^{3}$ included in parentheses. 

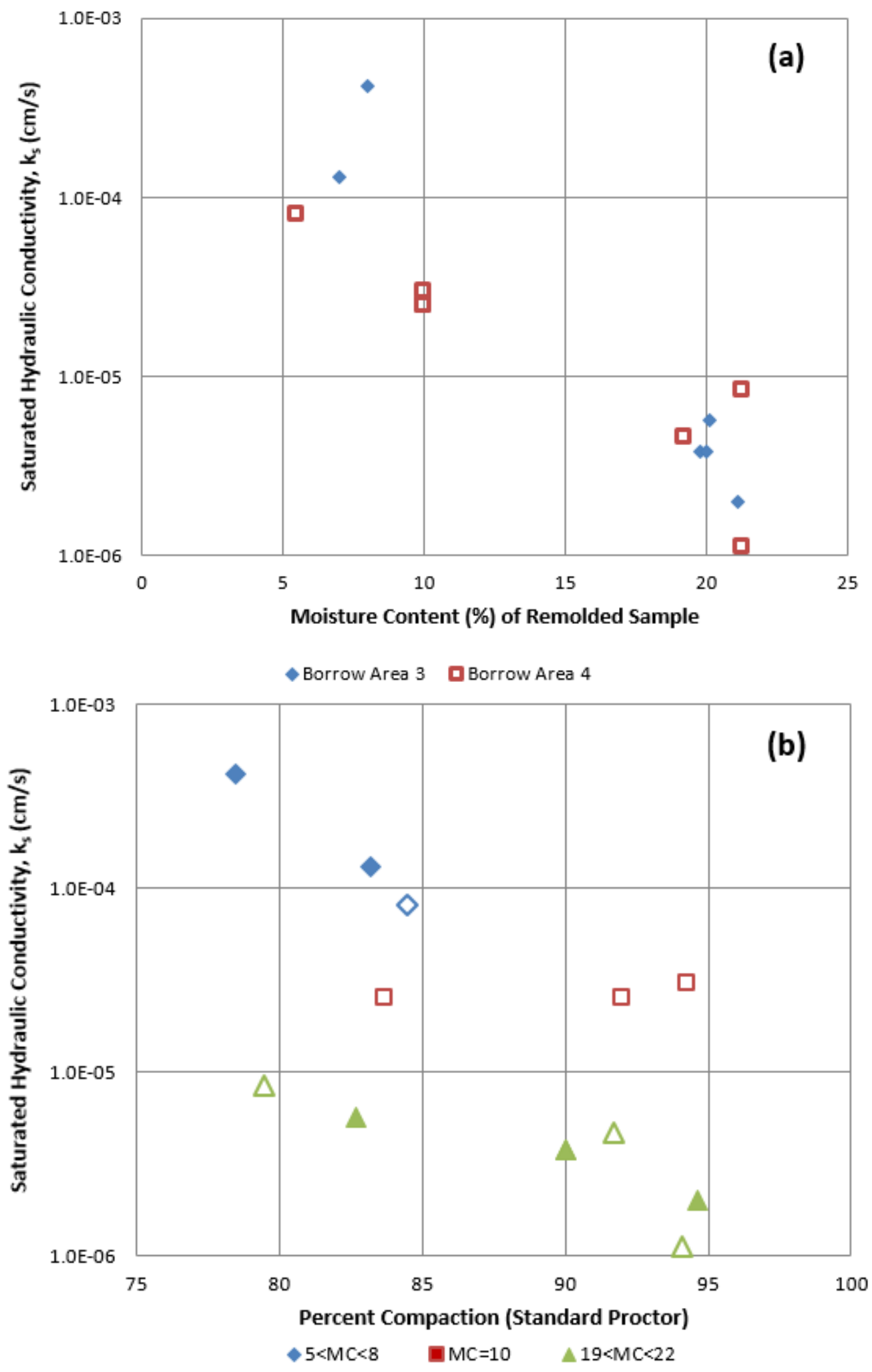

Closed symbols represent Borrow Area 3 and open symbols repreesent Borrow Area 4

Fig. 6.1. Saturated hydraulic conductivity of remolded borrow area soils versus (a) remolded moisture content and (b) remolded percent compaction and moisture content. 

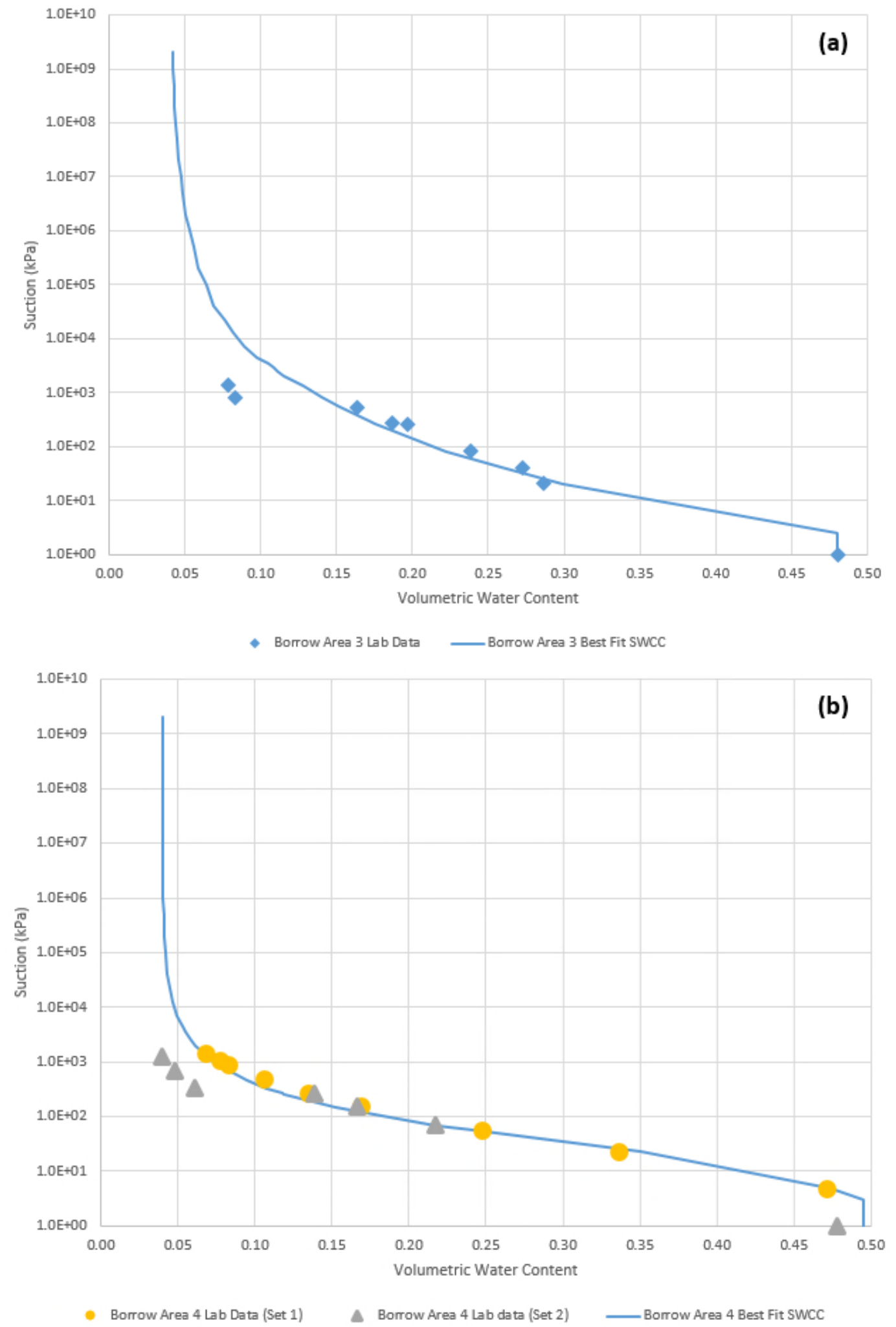

Fig. 6.2. Soil water characteristic curve and unsaturated flow laboratory test results from (a) Borrow Area 3 and (b) Borrow Area 4. 

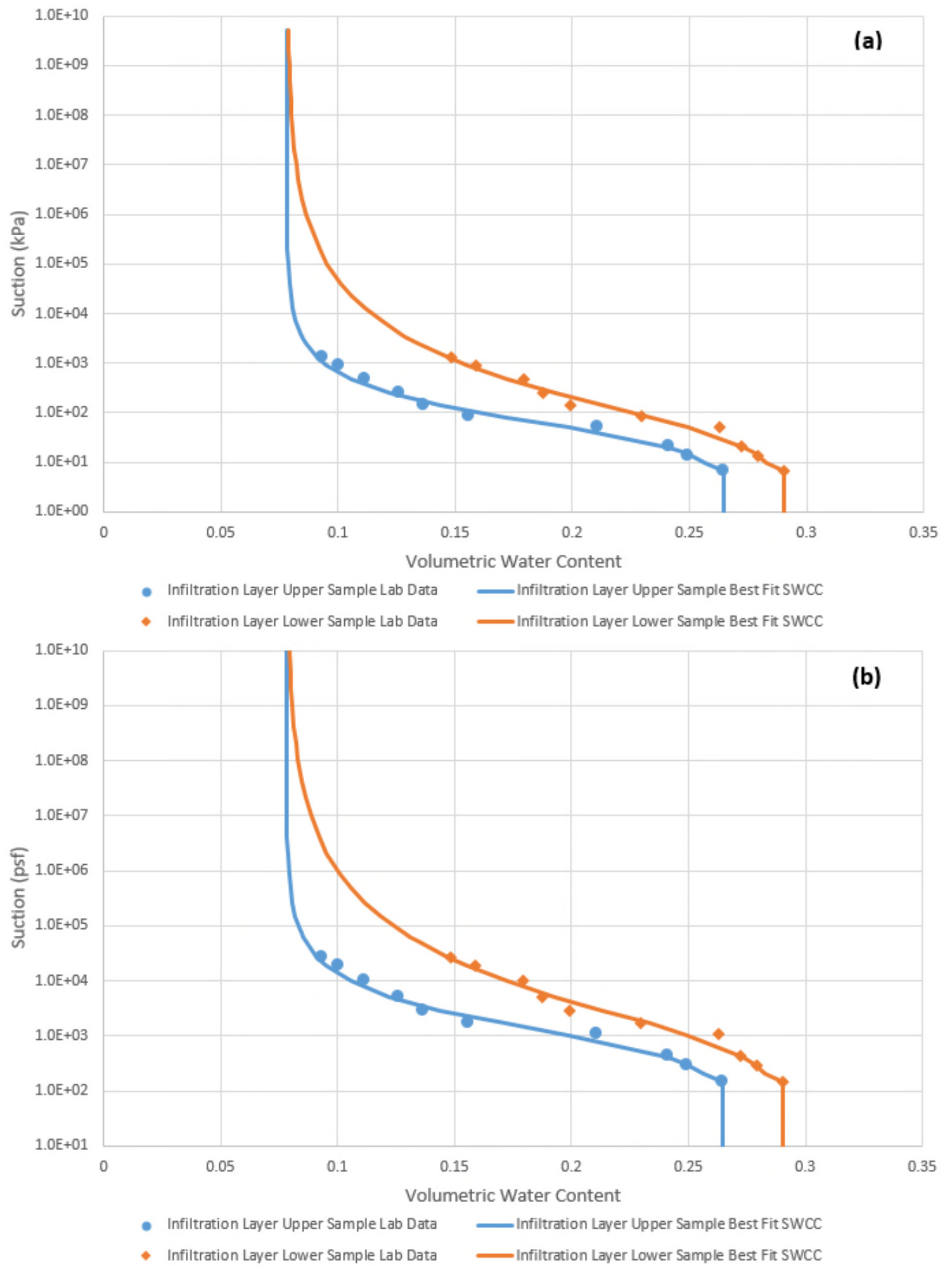

Fig. 6.3. Soil water characteristic curves for Phase 1 Infiltration Layer in (a) metric units and (b) English units. 

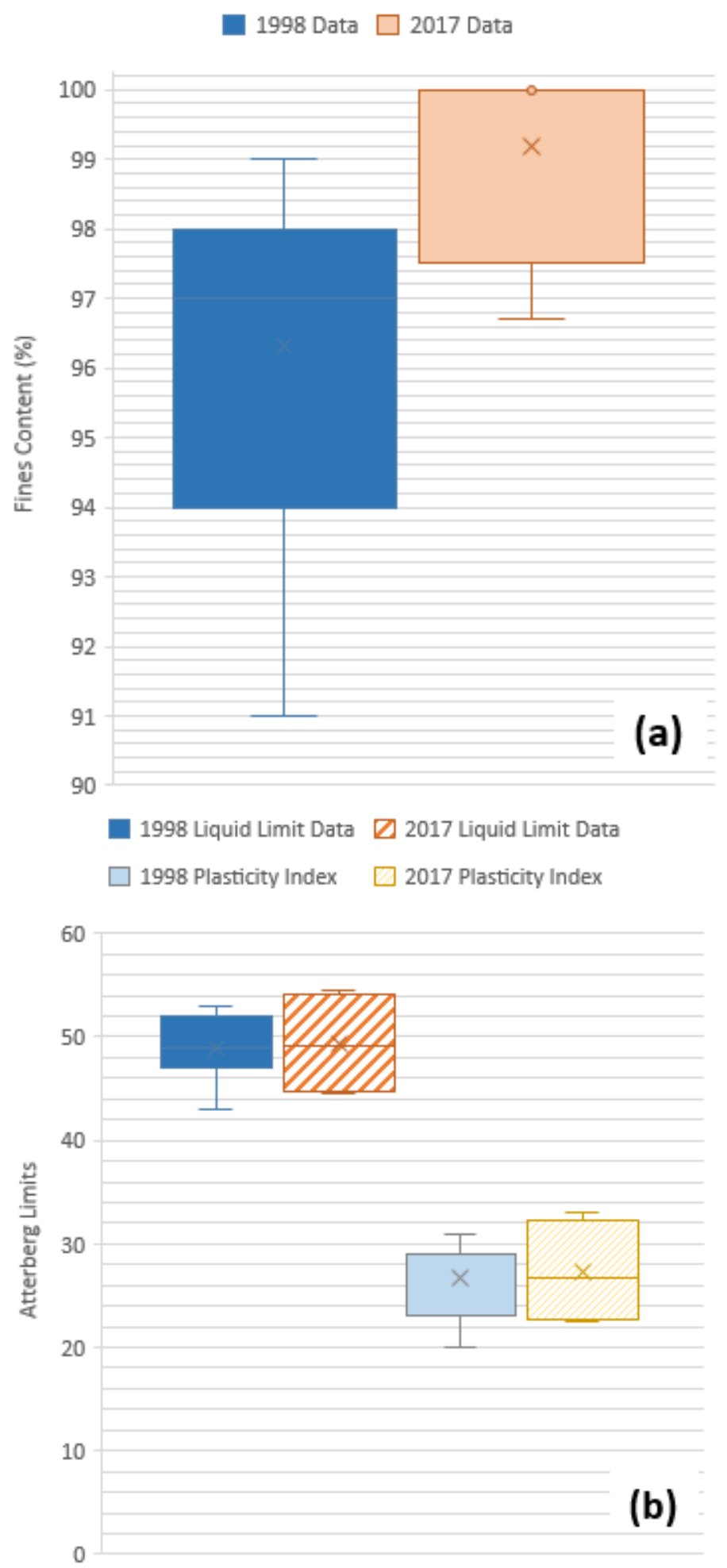

Fig. 6.4. Comparison of (a) fines content and (b) Atterberg limits determined from soil investigations conducted in 1998 and 2017 (this study). 

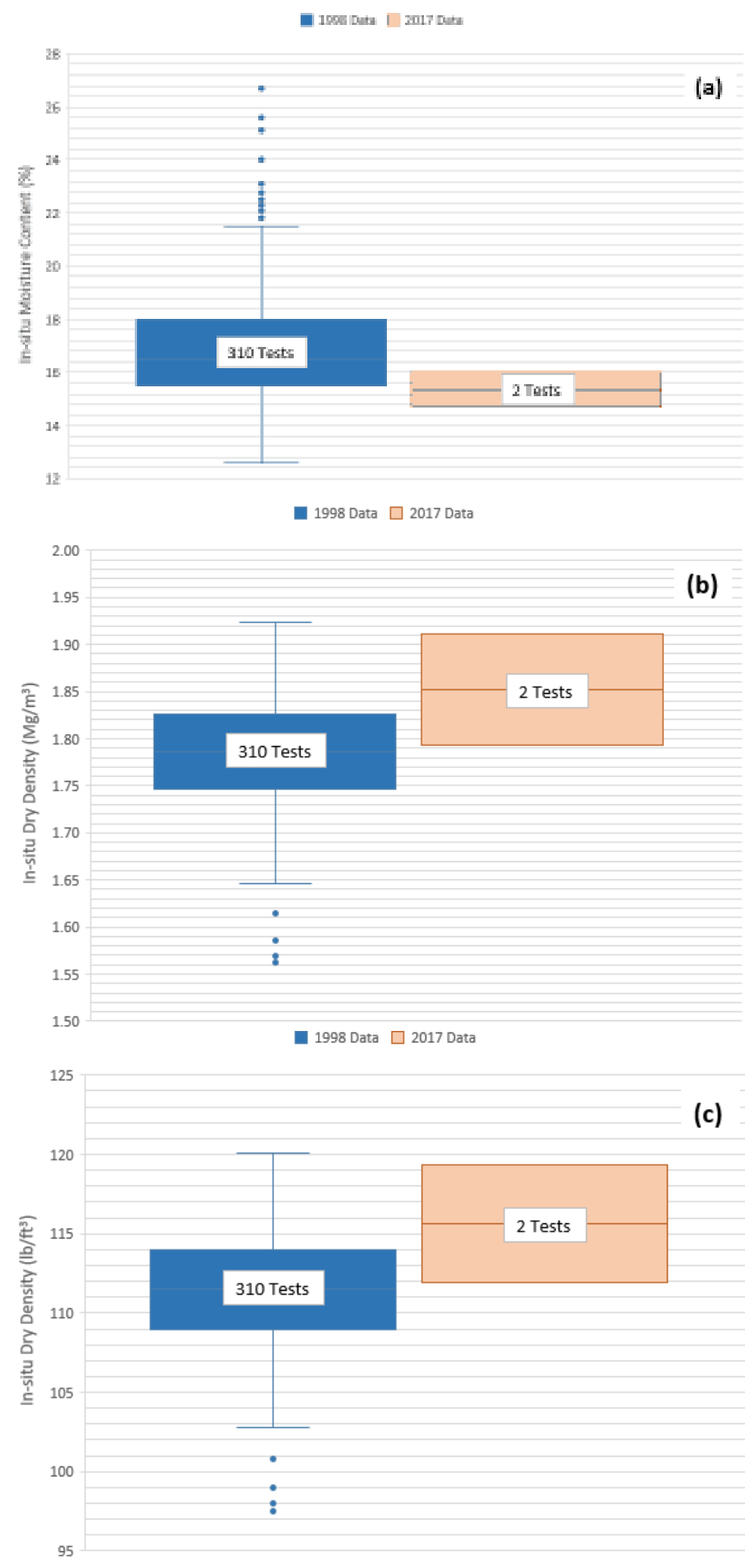

Fig. 6.5 Test results from 1998 and 2017 laboratory investigations of the Infiltration Layer for (a) in-situ moisture content, (b) dry density (metric units), and (c) dry density (English units). 


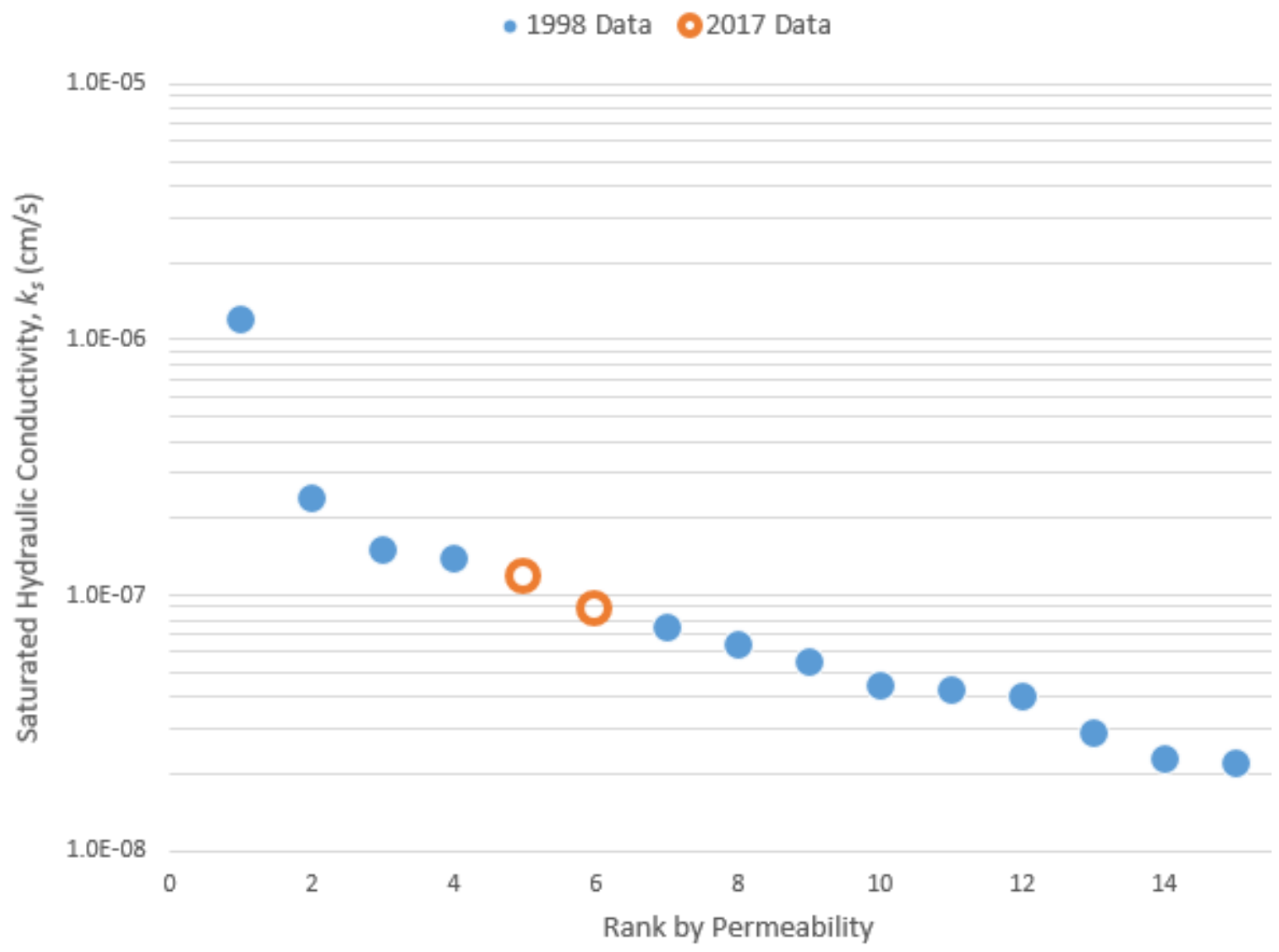

Fig. 6.6 In-situ dry density of the Infiltration Layer from the 1998 and 2017 investigations. 


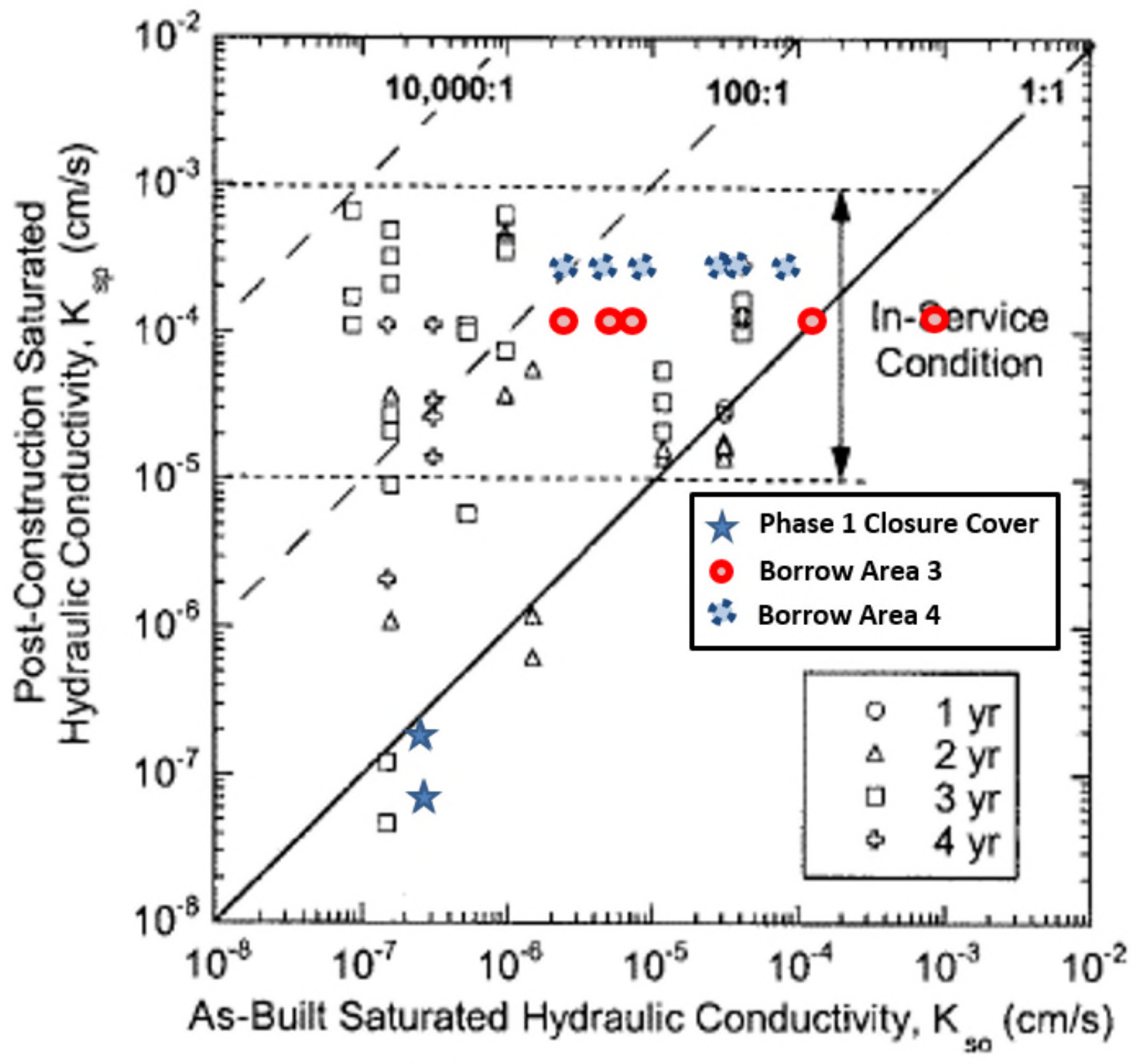

Fig. 6.7 Reproduced figure from Benson et al. (2007) supplemented with saturated hydraulic conductivity results from this study. 


\section{CHAPTER 7. VEGETATION}

Vegetation on a final cover removes water through transpiration and reduces erosion. A mixture of grass, shrub, and forb species was planted on the final cover at LCL as part of each closure phase. The Fromme Prairie seed mixture that was used for the final cover in Phase 1 of LCL is tabulated in Table 7.1. This mixture was applied at the rate of $8.03 \mathrm{~kg}(17.7 \mathrm{lb})$ of pure live seed per 0.40 ha ( 1 acre) using the drill seeding method. A qualitative survey of vegetation on the Phase 1 cover indicated that many of the species from the original seed mix were nonexistent and new species were present. Particularly predominant was the invasion of smooth brome grass and alfalfa that were speculated to have originated from the neighboring prairie and hay mulch, respectively. No shrubs were presently growing on the final cover at LCL at the time of this study.

A qualitative vegetation survey of the remaining borrow areas was also conducted. The borrow areas represent a more natural habitat than the final cover; however, select areas have been disturbed in the past for wheat farming and local recreation. Vegetation in the borrow areas is more diverse, with small trees, shrubs, and grasses. Vegetation in the borrow area is less dense, but the species have a deeper and denser root system than vegetation on the final cover. 
Table 7.1. Larimer County Landfill Phase 1 final cover seed mixture.

\begin{tabular}{|c|c|c|}
\hline Species & Purity (\%) & Germination (\%) \\
\hline Buffalograss & 31.66 & 86 \\
\hline Western Wheatgrass & 12.60 & 86 \\
\hline Sideoats Grama & 11.24 & 78 \\
\hline Bluebunch Wheatgrass & 9.18 & 86 \\
\hline Indian Ricegrass & 6.85 & 96 \\
\hline Needle and Thread & 4.62 & 95 \\
\hline Big Bluestem & 3.57 & 86 \\
\hline Purple Prairie Clover & 2.61 & 86 \\
\hline Lewis Flax & 2.06 & 85 \\
\hline Little Bluestem & 1.52 & 88 \\
\hline Blue Grama & 1.44 & 93 \\
\hline Upright Prairie Coneflower & 0.97 & 97 \\
\hline Rubber Rabbitbrush & 0.55 & 80 \\
\hline Fringed Sage & 0.52 & 85 \\
\hline Yarrow & 0.49 & 95 \\
\hline Pand & & $9 \%$ \\
\hline
\end{tabular}

Note: Additional contribution of $9.62 \%$ inert, $0.27 \%$ weeds, and $0.22 \%$ crop within the seed mixture. 


\section{CHAPTER 8. DESCRIPTION OF MODEL AND MODEL PARAMETERS}

Hydrologic modeling was conducted with the finite element program VADOSE/W in GeoStudio to assess the water balance of the final cover in Phase 1 and potential WBC at LCL. VADOSE/W is capable of simulating flow of water, heat, and vapor in saturated and unsaturated soils (GEO-SLOPE 2014). Variably saturated flow is simulated via the Richards equation and vapor flow is simulated via mathematical expressions in Wilson (1990) and Milly (1982). Actual evaporation of the soil layer is computed via the Penman-Wilson (1990) equation, and actual transpiration is determined by vegetative uptake combined with surface energy based on canopy cover (Tratch 1996). Root uptake of water within the soil layer depends on root depth and density, and water stress (i.e., soil suction). A three-stage modeling approach was implemented for all model simulations, whereby Stages 1 and 2 conditioned the model to create an end-state hydrologic profile within a cover system that simulated long-term conditions and Stage 3 included the unique 10-yr, daily MET data from 1992 to 2002 . Stage 3 model simulations were the simulations used to compare hydrologic performance of the final covers considered at LCL.

\subsection{Model Geometry}

The model geometry was one-dimensional (1-D) with cover thickness varying between 61 and $106.7 \mathrm{~cm} \mathrm{(2} \mathrm{and} 3.5 \mathrm{ft}$ ) depending on the scenario simulated. A 1-D model was used in this study to provide conservative water balance estimate and decrease computation time. The runoff component of the water balance equation is removed in VADOSE/W when using a 1-D simulation, which allows more available water to enter the cover; thus, yielding a conservative assessment of the water balance.

The model geometry with element mesh and boundary conditions is illustrated in Fig. 8.1. Surface layers were assigned within the model geometry to discretize the mesh and create 
a quadrilateral element mesh parallel to the primary gradient direction and perpendicular to the ground surface. The vertical element spacing varied between 9.5 and $76 \mathrm{~mm}$ (0.37 and 3 in) among the models, and a finer mesh was used near the surface where climate and vegetation interaction with the soil was more prevalent. Preliminary model simulations started with larger mesh spacing, which resulted in shorter computation times but larger water balance errors. If the water balance error exceeded $1 \%$ of the precipitation, results were considered inaccurate and the mesh size was reduced and the model was re-run until an acceptable water balance error was achieved.

\subsection{Boundary Conditions}

Boundary conditions were specified on the top and bottom boundaries of the 1-D simulations to drive hydraulic and heat flow and simulate evapotranspirative interactions between the cover soil and climate. VADOSE/W requires a steady state analysis to initially develop pore pressures (and corresponding volumetric water content) and temperature within the cover, which is used as a parent analysis to the transient analyses that simulates actual MET data over a modeled time period. Different boundary conditions were applied to the steady state model for Stage 1 than were used in the transient models for Stages 2 and 3 (Fig. 8.1).

The upper boundary condition in Stage 1 included assigned pore pressures and temperatures to approximate initial conditions. The model was run with a unit gradient as the bottom boundary condition to generate an initial distribution of pore pressure and temperature throughout the model domain. Final steady-state pore pressure and temperature profiles from Stage 1 were used as initial conditions for the model domain in Stage 2.

Transient analysis conducted in Stage 2 and 3 models included a climate boundary condition at the top boundary and unit gradient at the bottom. The climate boundary condition consisted of four components identified in VADOSE/W: (i) MET data set, (ii) leaf area index (LAI) function, (iii) rooting depth (RD) function, and (iv) plant moisture limiting (PML) function. 
The MET data set consisted of daily maximum and minimum temperature, maximum and minimum relative humidity, average wind speed, and precipitation. Radiation energy was estimated by VADOSE/W based on the specified site latitude (i.e., $40.5^{\circ} \mathrm{N}$ ). The other three components for the climate boundary condition deal with vegetation parameters (discussed subsequently).

The time period of MET data evaluated in this study was 1992 to 2002. Input MET data for VADOSE/W included 15 years of data: Years 1-5 were used for model conditioning (Stage 2) and Years 6-15 pertained to calendar years 1992-2002 (Stage 3). Stage 2 included data from 1996 cycled five times consecutively. The year 1996 was selected because this year received slightly above average precipitation based on precipitation data from 1889 to 2016 . Thus, the goal of Stage 2 was to generate a realistic soil moisture and temperature profile to be used as initial conditions for the Stage 3 simulation that included the years 1992 through 2002. A unit gradient boundary condition was assigned to the bottom of the model to allow pore water to freely flow through the bottom of the cover at a rate matching the hydraulic conductivity.

\subsection{Vegetation Properties}

Leaf area index (LAI) is an approximation of the plant canopy used by VADOSE/W to calculate actual evaporation by quantifying the amount of net radiation available at the soil surface. Temporal trends of two LAI functions that were used in the water balance modeling are shown in Fig. 8.2. One LAI function simulated a revegetated cover based on plant species present in the Phase 1 construction seed mix and observed on site. The other LAI function simulated a natural cover that represented vegetation observed in the borrow areas. The LAI function of the revegetated cover started May 1, peaked at an LAI = 3 from June 19 through July 11 , and then reduced to zero by October 28 when vegetation was assumed dormant. The peak LAI = 3 was based on the mean LAI computed from Scurlock et al. (2001) for "Grassland" 
and the U.S. EPA Hydrologic Evaluation of Landfill Performance (HELP) Model manual (Schroeder et al. 1994) for "a good stand of grass".

The natural cover was assumed to be a more diverse biome with shrubs, forbs, and grasses. The more diverse vegetation competes amongst itself for sunlight and grows vertically and laterally resulting in relatively dense cover in some areas but also bare locations as observed in the borrow areas. The diversity and native origin of species in the natural cover results in a longer growing season compared to the revegetated cover. The LAl function for the natural cover began on April 1, peaked at an LAI = 2 from June 20 through August 10, and then reduced to zero by November 16 when vegetation was assumed dormant. The peak $\mathrm{LAl}=2$ was based on Scurlock et al. (2001) for "Shrubs" in combination with qualitative observations from the borrow area.

The Rooting Depth $(\mathrm{RD})$ function specifies the density of root growth with depth during the time vegetation is assumed active (i.e., LAI > 0). A triangular distribution of roots was

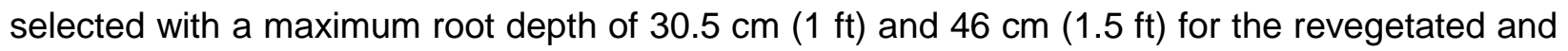
natural covers, respectively. These rooting depths were determined based on observations during sampling, and inherit differences between the revegetated grassland and more diverse plant species that represented the natural cover.

The Plant Moisture Limiting (PML) function was used to simulate the amount of available water in the soil matrix that vegetation can remove with respect to matric suction. The PML function (Fig. 8.3) begins at 1.0 as suction increases to $100 \mathrm{kPa}$ at which point the PML function decreases linearly until a value of 0.0 at a suction of $1,500 \mathrm{kPa}$. The $1,500 \mathrm{kPa}$ soil suction corresponds to the wilting point, whereupon most plants can no longer remove water from the soil matrix. The same PML function was used in the revegetated and natural cover. 


\subsection{Material Properties}

Material properties for the soil layers simulated in the water balance models were determined for Borrow Area 3, Borrow Area 4, and all three layers of the Phase 1 cover (i.e., topsoil, rooting/frost protection, and Infiltration layers). The rooting/frost protection and Infiltration layers were modeled as the same layer based on similarities between their particle size distribution, as-built compaction parameters, and observations during sampling. Laboratory test results for density, specific gravity, soil water retention, and $k_{s}$ were the basis of the hydraulic functions assigned for each material in GeoStudio. Soil water characteristic curves developed using the least means squared method presented in Chapter 6 were used for the water content functions (Fig. 8.4) of each layer except topsoil.

The topsoil water content function was calculated using van Genuchten parameters derived from the Rosetta Model (USDA, 2008) based on soil composition (percent sand, silt, and clay) and bulk density determined in the laboratory. Parameters from the Rosetta model for topsoil included $\theta_{s}=0.496, \theta_{r}=0.099, \alpha=0.0124$, and $n=1.386$, and the SWCC based on these parameters is shown in Fig. $8.4 \mathrm{~b}$.

The hydraulic conductivity function for each material was estimated using a method developed by Fredlund et al (1994). The method integrates along the volumetric water content function starting at $k_{s}$ until a maximum suction is reached (Fig. 8.5). The laboratory measured $k_{s}$ was used for each material except for topsoil where the Rosetta Model output of $1.2 \times 10^{-4} \mathrm{~cm} / \mathrm{s}$ was the basis for $k_{s}$. 

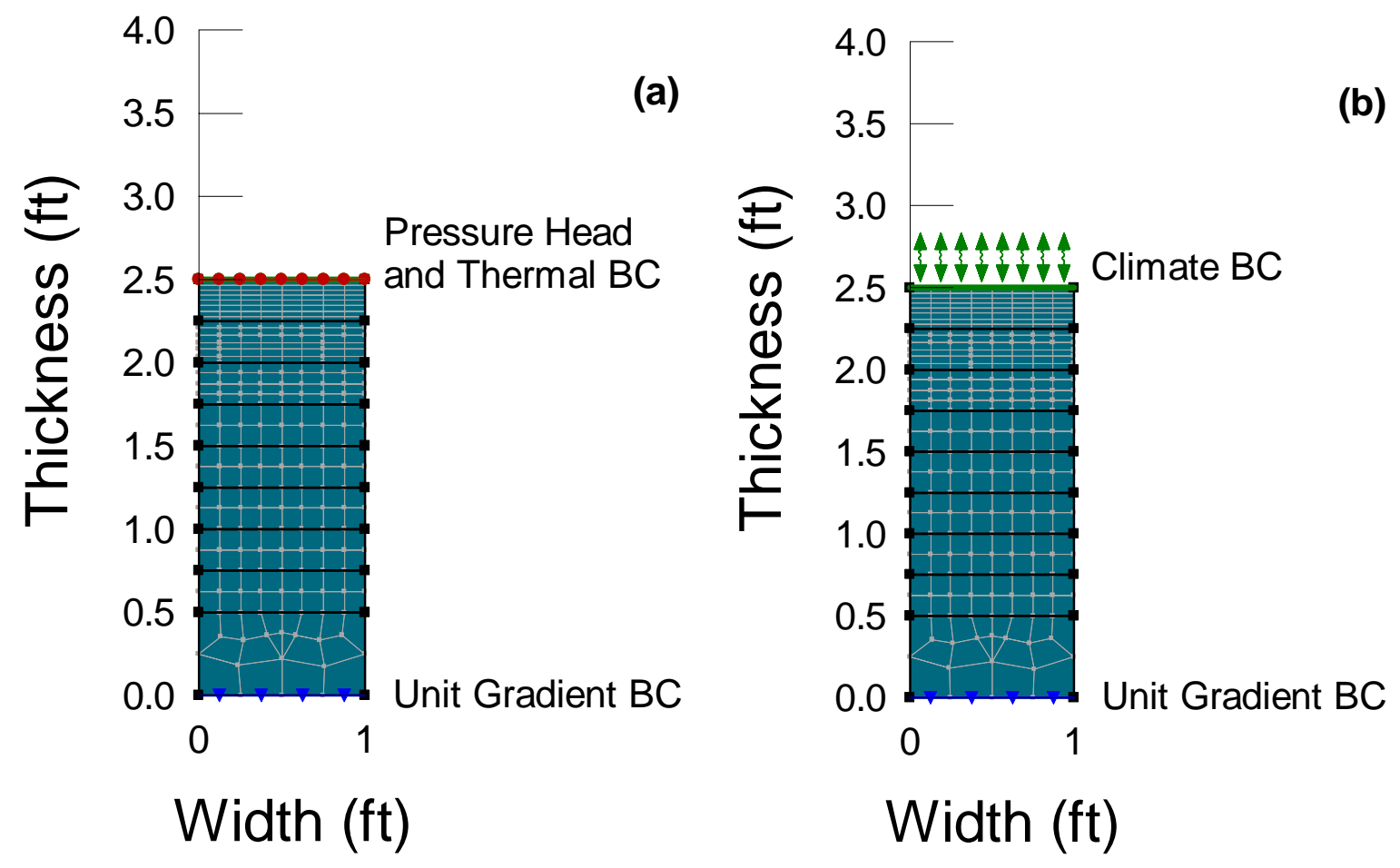

Fig. 8.1. Model geometry and boundary conditions for a 76.2 -cm-thick $(2.5 \mathrm{ft})$ cover simulation: (a) Stage 1 steady-state model and (b) Stages 2 and 3 transient models. 


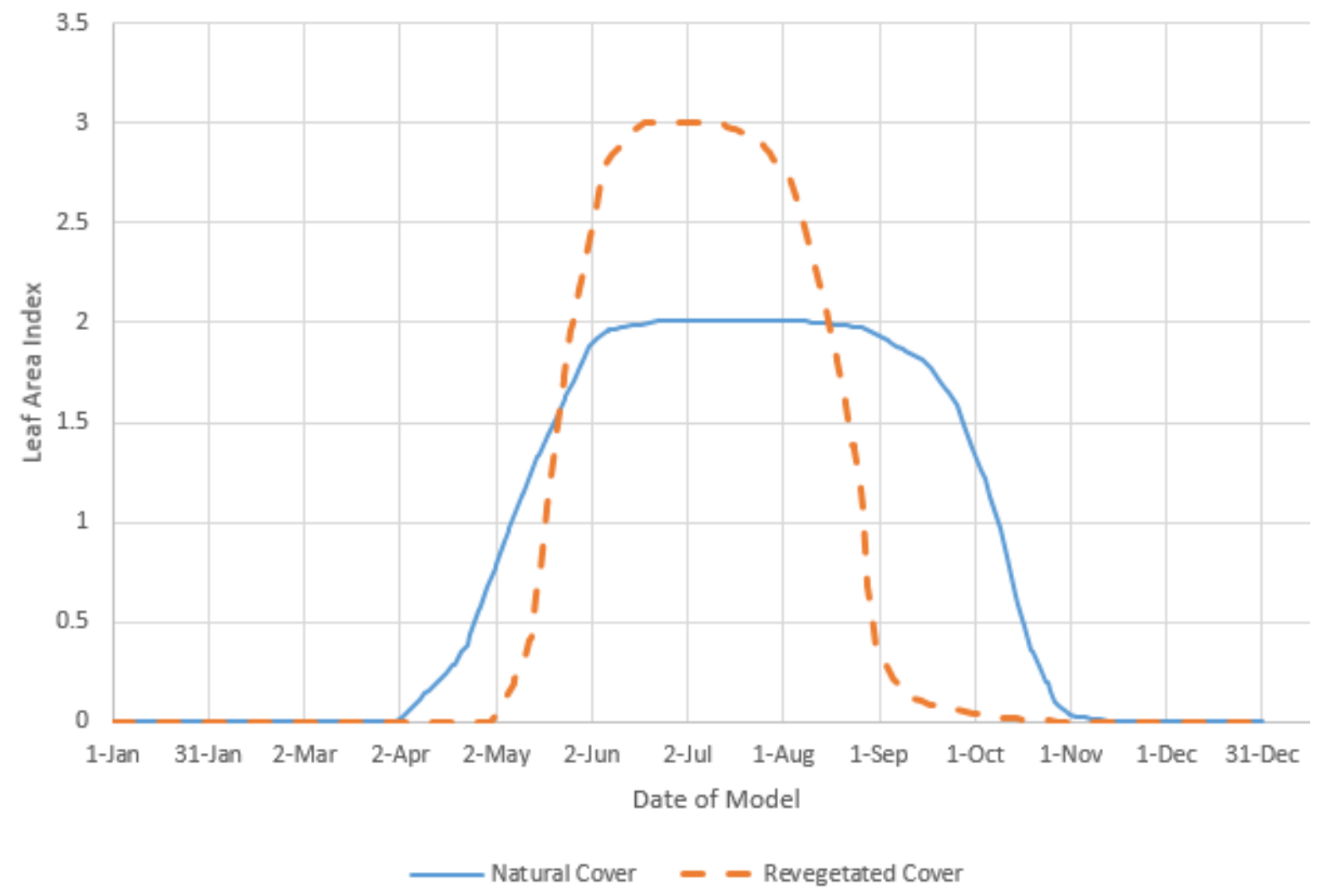

Fig. 8.2 Leaf area index functions. 


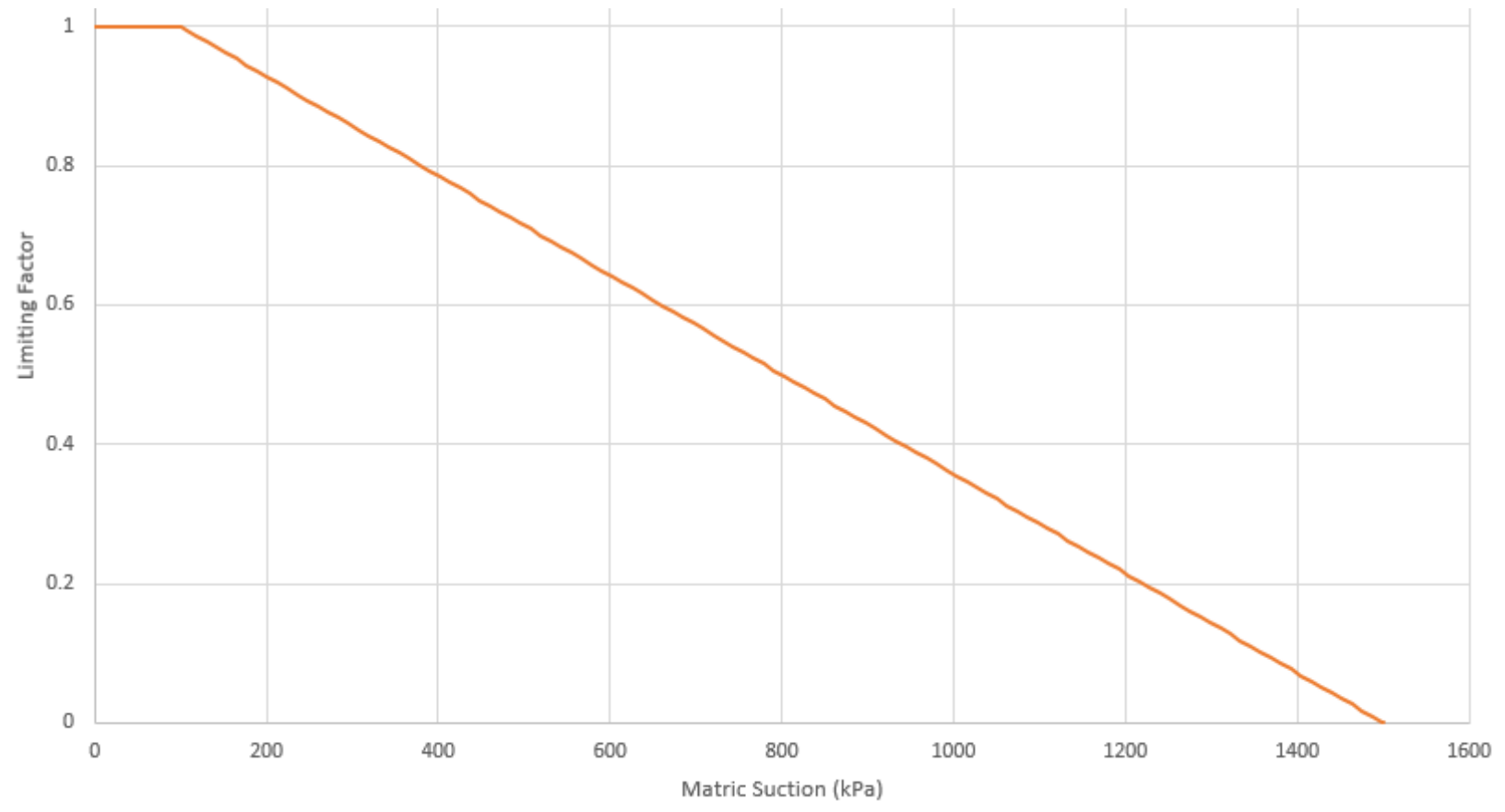

Fig. 8.3 Plant moisture limiting function. 

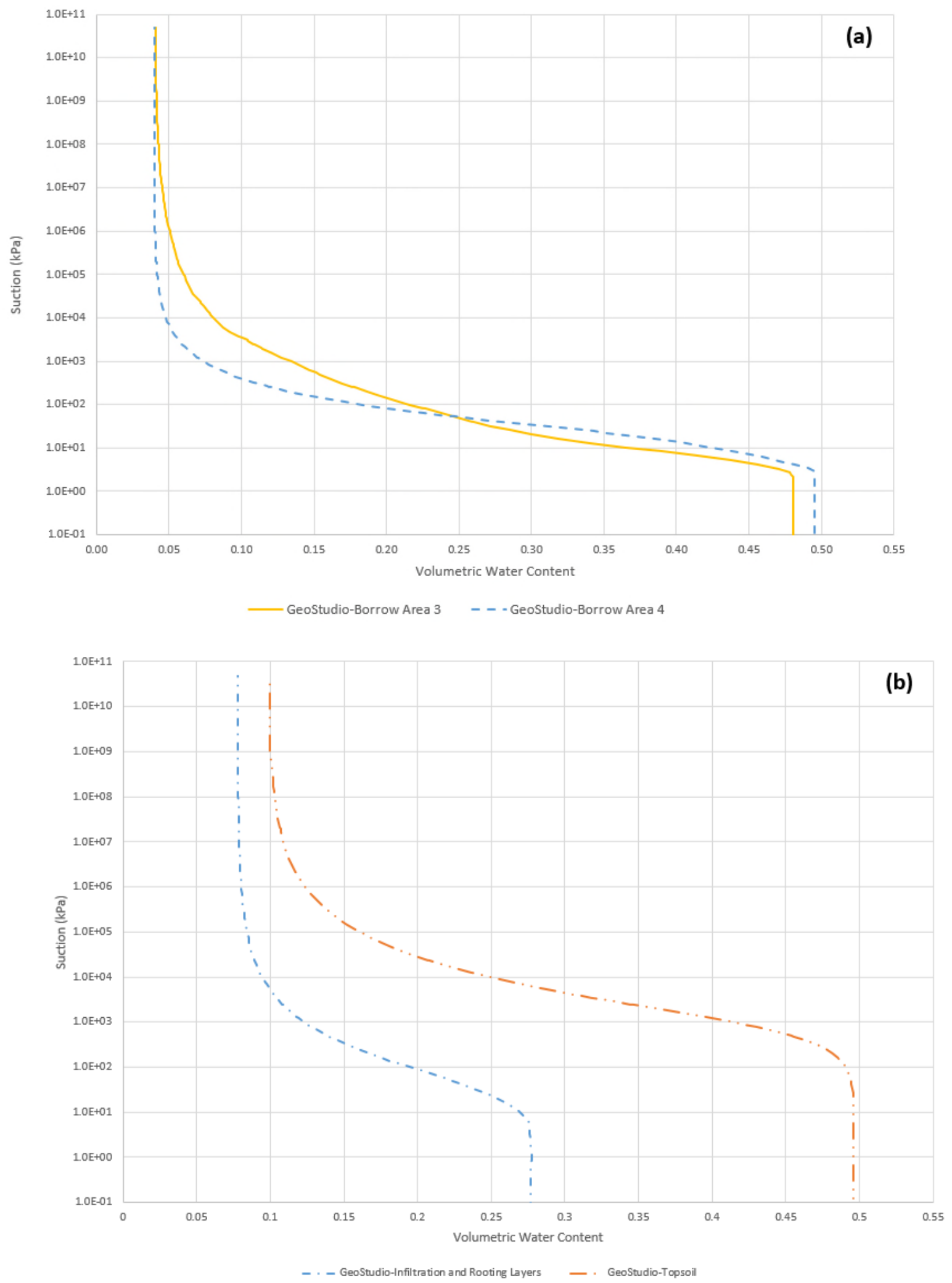

Fig. 8.4 Modeled soil water characteristic curves for (a) water balance cover and (b) Phase 1 final cover soils. 

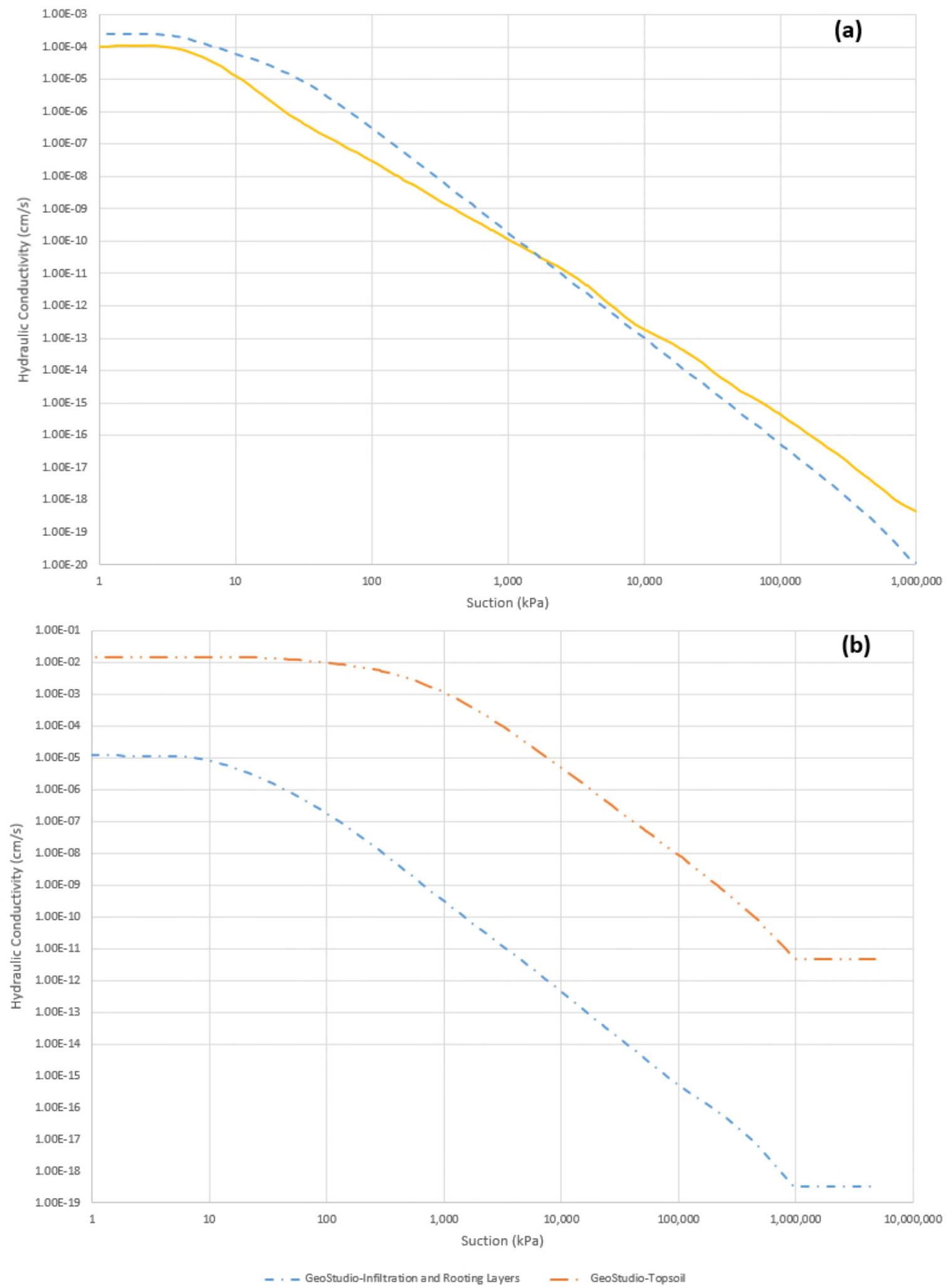

Fig. 8.5 Modeled hydraulic conductivity functions for (a) water balance cover and (b) Phase 1 final cover soils. 


\section{CHAPTER 9. MODEL RESULTS}

Variably saturated flow modeling using VADOSE/W (GeoStudio, 2016) was performed to compare the hydraulic performance of prescriptive and water balance covers. Schematics of the covers evaluated in this study are shown in Fig. 9.1. A sensitivity analysis was conducted for the

prescriptive covers that incorporated two $k_{s}\left(1.0 \times 10^{-5} \mathrm{~cm} / \mathrm{s}\right.$ or $\left.1.2 \times 10^{-7} \mathrm{~cm} / \mathrm{s}\right)$. Similarly, sensitivity analysis was conducted for the WBC models to compare cover thickness, soil from Borrow Area 3 versus Borrow Area 4, and revegetated versus natural vegetation. Components of the water balance equation (Eq. 2.1) were analyzed to compare the different covers simulated (Fig. 9.1) and assess the effects of model variables on water balance in the sensitivity analysis.

\subsection{Model Scenarios}

\subsubsection{Prescriptive}

The prescriptive cover model was based on thicknesses from CCR 1007-2, 40 CFR 258.60, and the CDPHE approved LCL design for the Phase 1 closure. The approved prescriptive cover design included from the surface down (i) $\geq 15 \mathrm{~cm}(0.5 \mathrm{ft})$ erosion layer capable of sustaining native plant growth (topsoil), (ii) $\geq 45.7 \mathrm{~cm}(1.5 \mathrm{ft}$ ) rooting layer, and (iii) $\geq$ $45.7 \mathrm{~cm}(1.5 \mathrm{ft})$ Infiltration layer with $k_{s} \leq 1 \times 10^{-5} \mathrm{~cm} / \mathrm{s}$ or $k_{s} \leq$ of any bottom liner, whichever is lower (Fig. 9.1). Although the Phase 1 cover at LCL was based on the aforementioned cover profile, the test pit excavated in Phase 1 revealed a thicker profile: (i) topsoil $\approx 30.5 \mathrm{~cm}(1 \mathrm{ft}$ ); (ii)

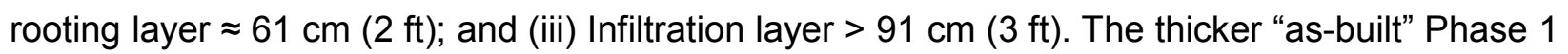
prescriptive cover was not modeled since the thicker cover profile was not considered representative of state or federal regulated prescriptive covers and may not be present across all LCL closure phases. 
The average $k_{s}$ was $1.6 \times 10^{-7} \mathrm{~cm} / \mathrm{s}$ among 13 construction quality assurance tests from the 1998 construction. The two samples collected from the Infiltration layer from this investigation had $k_{s}=1.2 \times 10^{-7} \mathrm{~cm} / \mathrm{s}$ for the upper sample and $8.9 \times 10^{-8} \mathrm{~cm} / \mathrm{s}$ for the lower sample. Modeling of the Phase 1 prescriptive cover was performed using the highest measured $k_{s}$ from this study $\left(k_{s}=1.2 \times 10^{-7} \mathrm{~cm} / \mathrm{s}\right)$ and the regulatory acceptable $k_{s}$ of $1 \times 10^{-5} \mathrm{~cm} / \mathrm{s}$.

\subsubsection{Water Balance Covers}

A 76.2-cm-thick (2.5 ft) WBC meets CDPHE requirements (2013) based on LCL being located in Ecozone 3 (Fig 2.1) and a USDA soil texture of clay loam identified for the borrow area soil (Fig. 2.2). Additional WBC models using a 76.2-cm-thick cover were completed to assess differences in soil properties between Borrow Area 3 and Borrow Area 4 and revegetated versus natural vegetation parameters. These models were completed to determine model sensitivity to soil and vegetation conditions and ultimately arrive at a recommended WBC design. In addition to the 76.2-cm-thick WBC, covers with thicknesses of $61 \mathrm{~cm}(2 \mathrm{ft})$ and 91.4 $\mathrm{cm}(3 \mathrm{ft})$ were modeled to quantify the effect of WBC thickness on percolation. For the models with varying cover thickness, Borrow Area 3 soil and revegetated conditions were used.

\subsection{CDPHE Accepted Covers Model Results}

Guidance and regulations from the state of Colorado indicate a prescriptive cover with a combined thickness of $106.7 \mathrm{~cm}(3.5 \mathrm{ft})$ or a WBC with a thickness of $76.2 \mathrm{~cm}(2.5 \mathrm{ft})$ would be acceptable for construction based on soil characteristics determined from investigations in Phase 1 and the borrow areas. Annual percolation and evapotranspiration $(E T)$ rates based on model simulations for the prescriptive cover and WBC for LCL are summarized in Table 9.1. The model results indicate an annual percolation rate $<0.1 \mathrm{~mm} / \mathrm{yr}$ for the prescriptive cover using $k_{s}$ measured in this study $\left(1.2 \times 10^{-7} \mathrm{~cm} / \mathrm{s}\right)$ and a percolation rate $2.2 \mathrm{~mm} / \mathrm{yr}$ for the prescriptive cover with the regulatory $k_{s}=1 \times 10^{-5} \mathrm{~cm} / \mathrm{s}$. The most effective WBC had an annual 
percolation rate of $6.3 \mathrm{~mm} / \mathrm{yr}$. The most effective WBC in terms of achieving low percolation rates were simulated with soil from either Borrow Area 3 or Borrow Area 4 and natural vegetation (Table 9.1). The maximum annual percolation of $11.3 \mathrm{~mm} / \mathrm{yr}$ resulted from a WBC simulated with Borrow Area 3 soil and vegetation simulating a revegetated cover.

Temporal trends of percolation and precipitation during the model simulation period for the CDPHE acceptable prescriptive and water balance covers are shown in Fig. 9.3. Cumulative percolation through the prescriptive cover with $k_{s}=1.2 \times 10^{-7} \mathrm{~cm} / \mathrm{s}$ was less than $1 \mathrm{~mm}$, which forced the percolation data to plot along the x-axis in Fig. 9.3. Percolation through the prescriptive cover with $k_{s}=1.0 \times 10^{-5} \mathrm{~cm} / \mathrm{s}$ and percolation through the WBC models reflect surges of percolation in response to precipitation events. This surge behavior is typical of simulated WBC and represents periods of high precipitation that coincided with high levels of soil saturation (Bareither et al. 2016). During these precipitation events, insufficient storage is available within the cover, which allows percolation to occur. In this study, these isolated, high percolation events represented the majority of percolation that was simulated.

CDPHE or federal regulations do not define an allowable percolation threshold for the bottom of a cover profile. Instead, percolation thresholds are defined from either (i) preconstruction or immediate post construction soil properties and layer thicknesses, or (ii) an equivalency demonstration in the case of a WBC (as described in Chapter 1). Interpretation of the model results presented in the WBC guidance document from CDPHE (2013) shown in Fig. 9.2 and the CDPHE acceptable thickness criteria (Fig. 2.2) indicate that a percolation rate ranging from 11.2 to $22.4 \mathrm{~mm} / \mathrm{yr}$ was used to determine acceptable cover thicknesses in the CDPHE WBC guidance document. Equivalency is not quantified in the regulations; thus, the acceptable difference in percolation between a prescriptive and water balance cover cannot be determined. However, all WBC simulations completed on acceptable CDPHE covers yielded percolation rates that were lower than the minimum CDPHE value of $11.2 \mathrm{~mm} / \mathrm{yr}$ except for the 
scenario of Borrow Area 3 soils and revegetated conditions which resulted in a percolation rate of $11.3 \mathrm{~mm} / \mathrm{yr}$.

Model output for percolation, ET, soil water storage (storage), and runoff was evaluated to assess the water balance in response to the simulated climatic conditions (Table 9.1). Percolation was low in all models, and calculated to be approximately $0.0 \%$ to $0.5 \%$ of the prescriptive cover water balance, and between $0.3 \%$ and $0.8 \%$ of the WBC water balance. Evapotranspiration was the dominant mechanism that removed water from the system, and in all model simulations ET removed between $94 \%$ and $102 \%$ of the precipitation during the modeled period. The similarity in magnitude of $E T$ and precipitation indicates the two were favorably balanced during the years simulated. Storage was the next most significant water balance component relative to $E T$, consisting of a gain of $2.4 \%$ or a cumulative loss of $0.3 \%$ in the prescriptive cover models and a loss of $2.2 \%$ to $3.4 \%$ in the WBC models. A gain in storage indicates the model geometry is accumulating water throughout the modeled period and a loss in storage indicates the model is losing water throughout the modeled period. Runoff was negligible in all models, which was expected for the 1-D simulations.

Annual average precipitation, evaporation, and transpiration for the water balance simulations are shown graphically on Fig. 9.4. The data in Fig. 9.4 demonstrate that in the prescriptive cover the dominant water balance component was evaporation, which removed 62 $\%$ and $67 \%$ of the precipitation. In contrast, transpiration was the dominant water balance component that removed precipitation from the WBC profiles, accounting for $58 \%$ to $73 \%$ of the cumulative precipitation. These data indicate that the lower permeability of the prescriptive cover soil stored precipitation closer to the surface where evaporation was most influential. In contrast, the higher permeability WBC allowed for deeper infiltration of the precipitation where transpiration was more influential. 


\subsection{Borrow Area 3 WBC Sensitivity Analysis Model Results}

Additional Borrow Area 3 WBC scenarios with varying thickness were modeled to quantify the effect of cover thickness on percolation and further assess equivalency relative to the prescriptive cover. Borrow Area 3 soils were selected for the sensitivity analysis because the 76.2-cm-thick (2.5 ft) CDPHE acceptable WBC had higher percolation than the Borrow Area 4 WBC with the same thickness and vegetation type. Model simulations were completed such that the cover thicknesses varied $\pm 15.2 \mathrm{~cm}(0.5 \mathrm{ft})$ from the acceptable thickness of $76.2 \mathrm{~cm}(2.5 \mathrm{ft})$.

Water balance modeling results for the Borrow Area 3 WBC with varying cover thickness are summarized in Table 9.2. Modeling results indicate a trend of decreasing percolation with increasing cover thickness. The maximum percolation of $13.2 \mathrm{~mm} / \mathrm{yr}$ was simulated for the 61 $\mathrm{cm}$-thick (2 ft) WBC with a revegetated cover, whereas a minimum percolation of $4.9 \mathrm{~mm} / \mathrm{yr}$ was simulated for the $91.4 \mathrm{~cm}$-thick ( $3 \mathrm{ft}$ ) WBC with a natural cover. Analysis of the water balance in Table 9.2 indicates that transpiration was the dominant component for the Borrow Area 3 WBC. Evaporation was also a relatively large contribution to the water balance when compared to the other components. Combined, ET contributed $92 \%$ to $95 \%$ of precipitation removed under revegetated conditions and 97 to $100 \%$ of precipitation removed under natural vegetation conditions. The similar magnitude of $E T$ and precipitation again demonstrates the balance between $E T$ and precipitation that was apparent in the CDPHE acceptable cover models. Annual storage showed a slight decrease in the rate of storage loss with an increase in the WBC thickness indicating the thinner covers lost slightly more water during the simulation.

\subsection{Further Detail of Model Results}

Volumetric water content $(\theta)$ of the modeled WBC constructed of Borrow Area 3 soils and revegetated cover characteristics were analyzed to further evaluate percolation. The WBC modeled with Borrow Area 3 soils and revegetated parameters was selected because this model scenario presented the highest percolation rate among the models. 
Temporal trends of $\theta$ at the bottom of the WBC and percolation during the 10-year simulation are shown in Figure 9.5 for the following time periods: (a) 1992-2002, (b) 1997 (wettest year on record), and (c) during the Spring Creek Floods of 1997. A 30-hr precipitation of $16.1 \mathrm{~cm}$ was measured at the CSU weather station during the Spring Creek Floods, which was a historically significant event to the city of Fort Collins. The shorter time periods in Fig. $9.5 \mathrm{~b}$ through $9.5 \mathrm{~d}$ were reviewed to analyze $\theta$ in response to higher-than-normal precipitation. Over the majority of the simulation, $\theta$ was lower for the thinner WBC; however, when precipitation events occurred, the thinner WBC had higher $\theta$ and a corresponding larger increase in percolation. This change in $\theta$ identified as a spike in response to precipitation events is referred to as amplitude. The larger amplitude of the thinner cover was attributed to lower available storage capacity in the thinner cover.

The lower available storage capacity of the thinner cover ultimately led to more percolation during high precipitation events due to the thinner cover having insufficient storage capacity to retain infiltrated water. As well as having a larger amplitude, the thinner WBC had a shorter duration of increased $\theta$ following precipitation events than the thicker WBC. This behavior was attributed to the transpiration component of the WBC. Transpiration removes a greater percentage of water from the thinner WBC compared to the thicker WBC because the revegetated rooting depth function of $30.5 \mathrm{~cm}(1 \mathrm{ft})$ consists of a greater percentage of total cover thickness in the thinner WBC. The average $\theta$ at the bottom of the cover from 1992-2002 with respect to depth is shown on Fig. 9.6. Despite allowing more percolation, the average $\theta$ of the thinner cover is less than the thicker cover and the difference increases with depth of the profile. As the thicker cover extends further beyond the limits of the revegetated rooting depth function, soil near the base of the thicker covers retained more water and had higher $\theta$.

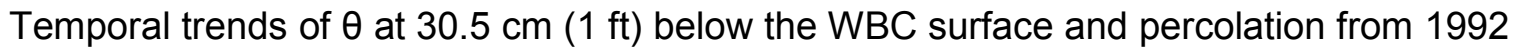
to 2001 are shown in Fig. 9.7. The $\theta$ in Fig. 9.7 shows a larger amplitude when compared to Fig. 9.5.a, which indicates that soil located closer to the surface was more sensitive to climatic 
conditions. Additionally, the difference in $\theta$ among the three cover thicknesses was less near the surface (Fig. 9.6) when compared to the difference in $\theta$ at the bottom of the covers (Fig. 9.5.a). This was attributed to climate and vegetation conditions being relatively the same at $30.5 \mathrm{~cm}$ below the surface and independent of the WBC thickness.

\subsection{Practical Implications of Research Results}

Results of this research indicate that on-site borrow soils at LCL meet regulatory requirements for either prescriptive or water balance final closure covers if regulatory design standards for layer thickness and/or $k_{s}$ are implemented. Regulatory compliance has been previously achieved through four closure phases with prescriptive covers at LCL, starting with Phase 1 in 1998. Variably saturated flow modeling of the prescriptive cover indicated an annual percolation rate of $<0.1$ to $2.2 \mathrm{~mm} / \mathrm{yr}$, dependent on $k_{s}\left(1.2 \times 10^{-7} \mathrm{~cm} / \mathrm{s}\right.$ or $\left.1.0 \times 10^{-5} \mathrm{~cm} / \mathrm{s}\right)$.

The WBC design was varied in regards to thickness, soil properties, and vegetation to assess the impact on percolation. Water balance models yielded percolation rates ranging between 6.3 and $11.3 \mathrm{~mm} / \mathrm{yr}$. The lowest percolation rates were independent of Borrow Area 3 or Borrow Area 4 soils, but corresponded to vegetation conditions represented by natural vegetation observed in the borrow areas during this study. Interpretation of model results from the CDPHE Water Balance Guidance (CDPHE 2013) indicated a percolation rate of 11.2 to 22.4 $\mathrm{mm} / \mathrm{yr}$ was used to assign acceptable layer thicknesses for covers composed of soils similar to those identified in Borrow Areas 3 and 4. However, Federal or Colorado regulations do not define equivalency or quantify allowable percolation through a WBC for comparison purposes to a prescriptive cover. Thus, percolation cannot be used solely to determine acceptance of a WBC at LCL. Instead, soil properties from the borrow areas and constructed layer thickness will be used to design a WBC that meets CDPHE regulations. When selecting between a prescriptive or WBC, Larimer County should consider the effects of pedogenesis on soil properties, stability of the cover system, constructability, and cost. 
The Engineering Design of Operations Plan (EDOP) must be revised for CDPHE approval prior to design of a WBC at LCL in the event the final cover design is changed from a prescriptive cover to a WBC. Soil particle size distribution, layer thickness, quality assurance testing, and seed mix of the cover must be updated in the EDOP. Larimer County Landfill has already sampled and characterized Borrow Area 3 and Borrow Area 4, which can be used to develop the WBC design. No discernible difference was observed in the soil characterized from material in the upper horizon of the borrow areas (topsoil) compared to the lower horizon; however, the upper material should be preserved and used as the topsoil layer during WBC construction to promote vegetation growth.

Construction quality controls such as surveys or staking rods should be used to verify layer thickness during construction. A construction quality assurance plan must meet the requirements of the CDPHE Water Balance Guidance (CDPHE 2013) that specifies types of tests and testing frequency. A seed mix with more diverse species that are native to the area should be used to represent the natural vegetation, which will be more effective at decreasing percolation via increasing transpiration. Requirements from the CDPHE Water Balance Guidance, as well as the effects of vegetation on erosion control, aesthetics, and long-term succession, should also be considered when selecting a revegetation seed mix. 
Table 9.1 Water balance metrics for prescriptive and water balance covers that met CDPHE regulations.

\begin{tabular}{|c|c|c|c|c|c|c|c|c|}
\hline Cover Type & $\begin{array}{c}\text { Cover Soil } \\
\text { Location }\end{array}$ & Vegetation & $\begin{array}{c}\text { Thickness } \\
\mathrm{cm}(\mathrm{ft})\end{array}$ & $\begin{array}{c}\text { Avg. Annual } \\
\text { Percolation } \\
(\mathrm{mm} / \mathrm{yr})\end{array}$ & $\begin{array}{c}\text { Avg. } \\
\text { Annual } \\
E T \\
(\mathrm{~mm} / \mathrm{yr})\end{array}$ & $\begin{array}{c}\text { Avg. Annual } \\
\text { Evaporation } \\
(\mathrm{mm} / \mathrm{yr})\end{array}$ & $\begin{array}{c}\text { Avg. Annual } \\
\text { Transpiration } \\
(\mathrm{mm} / \mathrm{yr})\end{array}$ \\
$\begin{array}{c}\text { Avg. } \\
\text { Annual } \\
\text { Storage } \\
(\mathrm{mm} / \mathrm{yr})\end{array}$ \\
\hline Prescriptive & $\begin{array}{c}\text { Phase 1, } \\
\text { Measured } k_{s}\end{array}$ & Revegetated & $106.7(3.5)$ & $<0.1$ & 425 & 277 & 148 & -2.9 \\
\hline Prescriptive & $\begin{array}{c}\text { Phase 1, } \\
k_{s}=1 . \times 10^{-5} \mathrm{~cm} / \mathrm{s}\end{array}$ & Revegetated & $106.7(3.5)$ & 2.2 & 398 & 259 & 138 & 10.2 \\
\hline WBC & Borrow Area 3 & Revegetated & $76.2(2.5)$ & 11.3 & 389 & 141 & 248 & -18.7 \\
\hline WBC & Borrow Area 3 & Natural & $76.2(2.5)$ & 6.3 & 411 & 114 & 296 & -19.9 \\
\hline WBC & Borrow Area 4 & Revegetated & $76.2(2.5)$ & 9.6 & 397 & 156 & 241 & -18.8 \\
\hline WBC & Borrow Area 4 & Natural & $76.2(2.5)$ & 6.3 & 420 & 127 & 293 \\
\hline
\end{tabular}

Note: $415 \mathrm{~mm} / \mathrm{yr}$ average annual precipitation over model years (1992-2002); Average annual runoff $<0.1 \mathrm{~mm} / \mathrm{yr}$ for all models 
Table 9.2 Water balance metrics for water balance covers simulated with Borrow Area 3 soil parameters but with varying vegetation parameters (revegetated versus natural) and cover thickness.

\begin{tabular}{|c|c|c|c|c|c|c|c|}
\hline Cover Type & Vegetation & $\begin{array}{c}\text { Thickness } \\
\mathrm{cm}(\mathrm{ft})\end{array}$ & $\begin{array}{l}\text { Avg. Annual } \\
\text { Percolation } \\
\text { (mm/yr) }\end{array}$ & $\begin{array}{l}\text { Avg. Annual } \\
\text { Evaporation } \\
\text { (mm/yr) }\end{array}$ & $\begin{array}{l}\text { Avg. Annual } \\
\text { Transpiration } \\
\text { (mm/yr) }\end{array}$ & $\begin{array}{l}\text { Avg. Annual } \\
\text { Storage } \\
\text { (mm/yr) }\end{array}$ & $\begin{array}{l}\text { Avg. Annual } \\
\text { Runoff } \\
\text { (mm/yr) }\end{array}$ \\
\hline WBC, BA3 & Revegetated & $61(2)$ & 13.2 & 141 & 241 & -18.9 & $<0.1$ \\
\hline WBC, BA3 & Revegetated & $76.2(2.5)$ & 11.3 & 141 & 248 & -18.7 & $<0.1$ \\
\hline WBC, BA3 & Revegetated & $91.4(3)$ & 10.1 & 142 & 252 & -18.5 & $<0.1$ \\
\hline WBC, BA3 & Natural & $61(2)$ & 8.1 & 115 & 288 & -20.4 & $<0.1$ \\
\hline WBC, BA3 & Natural & $76.2(2.5)$ & 6.3 & 114 & 296 & -19.9 & $<0.1$ \\
\hline WBC, BA3 & Natural & $91.4(3)$ & 4.9 & 115 & 301 & -19.7 & $<0.1$ \\
\hline
\end{tabular}

Note: $415 \mathrm{~mm} / \mathrm{yr}$ average annual precipitation over model years (1992-2002) 


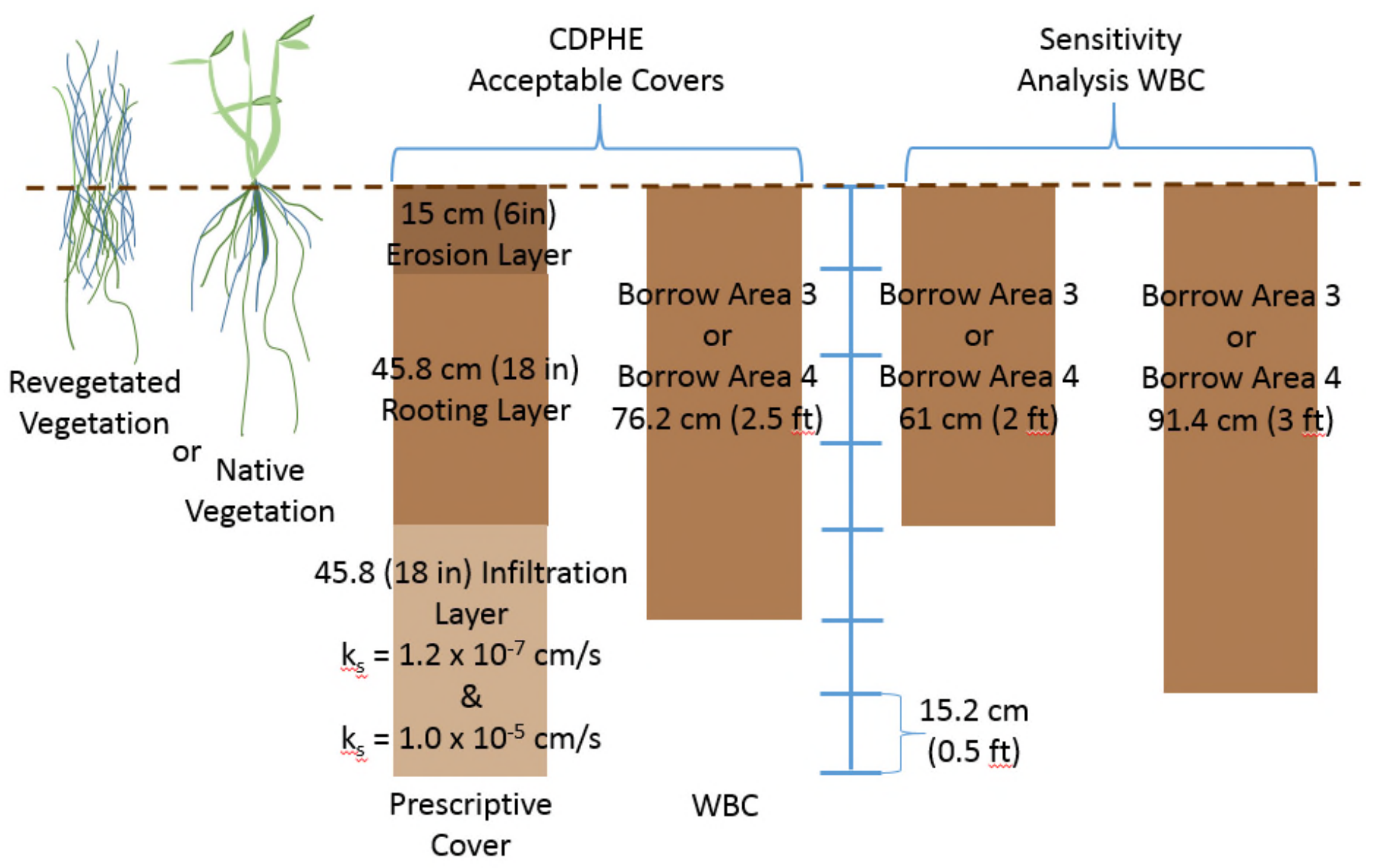

Fig. 9.1. Schematics of the prescriptive and water balance cover model scenarios analyzed for this study. 


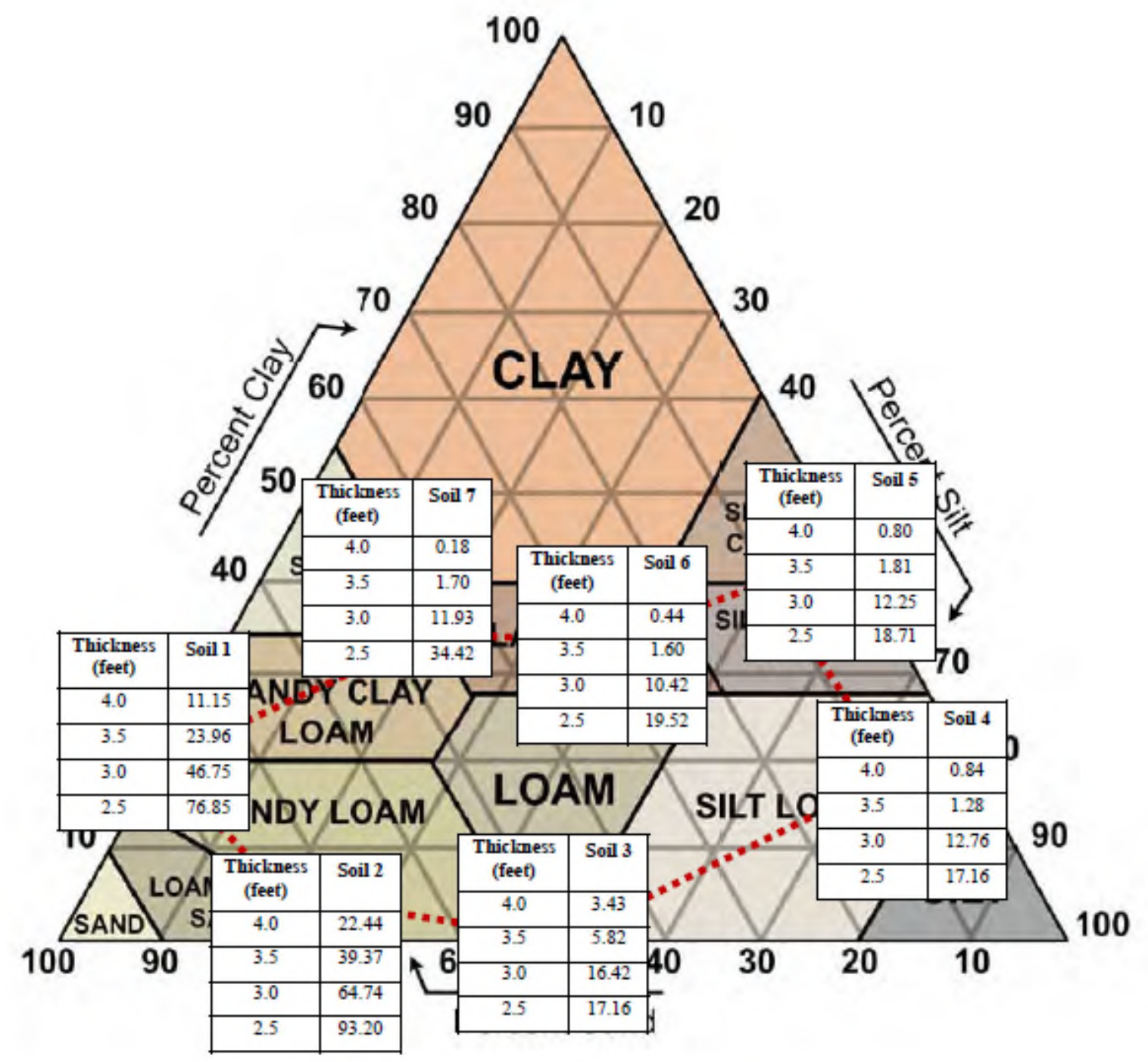

Fig 9.2. Model results for Ecozone 3 from Figure 19 of CDPHE Water Balance Guidance (2013). 


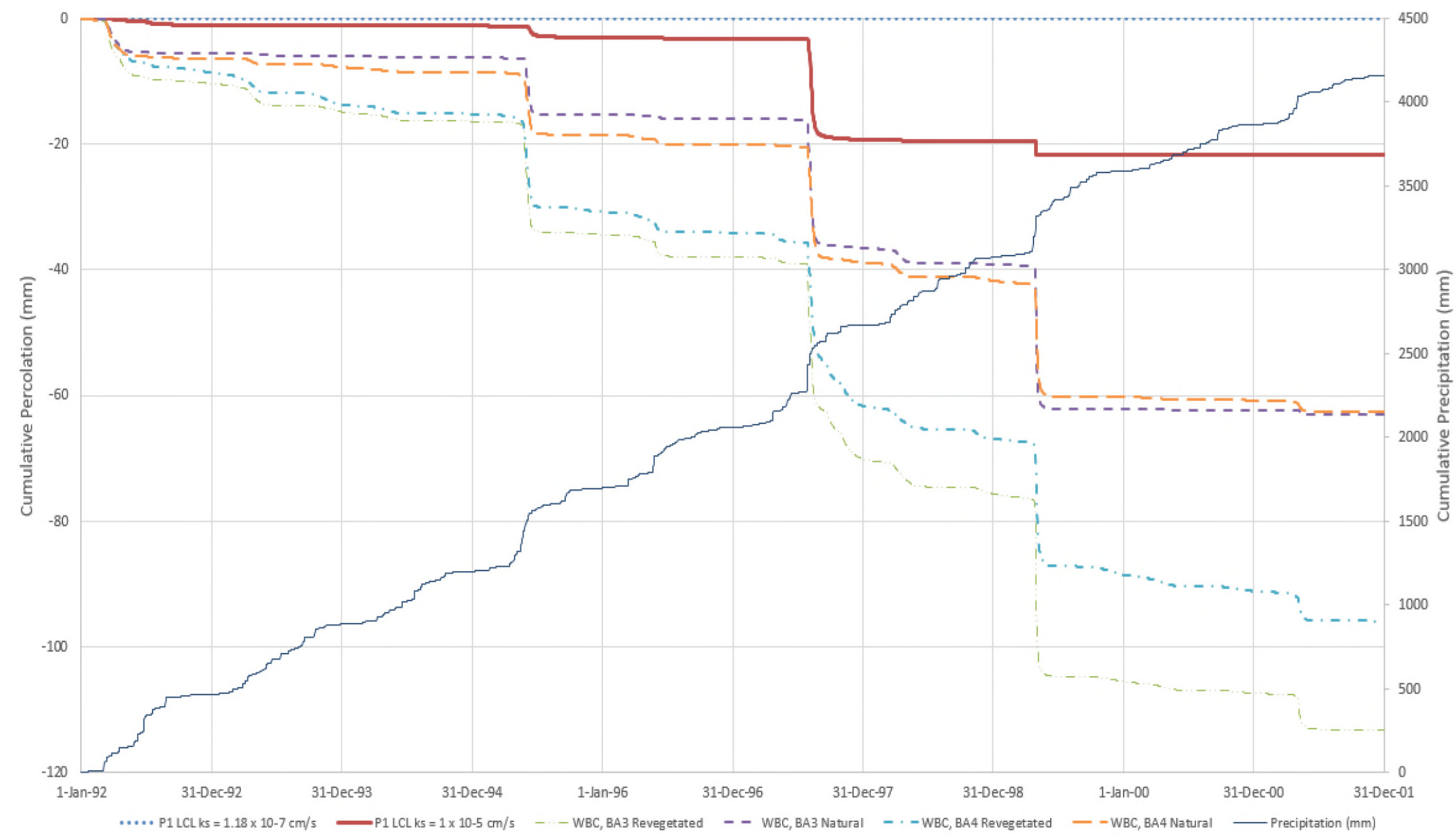

Fig 9.3. Temporal trends from 1992-2002 of cumulative precipitation and percolation from the prescriptive and water balance cover model simulations completed for the covers that met CDPHE regulations. 


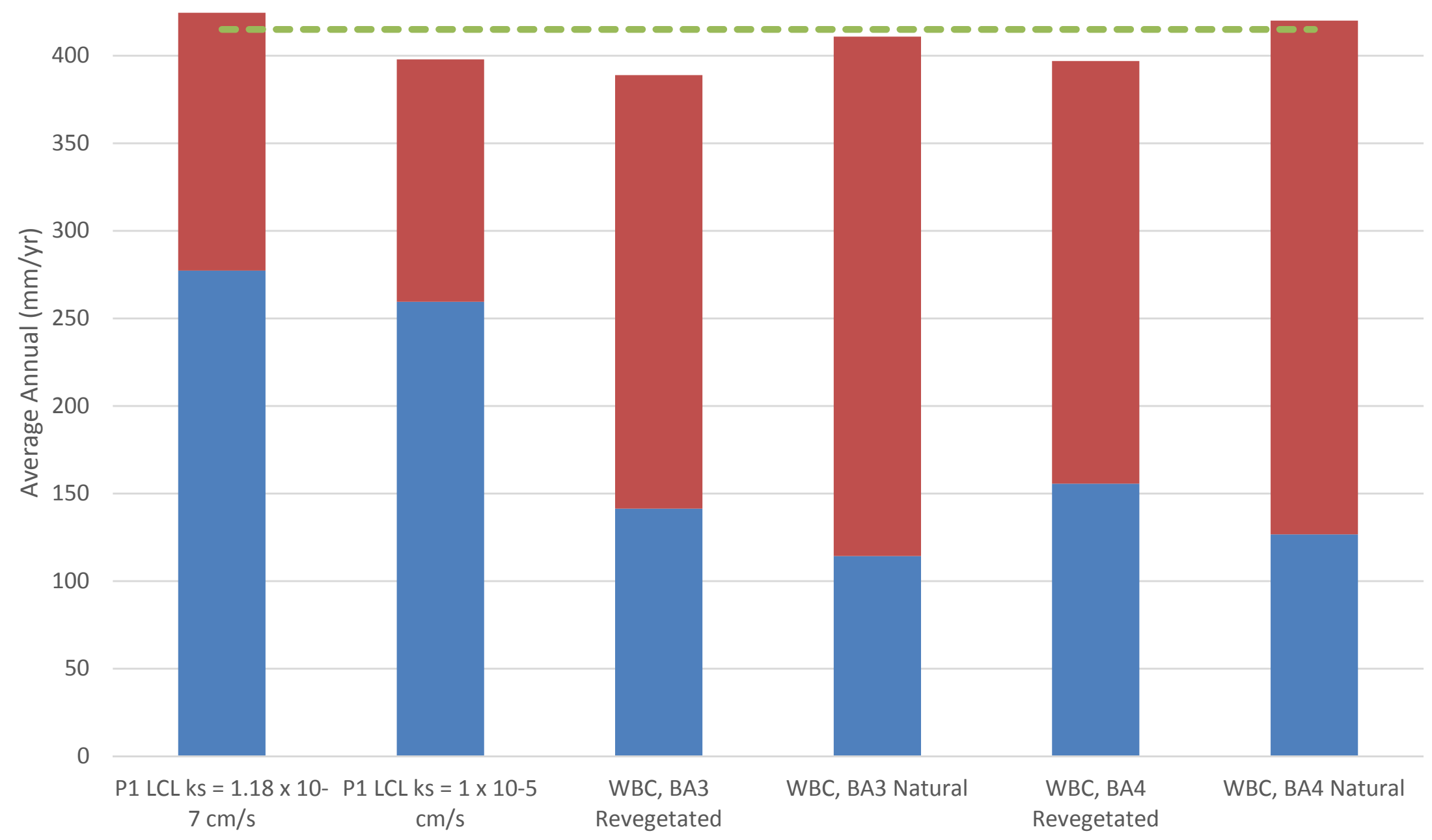

Average Annual Evaporation average Annual Transpiration - - • Average Annual Precipitation (1992-2001)

Fig 9.4. Average annual evaporation, transpiration, and precipitation the prescriptive and water balance cover model simulations completed for the covers that met CDPHE regulations. 


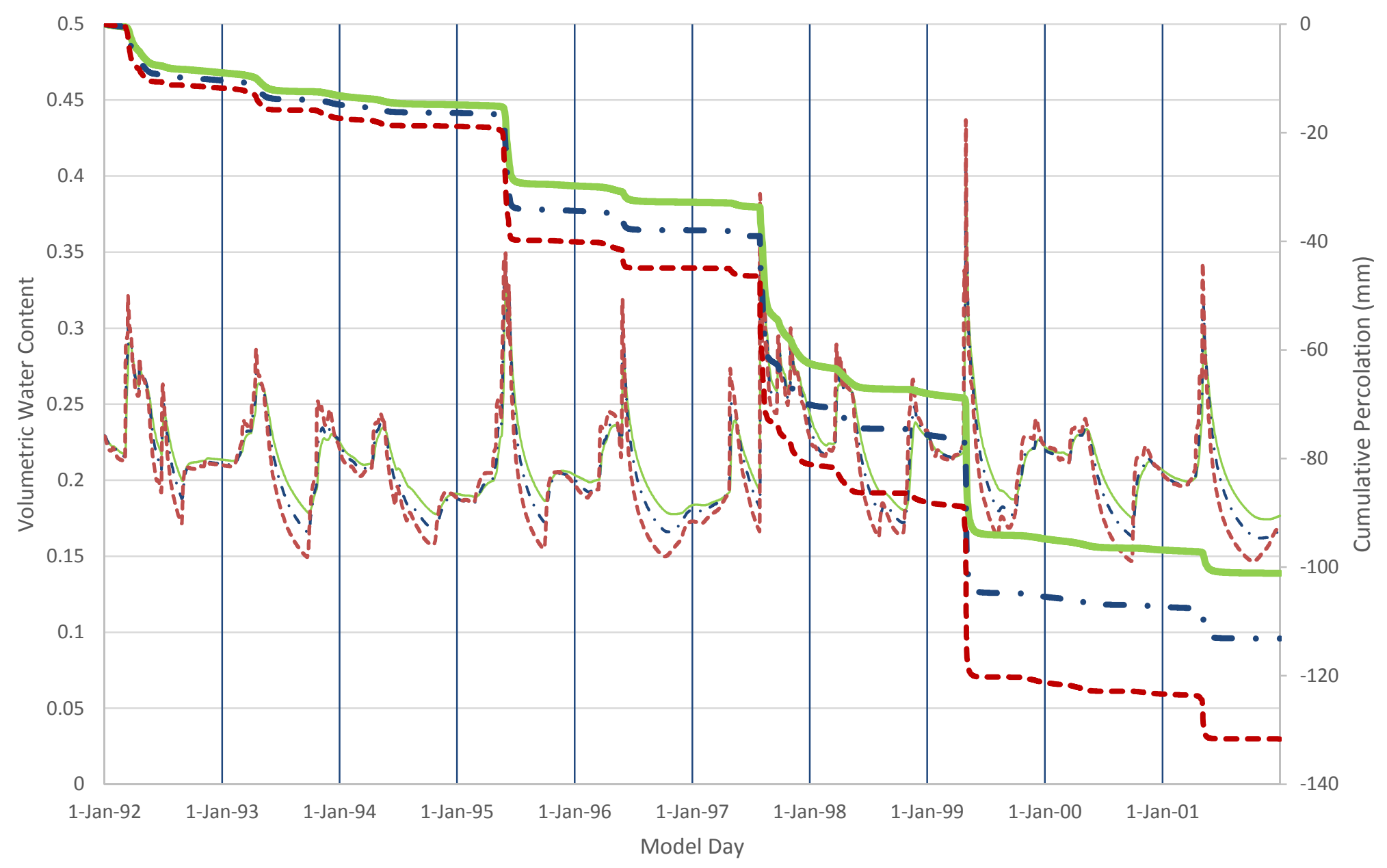

$91.4 \mathrm{~cm}(3 \mathrm{ft})$ thick cover

- - . $76.2 \mathrm{~cm}(2.5 \mathrm{ft})$ thick cover

-.-.-. $61 \mathrm{~cm}(2 \mathrm{ft})$ thick cover

Cumulative Percolation $91.4 \mathrm{~cm}$ cover

- Cumulative Percolation $76.2 \mathrm{~cm}$ cover

- Cumulative Percolation $61 \mathrm{~cm}$ cover

Fig. 9.5.(a) Percolation and volumetric water content from 1992-2002 at the bottom of the cover profile for water balance covers simulated with Borrow Area 3 soil, revegetated vegetation parameters, and varying thicknesses. 


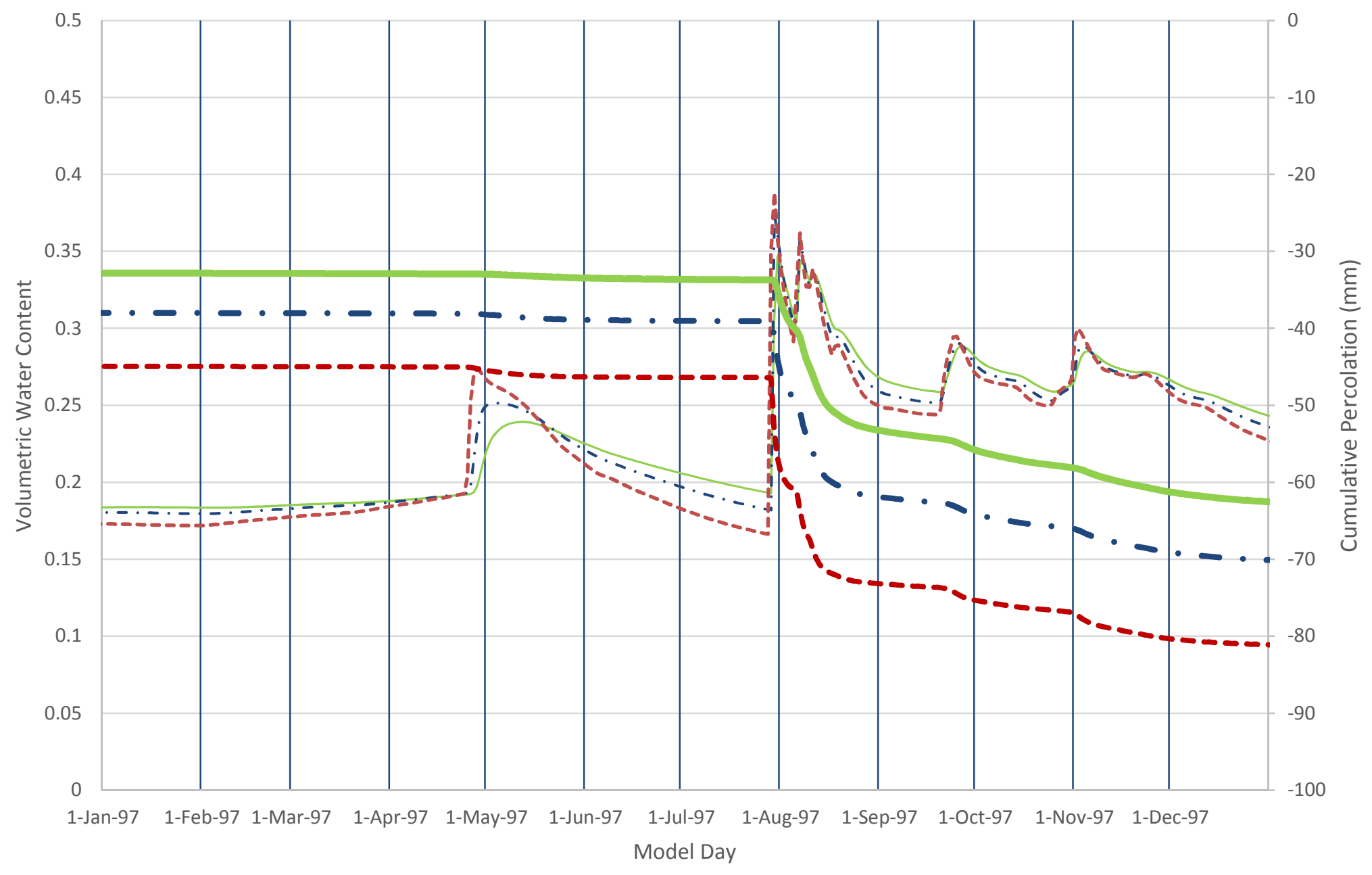

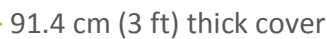

- - . $76.2 \mathrm{~cm}(2.5 \mathrm{ft})$ thick cover

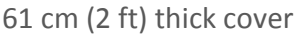

Cumulative Percolation $91.4 \mathrm{~cm}$ cover

- Cumulative Percolation $76.2 \mathrm{~cm}$ cover

- Cumulative Percolation $61 \mathrm{~cm}$ cover

Fig. 9.5.(b) Percolation and volumetric water content during 1997 (wettest year modeled) at the bottom of the cover profile for water balance covers simulated with Borrow Area 3 soil, revegetated vegetation parameters, and varying thicknesses. 


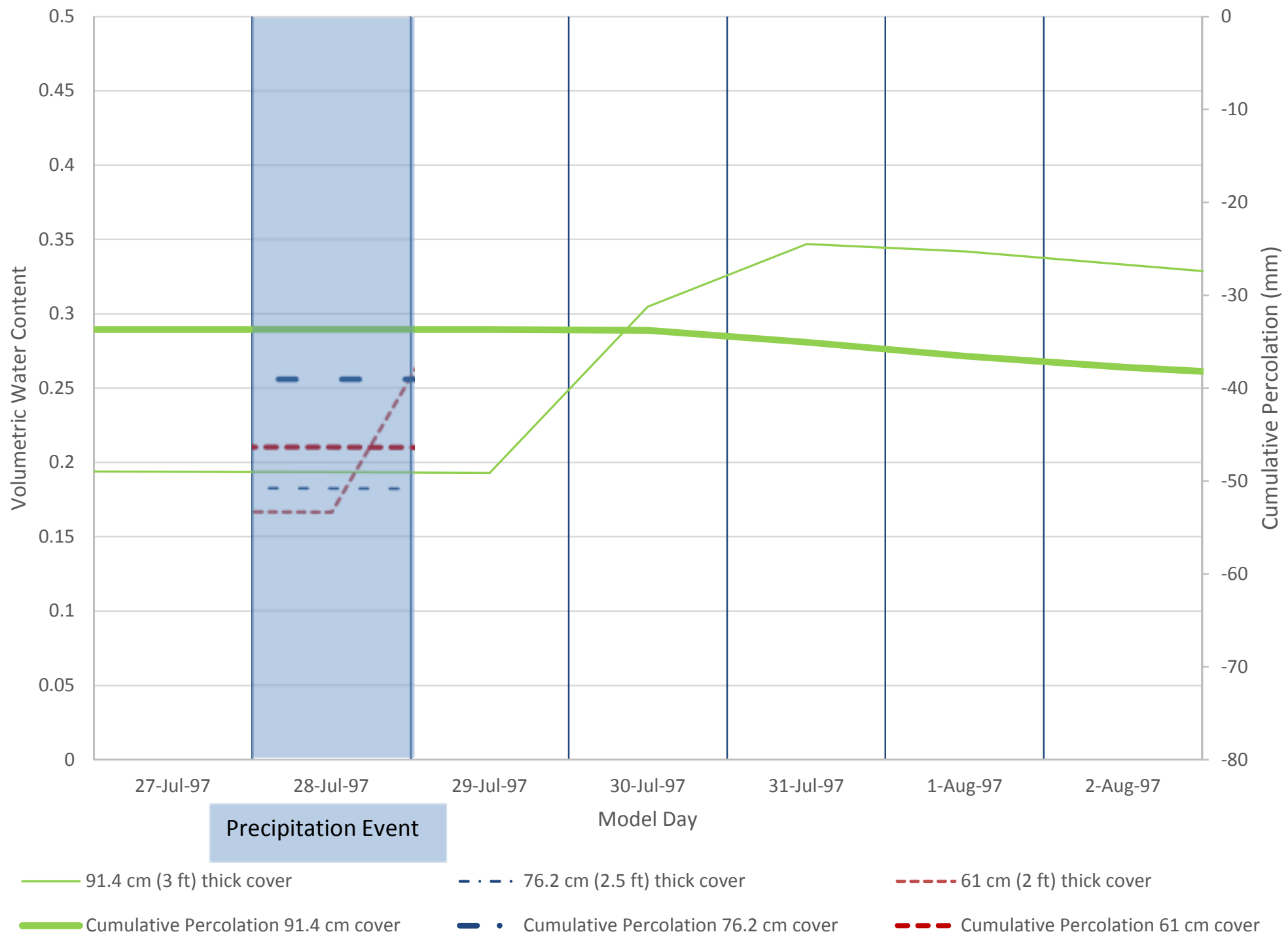

Fig. 9.5.(c) Percolation and volumetric water content during Spring Creek Floods of 1997 at the bottom of the cover profile for water balance covers simulated with Borrow Area 3 soil, revegetated vegetation parameters, and varying thicknesses. 


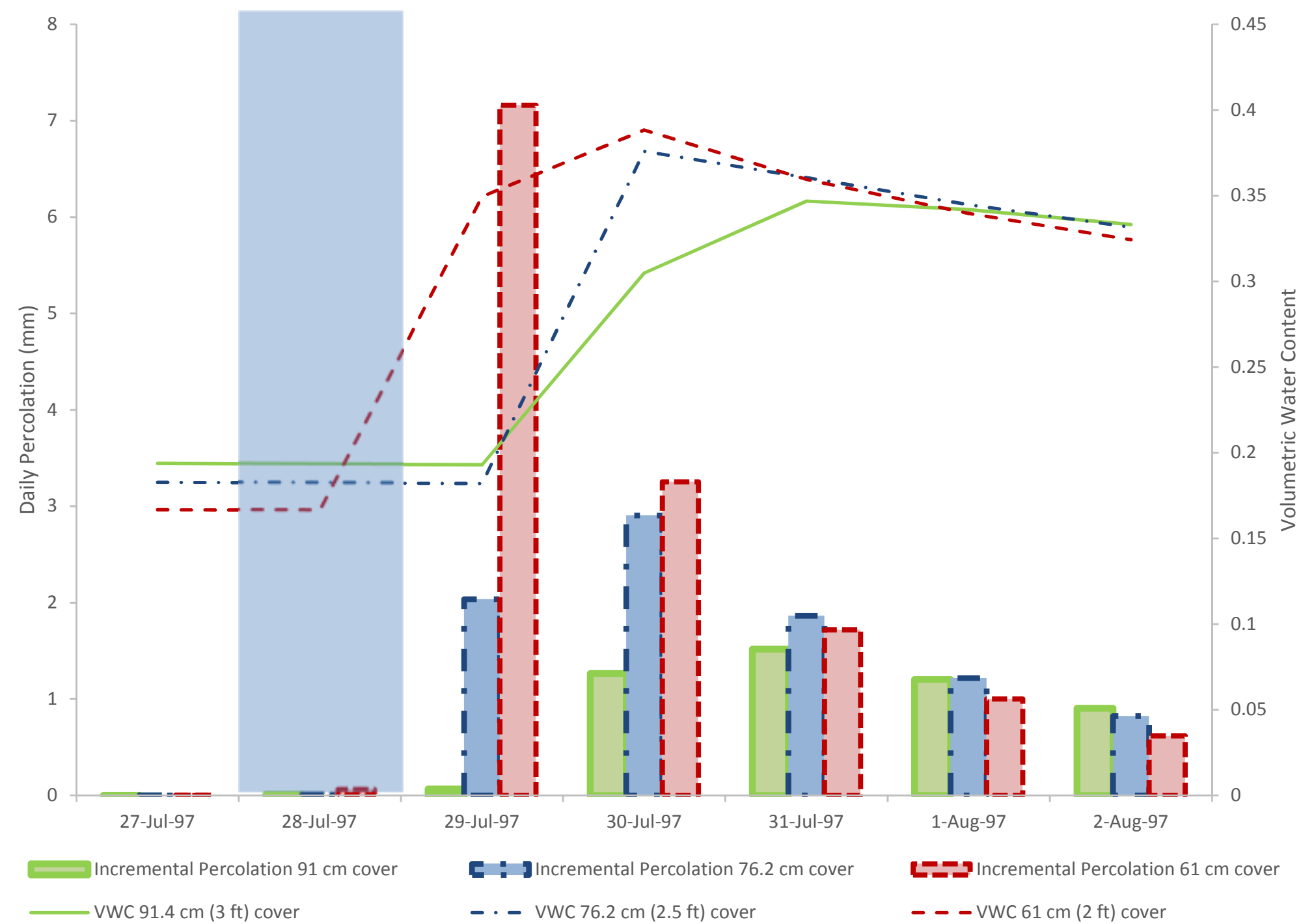

Fig. 9.5.(d) Volumetric water content and incremental percolation during Spring Creek Floods of 1997 at the bottom of the cover profile for water balance covers simulated with Borrow Area 3 soil, revegetated vegetation parameters, and varying thicknesses. 


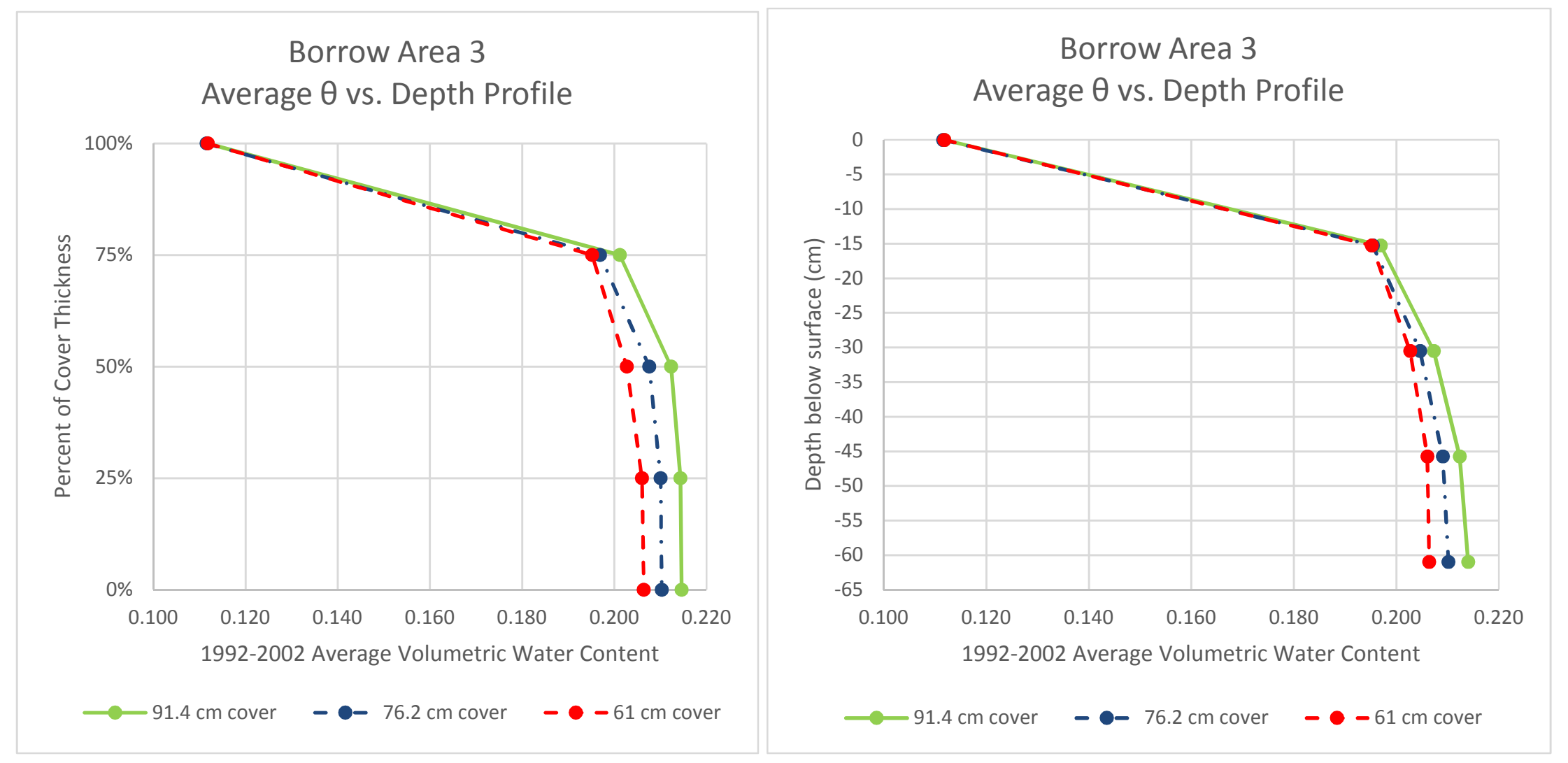

Fig. 9.6 Relationships of average volumetric water content versus (a) percent of cover thickness and (b) depth below the surface for three water balance covers with varying thickness simulated with Borrow Area 3 soil and revegeted vegetation parameters. 


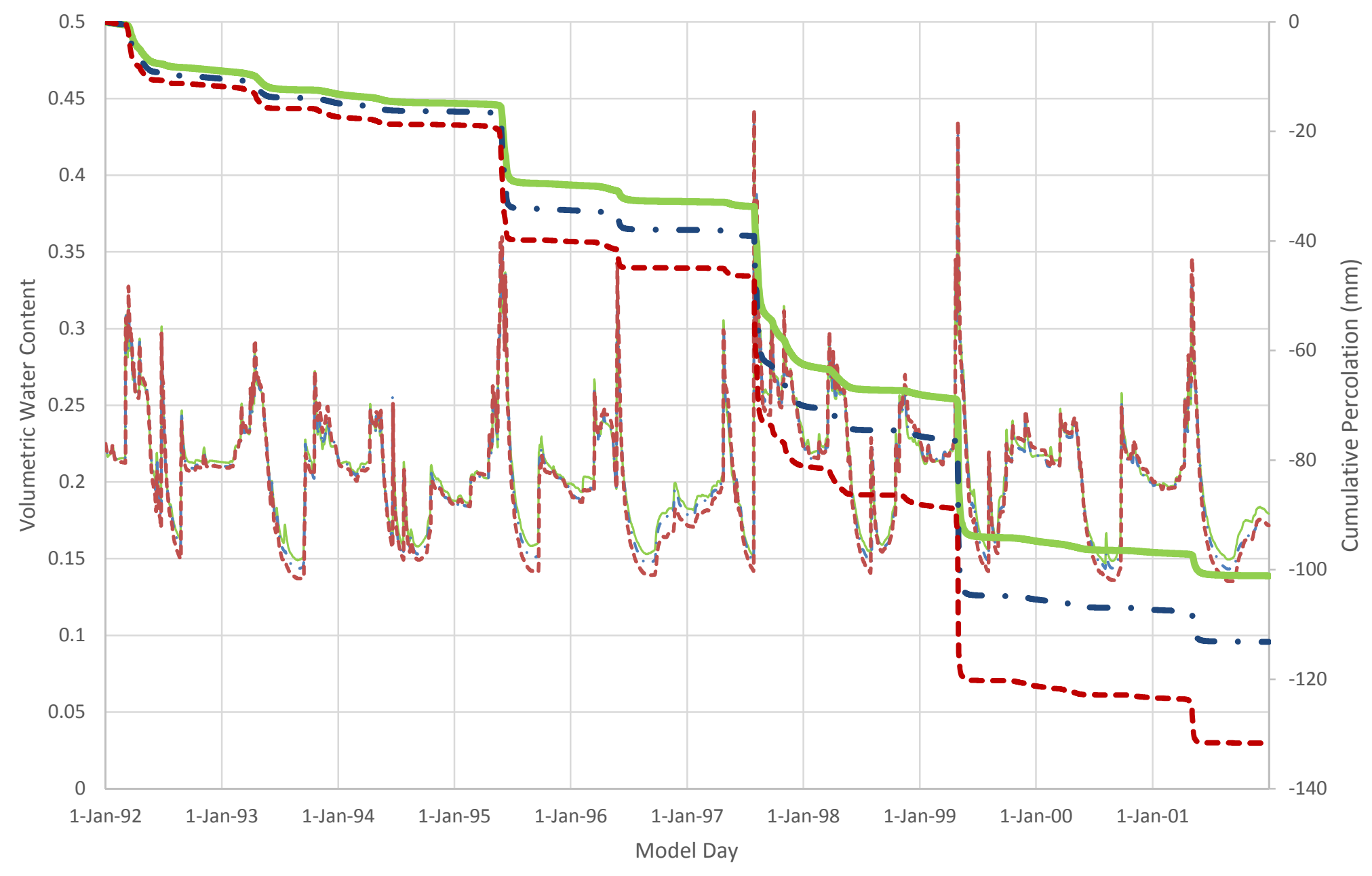

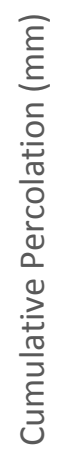

$91.4 \mathrm{~cm}(3 \mathrm{ft})$ thick cover

Cumulative Percolation $91.4 \mathrm{~cm}$ cover
- - $\cdot 76.2 \mathrm{~cm}(2.5 \mathrm{ft})$ thick cover

- Cumulative Percolation $76.2 \mathrm{~cm}$ cover
$---.61 \mathrm{~cm}(2 \mathrm{ft})$ cover

- Cumulative Percolation $61 \mathrm{~cm}$ cover

Fig. 9.7 Percolation and volumetric water content from $1992-2002$ at $30.5 \mathrm{~cm}$ below the ground surface for water balance covers simulated with Borrow Area 3 soil, revegetated vegetation parameters, and varying thicknesses. 


\section{CHAPTER 10. SUMMARY, CONCLUSIONS, AND FUTURE WORK}

\subsection{Summary and Conclusions}

The hydrologic performance of a prescriptive cover and WBC at LCL were evaluated in this study using variably-saturated flow modeling with parameters based on regulatory standards, field observations, laboratory testing data, MET data, and vegetation characteristics. Regulations for LCL specify a prescriptive cover must include a low-permeability layer (i.e., Infiltration layer) with a maximum $k_{s}$ of $1.0 \times 10^{-5} \mathrm{~cm} / \mathrm{s}$. Regulations for LCL allow for alternative closure covers (e.g., water balance cover) considering that equivalency is demonstrated relative to a prescriptive cover. Water balance cover designs for Colorado are recommended by the CDPHE based on the particle-size distribution of soil to be used for the cover and geographical location of the landfill.

Larimer County Landfill has constructed four phases of prescriptive closure covers since 1998, starting with the Phase 1 closure area. Excavation, sampling, and testing of the Phase 1 cover for this study indicated layer thicknesses exceeding the minimum required thicknesses and $k_{s}$ approximately two orders of magnitude lower than required. Soil characterization and engineering properties determined for soils from Phase 1 were similar to those measured during Phase 1 construction quality assurance testing. Sampling was also conducted in Borrow Areas 3 and 4 to evaluate suitability of the borrow area soils for use in a WBC. Based on the particlesize distribution and LCL located in Ecozone 3 (CDPHE 2013), the recommended WBC design was a $76.2-\mathrm{cm}$-thick $(2.5 \mathrm{ft})$ cover.

Finite element modeling using VADOSE/W was performed to predict the percolation rate through the prescriptive and water balance covers. The wettest ten consecutive years on record for Fort Collins that had a sufficiently complete MET data set (1992-2002) were selected for the analysis. Vegetation parameters were assigned to represent either the revegetated state observed over the existing closure phases or the natural conditions observed in the borrow 
areas. Predicted percolation through a prescriptive cover was $<0.1$ to $2.2 \mathrm{~mm} / \mathrm{yr}$ corresponding to an Infiltration layer with $k_{s}$ of $1.2 \times 10^{-7}$ or $1.0 \times 10^{-5} \mathrm{~cm} / \mathrm{s}$. Evaporation was the primary component for removing water from the prescriptive cover models with a contribution of 62 or 67 $\%$ of the water balance. WBC models predicted a percolation rate from 6.3 to $11.3 \mathrm{~mm} / \mathrm{yr}$ depending on the borrow area and vegetation parameters. Water balance covers that yielded the lowest percolation were simulated with either Borrow Area 3 or Borrow Area 4 soil and natural vegetation characteristics. Transpiration was the primary component for removing water from the WBC models with a contribution of 58 to $73 \%$ of the water balance. Within all of the CDPHE acceptable cover models, ET removed 94 to $102 \%$ of the precipitation received during the ten-year model simulations.

Results of this study indicate that either a prescriptive cover with a total thickness of $106.7 \mathrm{~cm}(3.5 \mathrm{ft})$ or a water balance cover with a thickness of $76.2 \mathrm{~cm}(2.5 \mathrm{ft})$ would meet CDPHE criteria for closure cover design at LCL. Water balance modeling predicted less percolation through the prescriptive cover relative to the WBC based on soil and vegetation parameters determined in this study. Regulations for final covers in Colorado do not include an acceptable amount of percolation or define what would be considered equivalent performance.

Pedogenesis was anticipated to increase $k_{s}$ of the compacted clay in the prescriptive cover after nearly $20 \mathrm{yr}$ of operation, but this phenomenon was not observed. Saturated hydraulic conductivities of $1.2 \times 10^{-7}$ and $8.9 \times 10^{-8} \mathrm{~cm} / \mathrm{s}$ were measured on samples from Phase 1 , whereas the average $k_{s}$ from 1998 construction quality assurance testing was $1.6 \times 10^{-7} \mathrm{~cm} / \mathrm{s}$. The similarity in $k_{s}$ from 1998 to 2017 was attributed to a lack of pedogenesis due to the thicker prescriptive cover that constructed in Phase 1 versus the design thickness. The as-constructed cover extended to greater depths, whereby the Infiltration layer (i.e., low $k_{s}$ layer) was sufficiently deep below the ground surface where pedogenesis has less influence. An increase in $k_{s}$ as a result of pedogenesis would have increased $k_{s}$ to a similar magnitude observed in the 
borrow area samples $\left(1.06 \times 10^{-4}\right.$ and $\left.2.43 \times 10^{-4} \mathrm{~cm} / \mathrm{s}\right)$. Higher $k_{s}$ would have resulted in higher percolation rates that were closer to those predicted by the WBC models.

\subsection{Future Work}

Further development of this study can proceed by constructing a field-scale lysimeter based on a recommended WBC design to monitor field performance and compare to the existing prescriptive cover and water balance simulations. An alternative to a single field-scale lysimeter would be multiple small-scale lysimeters constructed in the field to further assess variables such as soil source, vegetation, compaction effort, and moisture content during compaction on actual water balance performance. Assessing these variabilities would further help to understand the effects of each variable on WBC performance and yield valuable information for other sites considering closure cover design options. Measured percolation rates in the field lysimeters could be compared to predicted model results to evaluate accuracy of models and refine modeling procedures for future studies. Finally, monitoring lysimeters for several years would provide the ability to assess the effect of pedogenesis on soil covers.

Additional soil water retention (ASTM D6836) and permeability (ASTM D5084) laboratory testing on samples recovered from this study would provide a better understanding of the effect of particle size distribution, compaction effort, and moisture content during compaction on hydraulic parameters. Infiltration testing (ASTM D5093) on the existing closure cover phases would provide another data set of permeability to assess the effect of pedogenesis with time. Varying the depth of the field test within the covers would introduce another variable since pedogenesis is more prevalent on the surface than with depth where the upper soils provide less protection from climate and vegetation interaction.

Multiple finite element software programs are available to model variably saturated flow. VADOSE/W was used for variably saturated flow modeling of the covers as part of this study. 
Parameters used for modeling in this study could be used in other modeling programs to compare the water balance results, particularly with regards to percolation. 


\section{REFERENCES}

Albrecht, B.A. and Benson, C.H., 2001. Effect of desiccation on compacted natural clays. Journal of Geotechnical and Geoenvironmental Engineering. 127(1), 67-75.

Albright, W.H., Benson, C.H., and Waugh, W.J., 2010. Water balance covers for waste containment, principles and practice, American Society of Civil Engineers, ASCE Press, Reston, Virginia.

ASTM Standard D5084-16a, 2016. Standard test methods for measurement of hydraulic conductivity of saturated porous materials using a flexible wall permeameter. ASTM International, West Conshohocken, Pennsylvania.

ASTM Standard D5093-15e1, 2015. Standard test method for field measurement of infiltration rate using double-ring infiltrometer with sealed-inner ring. ASTM International, West Conshohocken, Pennsylvania.

ASTM Standard D6836-16, 2016. Standard test methods for determination of the soil water characteristic curve for desorption using hanging column, pressure extractor, chilled mirror hygrometer, or centrifuge. ASTM International, West Conshohocken, Pennsylvania.

Benson, C.H. and Bareither, C.A., 2012. Designing water balance covers for sustainable waste containment: transitioning state of the art to state of the practice. GeoCongress, March 2529.

Benson, C.H., Daniel, D. E., and Boutwell, G. P., 1999a. Field performance of compacted clay liners. Journal of Geotechnical and Geoenvironmental Engineering. 125(5), 390-403.

Benson, C.H., T. Abichou, X. Wang, G.W. Gee, and W. H. Albright. 1999b. NO. 99-3, Test section installation instructions: alternative cover assessment program. Geo Engineering Report. University of Wisconsin, Madison, WI. On-Line Service Accessed on February 28, 2018.

Benson, C.H., Sawangsuriya, A., Trzebiatowski, B., and Albright, W. H., 2007. Postconstruction changes in the hydraulic properties of water balance cover soils. Journal of Geotechnical and Geoenvironmental Engineering. 133(4), 349-359.

Braddock, W.A., Calvert, R.H., O'Connor, J.T., and Swann, G.A., 1989. Geologic map of the Horsetooth Reservoir Quadrangle, Larimer County Colorado, U.S. Geological Survey.

Buol, S., Hole, F., McCracken, R., and Southard, R., 1997. Soil genesis and classification, $4^{\text {th }}$ edition., lowa State University Press, Ames, lowa.

Colorado Department of Public Health and Environment (CDPHE), 2013. Final guidance document, water balance covers in Colorado, Hazardous Materials and Waste Management Division, Solid Waste and Materials Management Program. March.

Colorado State University (CSU), 2017. Fort Collins weather station data access, Retrieved from https://ccc.atmos.colostate.edu/ autowx/fclwx_access.php. 
Daniel, D. E. 1994. State-of-the-Art: Laboratory hydraulic conductivity tests for saturated soils, ASTM STP 1142, D.E. Daniel and S.J. Trautwein (Eds.), American Society for Testing and Materials, Philadelphia, 30-78.

Dwyer, S.F., and Reavis, B. 2002. Water balance performance of final landfill covers in an arid climate. WM Symposia 2002 Conference, Tucson, AZ. February 24-28.

Fredlund, D.G., Xing, A., and Huang, S., 1994. Predicting the permeability function of unsaturated soils using the soil-water characteristic curve. Canadian Geotechnical Journal, 31: 533-546.

GEO-SLOPE International, Ltd. (GEO-SLOPE, 2014). Vadose zone modeling with VADOSE/W, an engineering methodology, April.

Gurdal, T., Benson, C., and Albright, W., 2003. Hydrologic properties of final cover soils from the Alternative Cover Assessment Program. Geo Engineering Report Number 03-02, University of Wisconsin-Madison.

Othman, M.A. and Benson, C.H., 1992. Effect of freeze-thaw on the hydraulic conductivity and morphology of compacted clay. Canadian Geotechnical Journal, 30 236-246

Scurlock, J.M.O., Asner, G.P., and Gower, S.T. 2001. Worldwide historical estimates of leaf area index, 1932-2000, Oak Ridge National Laboratory, Department of Energy, December.

Schroeder, P.R., Aziz, N.M., Lloyd, C.M., and Zappi, P.A. 1994. The Hydrologic Evaluation of Landfill Performance (HELP) Model: User's Guide for Version 3, EPA/600/R-94/168a, September 1994, U.S. Environmental Protection Agency Office of Research and Development, Washington, DC.

Rawls, W.J., Brakensiek, D.L., and Saxton, K.E., 1982. Estimation of soil water properties. Transactions of the American Society of Agricultural Engineers, 25(5) 1316-1328.

Tinjum, J., Benson, C., and Blotz, L., 1997. Soil-water characteristic curves for compacted clays. Journal of Geotechnical and Geoenvironmental Engineering. 123 (11), 1060-1069.

Tweto and Ogden 1979, Geologic map of Colorado: U.S. Geological Survey Special Geologic Map, scale 1:500,000.

United States Department of Agriculture (USDA), 2008. ROSETTA Model Lite Version 1.1, Component of Hydrus-1D Version 4.16.0110.

United States Department of Agriculture, Natural Resource Conservation Survey (NRCS), 2017. Web Soil Survey. Retrieved from https://websoilsurvey.nrcs.usda.gov/app/WebSoilSurvey.aspx.

Weather Underground, 2017. Weather History for Fort Collins, CO. Retrieved from https://www.wunderground.com/history/airport/KFNL/1999/1/1/CustomHistory.html?dayend= 31 \&monthend $=12 \&$ yearend $=1999 \&$ req_city $=\& r e q \_s t a t e=\& r e q \_s t a t e n a m e=\& r e q d b . z i p=\& r e q$ db. magic $=\&$ reqdb. $w m o=$.

Van Genuchten, M. T., 1980. A closed-form equation for predicting the hydraulic conductivity of unsaturated soils, Soil Science Society of America Journal. 